"Efecto alelopático de residuos de rizomas de Sorghum halepense (L.) Pers. sobre la micorrización, producción de materia seca y aceites esenciales de plantas de Mentha x piperita L."

Tesis presentada para optar al título de Magister Scientiae en Protección Vegetal Facultad de Ciencias Agrarias y Forestales Universidad Nacional de la Plata
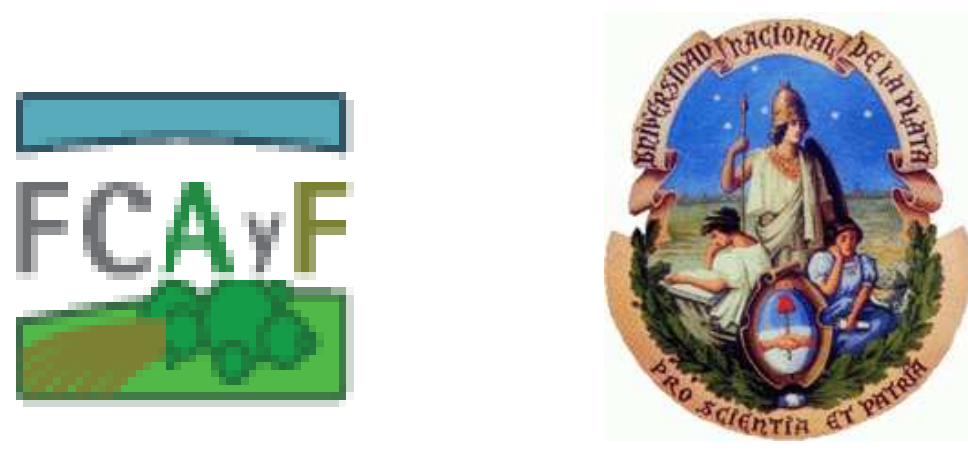

Ing. Agr. María Cecilia Arango

\title{
DIRECTOR
}

Ing. Agr. José Beltrano

CO-DIRECTOR

Ing. Agr. Jorge A. Ringuelet 


\section{Jurado de Tesis}

Lic. Dra. Marta Noemí Cabello

(Fac. Cs. Nat. Museo UNLP)

Ing. Agr. Claudio Marco Ghersa

(Universidad Nacional de Buenos Aires)

Dr (MSc) Ing. Agr. Horacio Abel Acciaresi

(EEA INTA Pergamino)

Fecha de defensa de la tesis

11 de diciembre de 2015 


\section{Agradecimientos}

Agradezco a la Facultad de Ciencias Agrarias y Forestales de la UNLP por haberme otorgado una beca para la realización de los cursos de la Maestría y poder obtener mi formación de postgrado.

A las autoridades del Instituto de Fisiología Vegetal (INFIVE-CONICET-UNLP) y del laboratorio del Curso de Bioquímica y Fitoquímica por facilitarme sus instalaciones para el desarrollo de este trabajo de investigación.

Quisiera expresar mi más sincero agradecimiento a las personas que hicieron posible la realización de este trabajo:

- A mi director, el Ing. Agr. José Beltrano, por transmitirme sus conocimientos y experiencias y por su paciencia, estímulo y confianza tanto en el aspecto laboral como humano.

- A mi Co-director el Ing. Agr. Jorge Ringuelet por su ayuda incondicional y calidez humana.

- A la Ing. Forestal Marcela Ruscitti por las horas de trabajo compartidas, y por su amistad.

- Al personal del INFIVE, técnicos, no docentes, especialmente a Marta Ronco, Daniel Giménez, Alejandra Carbone, por sus palabras de aliento, a Laura Wahnan y Olga Peluso por su colaboración en las tareas de laboratorio y su compañerismo, generando un clima de trabajo distendido.

- A mis compañeros del Curso de Bioquímica y Fitoquímica, Cynthia Henning, Mariel Yordaz y Sonia Viña por su compañía, comprensión y cariño.

- Al jurado de mi tesis, Dra. Marta Cabello, Ing. Agr. Claudio Ghersa y el Dr. Horacio Acciaresi, quienes amablemente participaron con su experiencia y conocimientos en la revisión de esta tesis, agradezco sus comentarios y sugerencias para mejorar la versión final del manuscrito.

- A mis padres que siempre me alentaron con cariño para que pudiera seguir estudiando.

- A Gustavo por su compañía y respeto por mi trabajo.

- A mis hijos Rocío y Marcos por ser la razón de mi existencia.

- A todos aquellos que de alguna manera colaboraron y me apoyaron en la culminación de este proyecto,

Muchas gracias! 


\section{Publicaciones derivadas de la Tesis}

- Arango, MC; M. Ruscitti, M. Ronco and José Beltrano. Influencia de residuos de rizomas de sorgo de Alepo (Sorghum halepense L. Pers.) sobre la micorrización y el crecimiento de plantas de Mentha x piperita L. Revista de la Asociación Argentina de Horticultura. 2013. P22-29 ISSN 18519342.www.horticulturaar.com.ar 


\section{Abreviaturas}

$\mathrm{AE}$

AF

ALP

Alt

Ar

$\mathrm{CRH}$

CRR

CS

DDE

DDP

DDT

DM

E

$\mathrm{H}$

HMA

IB1

IM

M

NI

PN

PSA

$\mathrm{PSH}$

PSR

PST

$\mathrm{R}$

R0

R1

R2

R3
Aceites esenciales

Área foliar

Fosfatasa alcalina

Altura

Arbúsculos

Conductividad relativa de hojas

Conductividad relativa de raíces

Conductancia estomática

Días después del primer riego con extracto acuoso

Días después de la plantación

Días después del trasplante

Dependencia micorrícica

Transpiración

Micorrización

Hongos micorrícicos arbusculares

Rizophagus intraradices cepa B1

Funneliformis mosseae

Micorrización

No inoculadas

Fotosíntesis neta

Peso seco aéreo

Peso seco de hojas

Peso seco de raíz

Peso seco de tallos

Rizomas de sorgo de Alepo

$0 \mathrm{~g}\left(0 \mathrm{~g} \mathrm{~m}^{-2} \mathrm{MS}\right)$ de rizomas de sorgo de Alepo

$10 \mathrm{~g}\left(250 \mathrm{~g} \mathrm{~m}^{-2} \mathrm{MS}\right)$ de rizomas de sorgo de Alepo

$20 \mathrm{~g}\left(500 \mathrm{~g} \mathrm{~m}^{-2} \mathrm{MS}\right)$ de rizomas de sorgo de Alepo

$32 \mathrm{~g}\left(800 \mathrm{~g} \mathrm{~m}^{-2} \mathrm{MS}\right)$ de rizomas de sorgo de Alepo 

$5 \%$ extracto acuoso de rizomas de sorgo de Alepo $15 \%$ extracto acuoso de rizomas de sorgo de Alepo $25 \%$ extracto acuoso de rizomas de sorgo de Alepo Sorghum halepense (L.) Pers.

SDH

Succinato deshidrogenasa

$\mathrm{V}$

Vesículas 


\section{Índice general}

\section{Abreviaturas}

\section{Capítulo1 Introducción 1}

Las plantas aromáticas 2

Mentha x piperita L 2

El sorgo de Alepo (Sorghum halepense (L.) Pers.) como maleza de cultivos agrícolas 7

Alelopatía 10

Micorrizas arbusculares $\quad 12$

Características del proceso de colonización 13

Importancia de las micorrizas arbusculares $\quad 15$

Interacción entre la alelopatía y la micorrización 17

Micorrización y plantas aromáticas 19

$\begin{array}{ll}\text { Objetivo general } & 20\end{array}$

Objetivos particulares 20

$\begin{array}{ll}\text { Hipótesis } & 21\end{array}$

Capítulo 2 Materiales y Métodos 22

Ubicación de los experimentos 23

Material Biológico 23

Material vegetal 23

Material fúngico, preparación del inóculo 23

Experimento $N^{\circ} 1$ : Evaluación de distintas concentraciones de extracto acuoso de rizomas de sorgo de Alepo sobre la micorrización y parámetros de crecimiento de plántulas de Mentha $\mathbf{x}$ piperita $\mathbf{L}$.

Material vegetal $\quad 24$

Preparación del extracto acuoso de rizomas de sorgo de Alepo 24

Solución nutritiva Hoagland 25

Condiciones de crecimiento 26

Tratamientos 27

Determinaciones realizadas a los 30 y 60 días después del trasplante $\quad 27$

Análisis de la infectividad de los hongos micorrícicos arbusculares 28

Tinción de raíces micorrizadas 28

Porcentaje de micorrización y eficiencia de la colonización micorrícica 28

Parámetros de crecimiento $\quad 29$

Altura de la planta $\quad 29$

Peso seco aéreo (de hojas y tallos) 29

Peso seco de raiz $\quad 29$

Longitud de raiz $\quad 29$

Análisis estadístico $\quad 29$

Experimento $N^{\circ}$ 2: Evaluación del efecto de extractos acuosos de rizomas de sorgo de Alepo sobre la micorrización, crecimiento, parámetros fisiológicos y bioquímicos de plantas de Mentha $x$ piperita $\mathrm{L}$. 
Material vegetal $\quad 30$

Condiciones de crecimiento 30

Tratamientos $\quad 30$

Análisis de la infectividad y eficiencia de la colonización micorrícica determinadas a los

30 y 60 días después del trasplante 31

Viabilidad de las estructuras fúngicas ( $\mathrm{SDH} \quad 31$

Parámetros de crecimiento medidos a los 30 días después del trasplante 32

Área foliar por planta $\quad 32$

Peso seco de hojas, tallos y raices y longitud de raiz

Determinaciones realizadas a los 60 días después del trasplante $\quad 32$

Parámetros de crecimiento $\quad 32$

Área foliar por planta $\quad 32$

Altura, peso seco de hojas, tallos y raices

$N^{\circ}$ hojas de los tallos $\quad 32$

Longitud de raiz, volumen de raíz 32

Determinación de la actividad de la enzima fosfatasa alcalina (ALP 32

Determinación de la conductividad relativa de membranas celulares en hojas y raices $\quad 32$

Determinación de la fotosintesis neta, transpiración y conductancia 33

Estimación del contenido de clorofila y carotenoides 33

Determinación del contenido de proteinas solubles en hojas 34

Análisis estadístico $\quad 34$

Experimento $N^{\circ}$ 3: Efecto de los aleloquímicos provenientes de los rizomas de sorgo de Alepo sobre la micorrización, la materia seca, parámetros fisiológicos y bioquímicos y aceites esenciales de plantas de Mentha x piperita $\mathrm{L}$.

Material vegetal $\quad 34$

Condiciones de crecimiento

Tratamientos 36

Análisis de la infectividad y eficiencia de la colonización micorrícica 36

Determinación de parámetros de crecimiento

$\begin{array}{ll}\text { Altura de la planta } & 37\end{array}$

Área foliar total $\quad 37$

Peso seco de hojas, tallos y raices

Determinación de la fotosíntesis neta y conductancia estomática 37

Estimación del contenido de clorofila y carotenoides

Determinación del contenido de proteinas solubles de hojas 37

Determinación de la conductividad relativa de hojas y raices 37

Extracción y cuantificación de aceites esenciales 38

Análisis estadístico 38

Capítulo 3 Resultados 40

Experimento 1

Evaluación del efecto de extractos acuosos de rizomas de sorgo de Alepo sobre la micorrización y el crecimiento de plantas de Mentha x piperita $\mathrm{L}$.

Colonización micorrícica y dependencia micorrícica 41

Parámetros de crecimiento $\quad 42$

Parámetros de crecimiento registrados a los 30 días después del trasplante $\quad 43$

Parámetros de crecimiento registrados a los 30 días después del trasplante 43 


\section{Experimento 2}

Evaluación del efecto de extractos acuosos de rizomas de sorgo de Alepo sobre la micorrización, parámetros morfológicos, fisiológicos y bioquímicos de plantas de Mentha $x$ piperita $\mathbf{L}$.

Colonización micorrícica y dependencia micorrícica 44

Actividad de la enzima fosfatasa alcalina en raices 46

Altura de plantas de Mentha x piperita al comienzo de los tratamientos con extractos de 47

$S A$

Parámetros de crecimiento medidos a los 30 días después de la plantación

Parámetros de crecimiento medidos a los 30 días después de la plantación

Parámetros de crecimiento y determinaciones medidas a los 60 días después de la plantación

Contenido de proteinas solubles en hojas

Contenido de clorofila total y carotenoides $\quad 54$

Fotosíntesis neta $\quad 56$

Transpiración $\quad 57$

Conductancia estomática 58

Conductividad relativa de raices $\quad 59$

$\begin{array}{ll}\text { Conductividad relativa de membranas de hojas } & 60\end{array}$

\section{Experimento 3}

Efecto de los aleloquímicos provenientes de los rizomas de sorgo de Alepo sobre la micorrización, la materia seca y aceites esenciales de plantas de Mentha $\mathbf{x}$ piperita L.

Colonización micorrícica y dependencia micorrícica $\quad 64$

Parámetros de crecimiento $\quad 65$

Área foliar, peso seco de hojas, tallos y raices 67

Proteinas foliares $\quad 69$

$\begin{array}{ll}\text { Clorofila y Carotenoides } & 70\end{array}$

Fotosintesis neta $\quad 72$

Conductancia Estomática 73

Conductividad relativa de hojas 74

Conductividad relativa de raices $\quad 75$

Aceites esenciales $\quad 76$

\section{Capítulo 4 Discusión $\quad 79$}

Efecto de los extractos acuosos de rizomas de sorgo de Alepo sobre la micorrización el crecimiento, parámetros fisiológicos y bioquímicos de plantas de Mentha $x$ piperita $L$. (Experimentos $\mathrm{N}^{\circ} 1$ y 2 )

Micorrización, viabilidad de la estructuras fúngicas y dependencia micorrícica $\quad 80$

$\begin{array}{ll}\text { Fosfatasa alcalina } & 83\end{array}$

Parámetros de crecimiento

Proteinas foliares $\quad 86$

Clorofila y carotenoides $\quad 86$

Fotosintesis neta $\quad 87$

Conductancia estomática y Transpiración $\quad 87$

Conductividad relativa de membranas de hojas y raices 88 
Efecto de los aleloquímicos provenientes de los rizomas de sorgo de Alepo sobre la micorrización, la materia seca, parámetros fisiológicos y bioquímicos y aceites esenciales de plantas de Mentha $x$ piperita L. (Experimento $N^{\circ} 3$ )

Micorrización y dependencia micorrícica $\quad 89$

Parámetros de crecimiento $\quad 90$

Proteinas foliares $\quad 91$

$\begin{array}{ll}\text { Clorofila y carotenoides } & 91\end{array}$

Fotosintesis neta y Conductancia estomática 91

Conductividad relativa de membranas de hojas y raices 92

Aceites esenciales 93

Capítulo 5 Conclusiones 95

$\begin{array}{ll}\text { Bibliografía } & 98\end{array}$ 


\section{Índice de Figuras}

Figura 1. Mentha x piperita L. Fuente propia

Figura 2: Superficie por provincia destinada a la producción de menta en Argentina. Fuente: Sistema Nacional de Vigilancia y Monitoreo de Plagas - SENASA. 26/11/2009 .................5

Figura 3. a) Planta entera y b) rizomas de Sorghum halepense (L) Pers........................8

Figura 4. Vías de liberación de aleloquímicos..............................................11

Figura 5. Raíces de plantas de Mentha x piperita L. micorrizadas, inoculadas con Funneliformis mosseae. Se observan, a: arbúsculos, h: hifas, v: vesículas. Fuente propia .....................14

Figura 6. Ciclo de infección de hongos micorrícicos. Adaptado de Varma A,B Hock, 1998.....15

Figura 7. a) Destilador de aceites esenciales de laboratorio. b) Trampa Clevenger de vidrio para aceites esenciales de menor densidad que el agua..........................................

Figura 8. Plantas de Mentha x piperita a los 30 días después del trasplante que crecieron con distintas concentraciones de extracto de sorgo de Alepo.

Figura 9: a) Tinción de succinato deshidrogenasa (SDH): hifas y vesículas teñidas de azul indicando actividad. b) tinción de hifas, vesículas y arbúsculos con azul de tripán. 46

Figura 10. Efecto de los extractos de rizomas de SA sobre la actividad de la enzima fosfatasa alcalina de raíces de plantas de Mentha x piperita L. no inoculadas (NI) o inoculadas con Funneliformis mosseae (IM) y Rhizophagus intraradices (IB1). Referencias: S0: 0\%; S1: 5\%; S2: $10 \%$; S3: $15 \%$.

Figura 11. Registro de altura de plantas de Mentha $\mathrm{x}$ piperita $\mathrm{L}$ tomados a partir de los 7 días después del primer riego con extracto acuoso de rizomas de sorgo de Alepo (DDE) y cada 3 días, no inoculadas (NI), inoculadas con Funneliformis mosseae (IM) y Rhizophagus intraradices (IB1). Referencias: S0: 0\%; S1: 5\%; S2: 10\%; S3: 15\%.

Figura 12. Efecto de los extractos de rizomas de sorgo de Alepo sobre el contenido de proteínas solubles de hojas plantas de Mentha x piperita L. no inoculadas (NI) o inoculadas con Funneliformis mosseae (IM) y Rhizophagus intraradices (IB1). Referencias: S0: 0\%; S1: 5\%; S2: $10 \%$; S3: 15\%.

Figura 13. Efecto de los extractos de rizomas de sorgo de Alepo sobre la concentración de clorofila total de plantas de Mentha x piperita L. no inoculadas (NI) o inoculadas con Funneliformis mosseae (IM) y Rhizophagus intraradices (IB1). Referencias: S0: 0\%; S1: 5\%; S2: $10 \%$; S3: $15 \%$.

Figura 14. Efecto de los extractos de rizomas de sorgo de Alepo sobre la concentración de carotenoides de plantas de Mentha x piperita L. no inoculadas (NI) o inoculadas con Funneliformis mosseae (IM) y Rhizophagus intraradices (IB1). Referencias: S0: 0\%; S1: 5\%; S2: $10 \%$; S3: $15 \%$. 
Figura 15. Efecto de los extractos de rizomas de sorgo de Alepo sobre la Fotosíntesis neta (PN) de plantas de Mentha x piperita L. no inoculadas (NI) o inoculadas con Funneliformis mosseae (IM) y Rhizophagus intraradices (IB1). Referencias: S0: 0\%; S1: 5\%; S2: 10\%; S3: 15\%.......57

Figura 16. Efecto de los extractos de rizomas de sorgo de Alepo sobre la transpiración (E) de plantas de Mentha x piperita L. no inoculadas (NI) o inoculadas con Funneliformis mosseae (IM) y Rhizophagus intraradices (IB1). Referencias: S0: 0\%; S1: 5\%; S2: 10\%; S3: 15\%.......58

Figura 17. Efecto de los extractos de rizomas de sorgo de Alepo sobre la conductancia estomática (CS) de plantas de Mentha x piperita L. no inoculadas (NI) o inoculadas con Funneliformis mosseae (IM) y Rhizophagus intraradices (IB1). Referencias: S0: 0\%; S1: 5\%; S2: $10 \%$; S3: $15 \%$.

Figura 18. Efecto de los extractos de rizomas de sorgo de Alepo sobre la conductividad relativa (CRR) de raíces de plantas de Mentha x piperita L. no inoculadas (NI) o inoculadas con Funneliformis mosseae (IM) y Rhizophagus intraradices (IB1). Referencias: S0: 0\%; S1: 5\%; S2: $10 \%$; S3: $15 \%$

Figura 19. Efecto de los extractos de rizomas de sorgo de Alepo sobre la conductividad relativa (CRH) de hojas de plantas de Mentha x piperita L. no inoculadas (NI) o inoculadas con Funneliformis mosseae (IM) y Rhizophagus intraradices (IB1). Referencias: S0: 0\%; S1: 5\%; S2: $10 \%$; S3: $15 \%$.

Figura 20. Speedling (A) y plantas (B) de plantas de Menta piperita 30 DDT. Referencias: 0\%, $5 \%, 10 \%$ y $15 \%$, concentraciones de extracto de rizomas de Sorgo de Alepo. NI: no inoculadas, IM: inoculadas con F. mosseae; IB1: inoculadas con $R$. intraradices.

Figura 21. Plantas de Menta piperita. 60 días después del trasplante. Referencias: $0 \%, 5 \%, 10 \%$ y $15 \%$, concentraciones de extracto de rizomas de sorgo de Alepo. NI: no inoculadas, IM: inoculadas con F. mosseae; IB1: inoculadas con $R$. intraradices.

Figura 22. Altura de plantas de Mentha x piperita L registrados a partir de los 30 días después de la plantación y durante 30 días, inoculadas con Funneliformis mosseae (IM) y Rhizophagus intraradices (IB1) en respuesta a los diferentes tratamientos distintas cantidades de rizomas de sorgo de Alepo.

Figura 23. Efecto de los aleloquimicos de rizomas de sorgo de Alepo sobre el Peso seco aéreo y el Peso seco de raíz de plantas de Mentha x piperita L. no inoculadas (NI) o inoculadas con Funneliformis mosseae (IM) y Rhizophagus intraradices (IB1). R0: $0 \mathrm{~g} \mathrm{~m}^{-2} \mathrm{MS}$ de rizomas, R1: $250 \mathrm{~g} \mathrm{~m}^{-2}$ MS de rizomas, R2: $500 \mathrm{~g} \mathrm{~m}^{-2}$ MS de rizomas, R3: $800 \mathrm{~g} \mathrm{~m}^{-2}$ MS de rizomas. 68

Figura 24. Efecto de los aleloquímicos de rizomas de sorgo de Alepo sobre el contenido de proteínas foliares de plantas de Mentha x piperita L. no inoculadas (NI) o inoculadas con Funneliformis mosseae (IM) y Rhizophagus intraradices (IB1). R0: $0 \mathrm{~g} \mathrm{~m}^{-2}$ MS de rizomas, R1: $250 \mathrm{~g} \mathrm{~m}^{-2}$ MS de rizomas, R2: $500 \mathrm{~g} \mathrm{~m}^{-2}$ MS de rizomas, R3: $800 \mathrm{~g} \mathrm{~m}^{-2} \mathrm{MS}$ de rizomas......

Figura 25. Efecto de los aleloquímicos de rizomas de sorgo de Alepo sobre la concentración de clorofila total de plantas de Mentha x piperita L. no inoculadas (NI) o inoculadas con Funneliformis mosseae (IM) y Rhizophagus intraradices (IB1). R0: $0 \mathrm{~g} \mathrm{~m}^{-2} \mathrm{MS}$ de rizomas, R1: $250 \mathrm{~g} \mathrm{~m}^{-2}$ MS de rizomas, R2: $500 \mathrm{~g} \mathrm{~m}^{-2}$ MS de rizomas, R3: $800 \mathrm{~g} \mathrm{~m}^{-2} \mathrm{MS}$ de rizomas........ 71

Figura 26 . Efecto de los aleloquímicos de rizomas de sorgo de Alepo sobre la concentración carotenoides de plantas de Mentha x piperita L. no inoculadas (NI) o inoculadas con 
Funneliformis mosseae (IM) y Rhizophagus intraradices (IB1). R0: $0 \mathrm{~g} \mathrm{~m}^{-2} \mathrm{MS}$ de rizomas, R1: $250 \mathrm{~g} \mathrm{~m}^{-2}$ MS de rizomas, R2: $500 \mathrm{~g} \mathrm{~m}^{-2}$ MS de rizomas, R3: $800 \mathrm{~g} \mathrm{~m}^{-2} \mathrm{MS}$ de rizomas..............

Figura 27 . Efecto de los de aleloquímicos de rizomas de sorgo de Alepo sobre la fotosíntesis neta (PN) de plantas de Mentha x piperita L. no inoculadas (NI) o inoculadas con Funneliformis mosseae (IM) y Rhizophagus intraradices (IB1). R0: $0 \mathrm{~g} \mathrm{~m}^{-2}$ MS de rizomas, R1: $250 \mathrm{~g} \mathrm{~m}^{-2} \mathrm{MS}$ de rizomas, R2: $500 \mathrm{~g} \mathrm{~m}^{-2} \mathrm{MS}$ de rizomas, R3: $800 \mathrm{~g} \mathrm{~m}^{-2} \mathrm{MS}$ de rizomas................................72

Figura 28 . Efecto de los aleloquímicos de rizomas de sorgo de Alepo sobre la conductancia estomática (CS) de plantas de Mentha x piperita L. no inoculadas (NI) o inoculadas con Funneliformis mosseae (IM) y Rhizophagus intraradices (IB1). R0: $0 \mathrm{~g} \mathrm{~m}^{-2}$ MS de rizomas, R1: $250 \mathrm{~g} \mathrm{~m}^{-2}$ MS de rizomas, R2: $500 \mathrm{~g} \mathrm{~m}^{-2}$ MS de rizomas, R3: $800 \mathrm{~g} \mathrm{~m}^{-2} \mathrm{MS}$ de rizomas. 73

Figura 29. Efecto de los aleloquímicos de rizomas de sorgo de Alepo sobre la conductividad relativa de hojas (CRH) de plantas de Mentha $\mathrm{x}$ piperita $\mathrm{L}$. no inoculadas (NI) o inoculadas con Funneliformis mosseae (IM) y Rhizophagus intraradices (IB1). R0: $0 \mathrm{~g} \mathrm{~m}^{-2} \mathrm{MS}$ de rizomas, R1: $250 \mathrm{~g} \mathrm{~m}^{-2}$ MS de rizomas, R2: $500 \mathrm{~g} \mathrm{~m}^{-2}$ MS de rizomas, R3: $800 \mathrm{~g} \mathrm{~m}^{-2} \mathrm{MS}$ de rizomas. . .74

Figura 30. Efecto de los aleloquímicos de rizomas de sorgo de Alepo sobre la conductividad relativa de raíces (CRR) de plantas de Mentha x piperita L. no inoculadas (NI) o inoculadas con Funneliformis mosseae (IM) y Rhizophagus intraradices (IB1). R0: $0 \mathrm{~g} \mathrm{~m}^{-2}$ MS de rizomas, R1: $250 \mathrm{~g} \mathrm{~m}^{-2} \mathrm{MS}$ de rizomas, R2: $500 \mathrm{~g} \mathrm{~m}^{-2} \mathrm{MS}$ de rizomas, R3: $800 \mathrm{~g} \mathrm{~m}^{-2} \mathrm{MS}$ de rizomas. 75

Figura 31. Efecto de los aleloquímicos de rizomas de sorgo de Alepo sobre el porcentaje de aceites esenciales (\% AE) de plantas de Mentha x piperita L. no inoculadas (NI) o inoculadas con Funneliformis mosseae (IM) y Rhizophagus intraradices (IB1). R0: $0 \mathrm{~g} \mathrm{~m}^{-2} \mathrm{MS}$ de rizomas, $\mathrm{R} 1: 250 \mathrm{~g} \mathrm{~m}^{-2} \mathrm{MS}$ de rizomas, R2: $500 \mathrm{~g} \mathrm{~m}^{-2} \mathrm{MS}$ de rizomas, R3: $800 \mathrm{~g} \mathrm{~m}^{-2} \mathrm{MS}$ de rizomas.. 76

Figura 32. Ensayo $\mathrm{N}^{\circ}$ 3. Plantas de Mentha x piperita L. no inoculadas o inoculadas con Funneliformis mosseae y Rhizophagus intraradices IB1creciendo en sustrato con distintas cantidades de rizomas de sorgo de Alepo...... .78

Figura 33 . Plantas de Mentha x piperita L. no inoculadas (NI) o inoculadas con Funneliformis mosseae (IM) y Rhizophagus intraradices (IB1). R0: $0 \mathrm{~g} \mathrm{~m}^{-2}$ MS de rizomas, R1: $250 \mathrm{~g} \mathrm{~m}^{-2} \mathrm{MS}$ de rizomas, R2: $500 \mathrm{~g} \mathrm{~m}^{-2} \mathrm{MS}$ de rizomas, $\mathrm{R} 3: 800 \mathrm{~g} \mathrm{~m}^{-2} \mathrm{MS}$ de rizomas. .78 


\section{Índice de Tablas}

Tabla 1. Fórmula de la solución nutritiva de Hoagland.

Tabla 2. Conductividad eléctrica $\left(\mathrm{mS} \mathrm{cm}^{-1}\right), \mathrm{pH}$ y fenoles totales $\left(\mu \mathrm{g}\right.$ de ácido gálico $\left.\mathrm{mL}^{-1}\right)$ de las distintas concentraciones de los extractos preparados a partir de rizomas de sorgo de Alepo. 26

Tabla 3. Tratamientos correspondientes al experimento $\mathrm{N}^{\circ}$ 1. NI: plantas no inoculadas, IB1: planas inoculadas con $R$. intraradices B1: S0: riego con Hoagland sin extracto; S1: riego con extracto al 5\%, S2: riego con extracto al $10 \%$; S3: riego con extracto al $15 \%$; S4; riego con extracto al $25 \%$

Tabla 4. Tratamientos correspondientes al experimento $\mathrm{N}^{\circ} 2$. NI: plantas no inoculadas, IB1: plantas inoculadas con $R$. intraradices $\mathrm{B} 1$, IM: plantas inoculadas con $F$. mosseae: S0: riego sin extracto; S1: riego con extracto al 5\%, S2 riego extracto al 10\%; S3: riego con extracto al $15 \%$

Tabla 5. Tratamientos correspondientes al experimento $\mathrm{N}^{\circ}$ 3. NI: plantas no inoculadas; IM: plantas inoculadas con $F$. mosseae; IB1: plantas inoculadas con $R$. intraradices, $\mathrm{R} 0,10 \mathrm{~g}$ de rizomas $\left(250 \mathrm{~g} \mathrm{~m}^{-2}\right)$, (R1), 20 de rizomas $\mathrm{g}\left(500 \mathrm{~g} \mathrm{~m}^{-2}\right)$, (R2) y 32 de rizomas $\mathrm{g}\left(800 \mathrm{~g} \mathrm{~m}^{-2}\right)$ (R3), cantidades equivalentes a 250,500 y $800 \mathrm{~g} \mathrm{~m}^{2} \mathrm{MS}$ de rizomas respectivamente. .36

Tabla 6. Colonización micorrícica $(\% \mathrm{M})$, arbúsculos $(\% \mathrm{Ar})$ y vesículas $(\% \mathrm{~V})$ en plantas de Mentha x piperita L. inoculadas con Rhizophagus intraradices (IB1) que crecieron con diferentes concentraciones de extracto de rizomas de SA. Mediciones registradas a los 60 días después del trasplante (60 DDT). Referencias: S0: 0\%; S1: 5\%; S2: 10\%; S3: 15\%; S4: $25 \%$..

Tabla 7. Efecto de los extractos de rizomas de SA sobre la altura de planta (Alt) peso seco aéreo (PSA), longitud de raíz (Long raíz) en plantas de Mentha x piperita L. no inoculadas (NI) o inoculadas con Rhizophagus intraradices (IB1). Mediciones registradas a los 30 días después del trasplante (30 DDT). Referencias: S0: $0 \%$; S1: 5\%; S2: 10\%; S3: $15 \%$; S4: $25 \%$. H: micorrización, S: extracto de rizomas de SA.

Tabla 8. Efecto de los extractos de rizomas de SA sobre la altura de planta (Alt) peso seco aéreo (PSA), longitud de raíz (Long. raíz) y peso seco de raíz (PSR) en plantas de Mentha x piperita L. no inoculadas (NI) o inoculadas con Rhizophagus intraradices (IB1). Mediciones registradas a los 60 días después del trasplante (60 DDT). Referencias: S0: 0\%; S1: 5\%; S2: 10\%; S3: 15\%; S4: 25\%. H: micorrización, S: extracto de rizomas de SA.

Tabla 9. Colonización micorrícica $(\% \mathrm{M})$, arbúsculos $(\% \mathrm{Ar})$ y vesículas $(\% \mathrm{~V})$ en plantas de Mentha x piperita L. inoculadas con Funneliformis mosseae (IM) y Rhizophagus intraradices (IB1) que crecieron con diferentes concentraciones de extracto de rizomas de SA. Referencias: S0: 0\%; S1: 5\%; S2: 10\%; S3: 15\%. Registros a los 30 días después del trasplante (30 DDT). H: micorrización, S: extracto de rizomas de SA.

Tabla 10. Colonización micorrícica $(\% \mathrm{M})$, arbúsculos $(\% \mathrm{Ar})$ y vesículas $(\% \mathrm{~V})$ en plantas de Mentha x piperita L. inoculadas con Funneliformis mosseae (IM) y Rhizophagus intraradices (IB1) que crecieron con diferentes concentraciones de extracto de rizomas de SA. Referencias: S0: 0\%; S1: 5\%; S2: 10\%; S3: 15\%. Registros a los 60 días después del trasplante (60 DDT). H: micorrización, S: extracto de rizomas de SA.......................................... 46 
Tabla 11. Análisis de Varianza de los efectos de la micorrización (NI, IM e IB1) y el extracto acuoso de rizomas de SA (S0, S1, S2 y S3) y su interacción sobre la Fosfatasa alcalina (UI $\mathrm{mg}^{1}$ ). Referencias: H: micorrización; S: extracto de rizomas de SA.

Tabla 12. Análisis de Varianza de los efectos de la micorrización (NI, IM e IB1), el extracto acuoso de rizomas de SA (S0, S1, S2 y S3) y la fecha de registro de altura (7, 10, 13, 16 y 19 DDE) y sus interacciones sobre la altura de plantas. H: micorrización; S: extracto de rizomas de SA; F: fecha de registro de altura.

Tabla 13. Efecto de los extractos de rizomas de SA sobre la altura de planta (Alt) área foliar (AF), peso seco de hojas (PSH), tallos (PST) y raíces (PSR) y longitud de raíz (Long raíz) en plantas de Mentha x piperita L. no inoculadas (NI) o inoculadas con Funneliformis mosseae (IM) y Rhizophagus intraradices (IB1). Referencias: S0: 0\%; S1: 5\%; S2: 10\%; S3: 15\%. Registros realizados a los 30 días después del trasplante (30 DDT). H: micorrización; S: extracto de rizomas de SA.

Tabla 14. Efecto de los extractos de rizomas de SA sobre la altura de planta (Alt) área foliar (AF), peso seco de hojas (PSH), tallos (PST) en plantas de Mentha x piperita L. no inoculadas (NI) o inoculadas con Funneliformis mosseae (IM) y Rhizophagus intraradices (IB1). Referencias: S0: 0\%; S1: 5\%; S2: 10\%; S3: 15\%. Registros a los 60 días después del trasplante (60 DDT). H: micorrización; S: extracto de rizomas de SA. .52

Tabla 15. Efecto de los extractos de rizomas de SA sobre el peso seco de raíces (PSR), longitud de raíz (Long raíz) y volumen de raíz (Vol. raíz) en plantas de Mentha x piperita L. no inoculadas (NI) o inoculadas con Funneliformis mosseae (IM) y Rhizophagus intraradices (IB1). Registros a los 60 días después del trasplante (60 DDT). Referencias: S0: 0\%; S1: 5\%; S2: 10\%; S3: 15\%. H: micorrización; S: extracto de rizomas de SA.

Tabla 16. Análisis de Varianza de los efectos de la micorrización (NI, IM e IB1) y el extracto acuoso de rizomas de SA (S0, S1, S2 y S3) y su interacción sobre la concentración de proteínas solubles de hoja ( $\mu \mathrm{g} \mathrm{g}^{-1} \mathrm{PF}$ ). Referencias: H: micorrización; S: extracto de rizomas de SA.

Tabla 17. Análisis de Varianza de los efectos de la micorrización (NI, IM e IB1) y el extracto acuoso de rizomas de SA (S0, S1, S2 y S3) y su interacción sobre la concentración de clorofila total $\left(\mu \mathrm{g} \mathrm{cm}^{-2}\right)$. Referencias: H: micorrización; S: extracto de rizomas de SA................55

Tabla 18. Análisis de Varianza de los efectos de la micorrización (NI, IM e IB1) y el extracto acuoso de rizomas de SA (S0, S1, S2 y S3) y su interacción sobre la concentración de carotenoides $\left(\mu \mathrm{g} \mathrm{cm}^{-2}\right)$. Referencias: H: micorrización; S: extracto de rizomas de SA.............56

Tabla 19. Análisis de Varianza de los efectos de la micorrización (NI, IM e IB1) y el extracto acuoso de rizomas de SA (S0, S1, S2 y S3) y su interacción sobre la Fotosíntesis neta (PN). Referencias: H: micorrización; S: extracto de rizomas de SA.

Tabla 20. Análisis de Varianza de los efectos de la micorrización (NI, IM e IB1) y el extracto acuoso de rizomas de SA (S0, S1, S2 y S3) y su interacción sobre la transpiración (E). Referencias: H: micorrización; S: extracto de rizomas de SA............................ 58

Tabla 21. Análisis de Varianza de los efectos de la micorrización (NI, IM e IB1) y el extracto acuoso de rizomas de SA (S0, S1, S2 y S3) y su interacción sobre la conductancia estomática (CS). Referencias: H: micorrización; S: extracto de rizomas de SA. 
Tabla 22. Análisis de Varianza de los efectos de la micorrización (NI, IM e IB1) y el extracto acuoso de rizomas de SA (S0, S1, S2 y S3) y su interacción sobre la conductividad relativa (CRR) de raíces. Referencias: H: micorrización; S: extracto de rizomas de SA .60

Tabla 23. Análisis de Varianza de los efectos de la micorrización (NI, IM e IB1) y el extracto acuoso de rizomas de SA (S0, S1, S2 y S3) y su interacción sobre la conductividad relativa $(\mathrm{CRH})$ de hojas de plantas. Referencias: H: micorrización; S: extracto de rizomas de SA......61

Tabla 24. Colonización micorrícica $(\% \mathrm{M})$, arbúsculos (\%Ar) y vesículas (\%) en plantas de Mentha x piperita L. inoculadas con Funneliformis mosseae (IM) y Rhizophagus intraradices (IB1) o no inoculadas, que crecieron con diferentes cantidades de rizomas de sorgo de Alepo. Referencias: R0: $0 \mathrm{~g} \mathrm{~m}^{-2}$ MS de rizomas, R1: $250 \mathrm{~g} \mathrm{~m}^{-2} \mathrm{MS}$ de rizomas, R2: $500 \mathrm{~g} \mathrm{~m}^{-2} \mathrm{MS}$ de rizomas, R3: $800 \mathrm{~g} \mathrm{~m}^{-2} \mathrm{MS}$ de rizomas.

Tabla 25. Análisis de Varianza de los efectos de la micorrización (NI, IM e IB1), rizomas de SA (R0, R1, R2 y R3) y la fecha de registro de altura (7, 10, 13, 16 y 19 DDE) y sus interacciones sobre la altura de plantas. H: micorrización; S: extracto de rizomas de SA; F: fecha de registro de altura $(30,40,50$ y 60 DDP $)$.

Tabla 26. Efecto de los aleloquímicos de rizomas de SA sobre el Área foliar (AF), Peso seco de hojas (PSH) y Peso seco e tallos (PST) de plantas de Mentha x piperita L. no inoculadas (NI) o inoculadas con Funneliformis mosseae (IM) y Rhizophagus intraradices (IB1). Referencias: R0: $0 \mathrm{~g} \mathrm{~m}^{-2} \mathrm{MS}$ de rizomas, R1: $250 \mathrm{~g} \mathrm{~m}^{-2}$ MS de rizomas, R2: $500 \mathrm{~g} \mathrm{~m}^{-2} \mathrm{MS}$ de rizomas, R3: $800 \mathrm{~g}$ $\mathrm{m}^{-2} \mathrm{MS}$ de rizomas.

Tabla 27. Análisis de Varianza de los efectos de la micorrización (NI, IM y IB1) y los rizomas de SA (R0, R1, R2 y R3) y su interacción sobre el Peso seco aéreo de plantas de Mentha x piperita L. no inoculadas (NI) o inoculadas con Funneliformis mosseae (IM) y Rhizophagus intraradices (IB1). Referencias: H: micorrización, R: rizomas de SA.....................68

Tabla 28. Análisis de Varianza de los efectos de la micorrización (NI, IM y IB1) y los rizomas de SA (R0, R1, R2 y R3) y su interacción sobre el Peso seco de raíz de plantas de Mentha $\mathrm{x}$ piperita L. no inoculadas (NI) o inoculadas con Funneliformis mosseae (IM) y Rhizophagus intraradices (IB1). Referencias: H: micorrización, R: rizomas de SA.......................69

Tabla 29. Análisis de Varianza de los efectos de la micorrización (NI, IM y IB1) y los rizomas de SA (R0, R1, R2 y R3) y su interacción sobre el contenido de proteínas foliares $\left(\mu \mathrm{g} \mathrm{cm}^{-2}\right)$. Referencias: H: micorrización, R: rizomas de SA.................................... 70

Tabla 30 . Análisis de Varianza de los efectos de la micorrización (NI, IM e IB1) y los rizomas de SA (R0, R1, R2 y R3) y su interacción sobre la concentración de clorofila total $\left(\mu \mathrm{g} \mathrm{cm}^{-2}\right)$. Referencias: H: micorrización, R: rizomas de SA.

Tabla 31. Análisis de Varianza de los efectos de la micorrización (NI, IM y IB1) y los rizomas de SA (R0, R1, R2 y R3) y su interacción sobre la concentración carotenoides $\left(\mu \mathrm{g} \mathrm{cm}^{-2}\right)$. Referencias: H: micorrización, R: rizomas de SA.....

Tabla 32. Análisis de Varianza de los efectos de la micorrización (NI, IM e IB1) y los rizomas de SA (R0, R, R2 y R3) y su interacción sobre la fotosíntesis neta (PN). Referencias: H: micorrización, R: rizomas de $\mathrm{SA}$. .73

Tabla 33. Análisis de Varianza de los efectos de la micorrización (NI, IM e IB1) y los rizomas de SA (R0, R1, R2 y R3) y su interacción sobre la conductancia estomática (CS). Referencias: $\mathrm{H}$ : micorrización, R: rizomas de SA 
Tabla 34. Análisis de Varianza de los efectos de la micorrización (NI, IM e IB1) y los rizomas de SA (R0, R1, R2 y R3) y su interacción sobre la conductividad relativa de hojas (CRH). Referencias: H: micorrización, R: rizomas de SA........................................ 75

Tabla 35. Análisis de Varianza de los efectos de la micorrización (NI, IM e IB1) y los rizomas de SA (R0, R1, R2 y R3) y su interacción sobre la conductividad relativa de raíces (CRR).

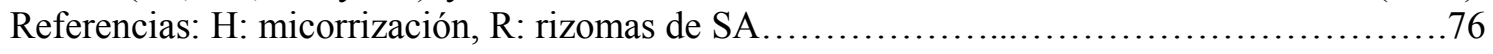

Tabla 36 .Análisis de Varianza de los efectos de la micorrización (NI, IM e IB1) y los rizomas de SA (R0, R1, R2 y R3) y su interacción sobre el porcentaje de aceites esenciales (\% AE). Referencias: H: micorrización, R: rizomas de SA....................................... 77 


\section{Resumen}

La Mentha x piperita es una especie herbácea de ciclo perenne y producción estival, utilizada en Argentina como hoja seca, fresca o para la obtención de aceites esenciales con aplicación en las industrias cosmetológica, alimenticia y medicinal. En el cultivo de menta un alto grado de enmalezamiento provoca importantes daños económicos. El sorgo de Alepo (Sorghum halepense L.) (SA) es una maleza presente en áreas de cultivo de esta especie. El SA es considerada una de las principales malezas invasoras perennes que ocasiona serios inconvenientes en el crecimiento y desarrollo de cultivos estivales como resultado de la competencia por agua, luz y nutrientes y por la producción de sustancias alelopáticas. Las sustancias alelopáticas pueden incrementar la habilidad competitiva de las plantas mediante un efecto directo sobre los individuos próximos, o induciendo efectos indirectos al provocar disturbios en la asociaciones benéficas de cierta plantas con hongos formadores de micorrizas arbusculares (HMA). Aproximadamente un $80 \%$ de las familias de plantas tienen la potencialidad de formar este tipo de asociación. Las plantas micorrizadas presentan una mayor capacidad de resistencia/tolerancia a los estreses bióticos y abióticos. Considerando la importancia económica del cultivo de menta, la respuesta favorable a la micorrización con HMA y teniendo en cuenta los comprobados efectos alelopáticos del sorgo de Alepo (SA), el objetivo general del trabajo fue determinar el efecto de los aleloquímicos provenientes de los de rizomas de SA sobre el crecimiento, la producción de aceites esenciales y la micorrización de plantas de menta piperita.

Se evaluaron distintas concentraciones de extractos acuosos de rizomas y distintas cantidades de rizomas de SA, sobre plántulas de menta obtenidas a partir de estolones, estacas o plantines inoculados con diferentes especies de HMA (Funneliformis mosseae y Rhizophagus intraradices B1). Se realizaron mediciones morfológicas (peso seco, área foliar, longitud de raíz), fisiológicas (fotosíntesis y transpiración, conductividad relativa de membranas celulares), bioquímicas (clorofila, proteínas, ALP) y porcentaje de aceites esenciales. Además, se evaluó el porcentaje de micorrización y la viabilidad de las estructuras fúngicas. Tanto los extractos acuosos como los compuestos liberados por los rizomas de SA en el sustrato, interfirieron en la micorrización de las plantas de Menta piperita y su efecto fue dependiente de la 
concentración tanto de extracto como de la densidad de rizomas. El mayor nivel de colonización micorrícica se presentó en los tratamientos libres de SA tanto para $F$. mosseae como $R$. intraradices disminuyendo significativamente con la mayor dosis de extracto. El alto grado de dependencia micorrícica en presencia de SA, puso de manifiesto la importancia de la simbiosis para sobrellevar esa situación de estrés. El crecimiento disminuyó por la presencia de los extractos acuosos de rizomas y no fue afectado por los aleloquímicos liberados por los rizomas en el suelo. Las mayores concentraciones de extracto redujeron la fotosíntesis neta, y aumentaron la conductividad relativa de las membranas de hojas y raíces. La inoculación con HMA morigeró estos efectos adversos. Las mayores concentraciones de aleloquímicos provenientes de los rizomas de SA, provocaron un daño significativo en las membranas celulares de las raíces de las plantas no inoculadas, mientras que las raíces de las plantas inoculadas no mostraron daño. La reducción en el crecimiento de las raíces por parte de los aleloquímicos, condujo a un menor desarrollo aéreo, la micorrización, en parte, revirtió esta situación. La inoculación con hongos micorrícicos arbusculares incrementó el porcentaje de aceites esenciales en todos los tratamientos. Estos resultados se correlacionan con la mayor producción de materia seca de las plantas inoculadas. Los mecanismos que provocaron las reducciones observadas en el crecimiento y la micorrización de las plantas de Menta piperita no son claros. Este trabajo aporta al conocimiento sobre el impacto del estrés alelopático en la simbiosis de HMA con plantas de Menta piperita. Teniendo en cuenta que existe cierto grado de variación de los efectos inhibitorios de acuerdo al origen y la concentración de los aleloquímicos en la colonización y el crecimiento de las plantas, se requieren futuras investigaciones para determinar el posible grado de interferencia de los mismos. Se concluye que en las condiciones experimentadas, la inoculación con HMA modera los efectos adversos causados por las altas concentraciones de aleloquímicos provenientes de rizomas de SA en los extractos acuosos y en los sustratos utilizados. El uso de hongos micorrícicos puede ser una alternativa de interés para mejorar la productividad de los cultivos y la eficiencia de los agroecosistemas especialmente bajo situaciones de estrés, al optimizar el uso de los recursos y propiciar un sistema de producción sustentable. 


\section{Abstract}

Mentha $\mathrm{x}$ piperita is a herbaceous species of perennial cycle and summer production In Argentina is used as dry or fresh leaf or to obtain essential oils to be applied in cosmetology, food and medical industries. In Mint crops a high level of weed causes significant economic damage. The Johnson grass (Sorghum halepense L.) (SA) is a weed that is present in cultivation areas of this species. The SA is considered one of the most invasive perennial weeds that causes serious problems in the growth and development of summer crops as a result of competition and production of allelopathic substances. Allelopathic substances can increase the competitive ability of plants through a direct effect on nearby individuals, or by inducing indirect effects causing disturbances in the beneficial properties of some plants with arbuscular mycorrhizal fungi (AMF). About $80 \%$ of plant families have the potentiality to form this kind of association. Mycorrhizal plants show greater resistance / tolerance to biotic and abiotic stress. Considering the economic importance of mint crops, the favorable response to mycorrhization with HMA and given the proven allelopathic effects of Johnson grass (SA), the objective of this research was to determine the effect of allelochemicals from the rhizome SA on the growth and the mycorrhizal of the peppermint plant. Different concentrations of aqueous extracts of rhizomes and of different amounts of SA rhizomes were evaluated on mint seedlings obtained from stolons, cuttings or seedlings inoculated with different species of HMA (Funneliformis mosseae and Rhizophagus intraradices B1), grown in speedling and pots. Several measurements were carried out: Morphological (dry weight, leaf area, root length), physiological (photosynthesis and transpiration, relative conductivity of cell membranes), biochemical (chlorophyll, protein, ALP) and percentage of essential oils. In addition, the percentage of mycorrhizal and viability of fungal structures were evaluated. The aqueous extracts and the compounds released from the rhizomes of SA on the substrate, interfered in the mycorrhization of Menta piperita plants and its effect was dependent on the concentration of both extract and rhizomes density. The highest level of mycorrhizal colonization was presented in free treatments for both SA and F. mosseae and R. intraradices significantly reducing with the highest dose of extract. The 
high level of mycorrhizal dependency in the presence of SA, highlighted the importance of symbiosis to cope with that stress. The growth decreased by the presence of aqueous extracts of rhizomes and was not affected by allelochemicals released by the rhizomes in the ground. Higher concentrations of extract reduced net photosynthesis and increased the relative conductivity of membranes leaves and roots. Inoculation with AMF reduced these adverse effects. The highest concentrations of allelochemicals from rhizomes SA, caused significant damage to the cell membranes of the roots of noninoculated plants, while roots of inoculated plants showed no damage at membrane levels. The reduction in root growth by allelochemicals led to lower aerial part development, mycorrhizal partially reversed this situation. Inoculation with arbuscular mycorrhizal fungi increased the percentage of essential oils in all treatments. These results correlate with greater dry matter production of inoculated plants. The mechanisms that caused the observed reductions in growth and mycorrhizal of Peppermint plants are unclear. This work contributes to the knowledge on the impact of allelopathic stress in symbiosis AMF-Peppermint plants. Given that there is some degree of variation in the inhibitory effects according to the origin and concentration of allelochemicals in colonization and plant growth, future research is needed to determine the possible degree of interference. We conclude that in the conditions experienced, inoculation with HMA alleviates adverse effects caused by high concentrations of allelochemicals from rhizomes SA in aqueous extracts and the substrates used. The use of mycorrhizal fungi can be an interesting alternative to improve crop productivity and efficiency of agro-ecosystems under stress especially, optimizing the use of resources and promoting a sustainable production system. 
Capítulo 1

Introducción 


\section{Las plantas aromáticas}

Las plantas aromáticas se definen como aquellas que pueden generar por algún proceso fisicoquímico un producto con olor o sabor determinado, independientemente de su calidad comercial o estética (Bandoni, 2002)

Estas especies vegetales son utilizadas a nivel comercial o industrial como material vivo, fresco o desecado o para la obtención de extractivos y aceites esenciales debido a sus características organolépticas, que otorgan aromas, colores y sabores característicos a los alimentos (Bandoni, 2002).

Los aceites esenciales, son líquidos oleosos, aromáticos, pertenecientes al metabolismo secundario de las plantas, formados por una mezcla de diversos compuestos químicos de estructuras diferentes entre los que se incluyen algún tipo de terpenoide (Ringuelet and Viña, 2013). Se obtienen a partir de distintos materiales vegetales, tales como flores, yemas, semillas, hojas, brotes, corteza, madera, frutos, raíces, etc. (Ringuelet and Viña, 2013). Se destinan principalmente a la industria perfumística. Muchos de ellos, o alguno de sus componentes presentan propiedades antimicrobianas e insecticidas (Burt, 2004).

\section{Mentha x piperita $L$.}

Con el nombre de mentas se conocen a una gran cantidad de especies pertenecientes a la Familia Labiatae. En la actualidad se reconocen 18 especies y 11 híbridos con la denominación de Mentha (Lawrence, 2007). El cultivo y utilización de estas especies data de varios siglos, su centro de origen se encuentra en Asia Central y el Medio Oriente (Harley, 1977), diseminadas por los árabes durante el Medioevo por Europa y Norte de África, posteriormente fueron introducidas en América y cultivadas en regiones subtropicales (Ribeiro and Diniz, 2008). Se les atribuye propiedades digestivas, calmantes, anestésicas, como así también culinarias y cosméticas (Bruneton, 1991; Derwich et al., 2010; Kumar et al., 2011).

Entre las especies que se destacan por su importancia económica se encuentra la Mentha $x$ piperita L, (menta inglesa, menta Mitcham), Mentha arvensis L. (menta japonesa); la Mentha spicata (Spearmint americana); y la Mentha cardiaca (Spearmint escocesa) (Rouquaud y Lúquez, 2004). 


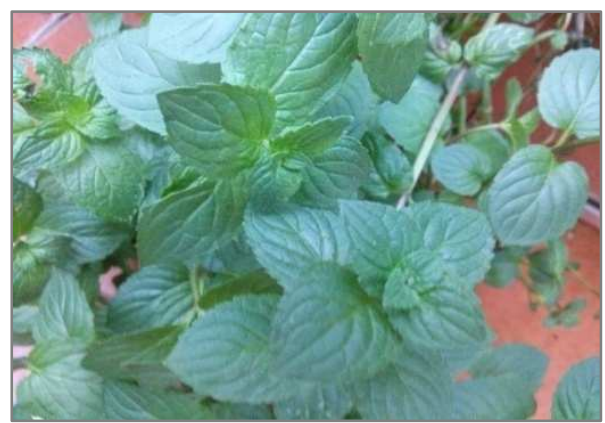

Figura 1. Mentha x piperita L. Fuente propia

La Mentha x piperita L es producto de hibridaciones espontáneas (cruzamientos entre individuos) y luego multiplicada en forma vegetativa, siendo una de las especies de menta mas cultivadas en Argentina (Bandoni, 2002). El valor comercial de esta especie está dado por su aceite esencial, cuyo componente mayoritario es el mentol, utilizado en la industria alimenticia, para la fabricación de licores y golosinas, para dar el sabor conocido como "peppermint" y en la industria perfumística (Alippi et al, 1996). También se comercializan sus hojas desecadas, utilizadas para infusiones y sus hojas frescas con aplicaciones culinarias. Entre sus propiedades medicinales, se destaca por su capacidad estimulante, antisépticas y analgésicas (Sánchez, 1996). El sabor a "menta" es el tercero en importancia en todo el mundo, después de la vainilla y el limón (Arizio et al., 2008). La popularidad de este sabor se asocia sobre todo, a conceptos de frescor e higiene.

Su cultivo presenta expectativas de expansión en una amplia región geográfica del país; existiendo un aumento de la demanda del producto seco y fresco, como así también de su aceite esencial.

La importancia de esta especie se debe a que la Argentina tiene ventajas comparativas para la producción de hierbas aromáticas, debido a su diversidad de climas y la gran extensión de su territorio, apto para el desarrollo de numerosas especies aromáticas y medicinales. Los cambios en los hábitos de los consumidores, especialmente en países industrializados, han influenciado, en gran medida, la selección de materias primas, su industrialización y el comercio de productos naturales.

Las preferencias por una vida sana y nuevos estudios sobre aditivos, han impulsado el reemplazo de substancias químicas artificiales por productos naturales y mayor uso de especias (Arizio y Curioni, 2003). La Argentina tiene la posibilidad de 
llegar a ser competitiva e incrementar su participación en el comercio mundial debido no solo a esta especie, sino a la variedad de especies aromáticas cultivadas y nativas y a la excelente calidad de sus aceites esenciales (www.cofecyt.mincyt.gov.ar/pcias_pdfs/.../uia_esp_hierbas_08.pdf).

De acuerdo a los datos estadísticos oficiales correspondientes al censo nacional agropecuario 2002, la superficie destinada en la Argentina al cultivo de menta totaliza las 96 ha (CNA, 2002). En la figura 2, se presentan los registros de superficie por provincia destinada a la producción de menta en Argentina, a campo y bajo cubierta. (Sistema Nacional de Vigilancia y Monitoreo de Plagas - SENASA. 26/11/2009). La principal zona de cultivo es la provincia de Córdoba, registrándose también cultivos en las provincias de San Luis, San Juan, Mendoza, Buenos Aires y Tucumán (Hierbas en Argentina: Secretaría de Agricultura, Ganadería, Pesca y Alimentos, 2000).

La Mentha x piperita L es una especie herbácea, perennes, productora de gran cantidad de estolones. Los tallos son cuadrangulares, color púrpura. Las flores son blancas o lilas dispuestas en inflorescencias espiciformes terminales. Las hojas poseen pelos glandulares (Curioni and Arizio, 2006). Se cultivan dos tipos o variedades: la negra, es la variedad vulgaris Solé y la blanca es la var. Officinalis Solé. La variedad negra tiene tallos purpúreos y hojas verde-oscuras, con nervaduras purpúreas; es la más difundida, de gran desarrollo, rusticidad y de mayor rendimiento en aceite esencial, pero de menor calidad que la blanca. La variedad blanca tiene hojas y tallos verde claro (Curioni and Arizio, 2006).

Comercialmente, esta especie se reproduce por vía agámica o vegetativa, ya que raramente da semillas fértiles o presentan una gran variabilidad genética. Se implanta comúnmente por medio de estolones o plantines. Los estolones pueden implantarse en cualquier momento del año, aunque se recomienda en otoño o invierno; mientras que la implantación por plantines se recomienda hacerla a principios de primavera cuando estos alcanzan 10 a $15 \mathrm{~cm}$ de altura (Ringuelet and Cerimele, 2002). 


\begin{tabular}{|c|c|c|}
\hline Provincia & Tipo & Cantidad \\
\hline Total del País & $\begin{array}{c}\text { A campo (ha) } \\
\text { Bajo Cubierta }\left(\mathrm{m}^{2}\right)\end{array}$ & $\begin{array}{c}96 \\
4477,0 \\
\end{array}$ \\
\hline Buenos Aires & $\begin{array}{c}\text { A campo (ha) } \\
\text { Bajo Cubierta }\left(\mathrm{m}^{2}\right)\end{array}$ & $\begin{array}{c}8,8 \\
3788,0\end{array}$ \\
\hline Catamarca & $\begin{array}{c}\text { A campo (ha) } \\
\text { Bajo Cubierta }\left(\mathrm{m}^{2}\right)\end{array}$ & $\begin{array}{c}0,4 \\
200,0\end{array}$ \\
\hline Córdoba & $\begin{array}{c}\text { A campo (ha) } \\
\text { Bajo Cubierta }\left(\mathrm{m}^{2}\right)\end{array}$ & $\begin{array}{c}42 \\
-\end{array}$ \\
\hline Chubut & $\begin{array}{c}\text { A campo (ha) } \\
\text { Bajo Cubierta }\left(\mathrm{m}^{2}\right)\end{array}$ & $\begin{array}{c}0,7 \\
-\end{array}$ \\
\hline Entre Ríos & $\begin{array}{c}\text { A campo (ha) } \\
\text { Bajo Cubierta }\left(\mathrm{m}^{2}\right)\end{array}$ & $\begin{array}{c}7,2 \\
450,0\end{array}$ \\
\hline Jujuy & $\begin{array}{c}\text { A campo (ha) } \\
\text { Bajo Cubierta }\left(\mathrm{m}^{2}\right)\end{array}$ & $\begin{array}{c}0,4 \\
10,0\end{array}$ \\
\hline La Pampa & $\begin{array}{c}\text { A campo (ha) } \\
\text { Bajo Cubierta }\left(\mathrm{m}^{2}\right)\end{array}$ & $\begin{array}{c}0,1 \\
-\end{array}$ \\
\hline La Rioja & $\begin{array}{c}\text { A campo (ha) } \\
\text { Bajo Cubierta }\left(\mathrm{m}^{2}\right)\end{array}$ & $\begin{array}{c}2,2 \\
-\end{array}$ \\
\hline Mendoza & $\begin{array}{c}\text { A campo (ha) } \\
\text { Bajo Cubierta }\left(\mathrm{m}^{2}\right)\end{array}$ & $\begin{array}{c}6,1 \\
-\end{array}$ \\
\hline Neuquén & $\begin{array}{c}\text { A campo (ha) } \\
\text { Bajo Cubierta }\left(\mathrm{m}^{2}\right)\end{array}$ & $\begin{array}{l}1,4 \\
4,0 \\
\end{array}$ \\
\hline Río Negro & $\begin{array}{c}\text { A campo (ha) } \\
\text { Bajo Cubierta }\left(\mathrm{m}^{2}\right)\end{array}$ & $\begin{array}{c}0,2 \\
10,0\end{array}$ \\
\hline San Juan & $\begin{array}{c}\text { A campo (ha) } \\
\text { Bajo Cubierta }\left(\mathrm{m}^{2}\right)\end{array}$ & $\begin{array}{c}12,6 \\
-\end{array}$ \\
\hline Santa Fe & $\begin{array}{c}\text { A campo (ha) } \\
\text { Bajo Cubierta }\left(\mathrm{m}^{2}\right)\end{array}$ & $\begin{array}{c}9,3 \\
15,0 \\
\end{array}$ \\
\hline Santiago del Estero & $\begin{array}{c}\text { A campo (ha) } \\
\text { Bajo Cubierta }\left(\mathrm{m}^{2}\right)\end{array}$ & $\begin{array}{c}4,6 \\
-\end{array}$ \\
\hline
\end{tabular}

Figura 2: Superficie por provincia destinada a la producción de menta en Argentina, a campo y bajo cubierta. Fuente: Sistema Nacional de Vigilancia y Monitoreo de Plagas - SENASA. 26/11/2009.

Las mentas se desarrollan bien en climas templados a templados cálidos, con elevada luminosidad. En la provincia de Buenos Aires se planta en los meses de octubre y noviembre. El momento de cosecha depende de cuál sea el destino de la producción. Para la obtención de aceite esencial, se realiza un primer corte en plena floración. En cambio si su destino es la producción de hoja seca, la cosecha comienza en prefloración concluyendo en plena floración, dependiendo de la capacidad de secado (Prakash, 1990). 
El rendimiento en materia verde aproximado es de 7.000 a $12.000 \mathrm{~kg} \mathrm{ha}^{-1}$ equivalente a 2.000 a $3.000 \mathrm{~kg} \mathrm{ha}^{-1}$ de material seco. El rendimiento en aceite esencial es de 20 a $45 \mathrm{~kg} \mathrm{ha}^{-1}$, cuyo componente principal es el mentol. Dicho compuesto se halla en diferentes proporciones dependiendo de las condiciones ambientales donde se desarrolla el cultivo y de factores genéticos, pudiéndose encontrar al estado libre y/o combinado con ésteres (Curioni and Arizio, 2006).

Al ser una hierba perenne puede vegetar durante varios años en un mismo sitio. El ciclo vegetativo económico de la menta es de aproximadamente 150 días, durante el período estival. En otoño cae su follaje, entrando en un estado de reposo, manteniendo los rizomas por debajo y los estolones por encima de la superficie del suelo. Durante este periodo deben realizar las labores culturales para mantener el cultivo libre de malezas mediante carpidas y uso de herbicidas, hasta el momento en que el desarrollo de la planta cubra el terreno.

En el cultivo de menta las malezas no solo compiten por los nutrientes, luz, agua y espacio sino que también, en la cosecha, las malezas que conviven con ella dificultan la tarea y en muchos casos se incorporan al proceso de destilación perjudicando la calidad del aceite esencial o contaminando la hierba deshidratada (Curioni, 2000). Un elevado grado de enmalezamiento del cultivo provoca importantes pérdidas y en muchos casos significará la renovación total de la superficie plantada al finalizar el primer año. Curioni, (2000), recomienda renovar el cultivo anualmente o cada dos años si no se realizó un control anticipado de las malezas.

Tradicionalmente, el control de malezas en estos cultivos se realiza mecánicamente y, en menor medida, en forma manual. En el país existen muy pocos estudios sobre el comportamiento de herbicidas en éstas y otras aromáticas cultivadas, tanto en lo que respecta a su eficiencia de control de las malezas como a su efecto sobre el cultivo (Darré et al., 2004). Existen algunos trabajos extranjeros sobre el uso de herbicidas en Mentha spp. (Pank, 1990; Hartley, 1993). El análisis de estos trabajos, muestran que no existe un paquete tecnológico importante para controlar el desarrollo de las malezas, aunque su control se justificaría por las pérdidas ocasionadas.

Entre las malezas frecuentes en el cultivo se pueden mencionar de hoja ancha: ortiga, enredadera anula, quínoa, yuyo colorado, verdolaga, fumaria, etc., y entre las gramíneas: cebollín, Ray grass y sorgo de Alepo (Darré et al., 2004). No se han hallado 
publicaciones sobre el grado de interferencia del Sorghum halepense sobre el cultivo de menta, a pesar que las áreas de su cultivo se superponen con el de esta maleza.

\section{Sorgo de Alepo (Sorghum halepense (L.) Pers.) como maleza de cultivos agrícolas.}

Se considera malezas a aquellas especies espontáneas que interfieren con el uso que el hombre da a la tierra (Rejmanek, 2005). Para el productor agropecuario las malezas son consideradas como plantas que crecen fuera de lugar, generando pérdidas económicas en forma directa, disminuyendo el rendimiento de los cultivos. En un agroecosistema, las malezas pueden interferir compitiendo con los cultivos por el espacio, agua, luz y nutrientes (Leguizamón, 1999, Zimdahl, 2007). Además, algunas malezas pueden interferir a través de efectos alelopáticos, debido a la liberación de compuestos químicos que inhiben el crecimiento de los cultivos (Bhowmik and Inderjit, 2003; Laynez-Garsaball and Méndez-Natera, 2006).

Sorghum halepense (L.) Pers. es una maleza que compite por recursos y ejerce una importante acción alelopática sobre cultivos de verano con como maíz (Zea mays L.), soja (Glycine max Merr), sorgo granífero y algodón (Gossypium hirsutum L.), entre otros (Lolas and Coble 1982; Rosales Robles et al., 1999). Es una gramínea invasora perenne, de desarrollo vegetativo estival, considerada una de las 10 malezas más importantes del mundo (Holm et al., 1977), originaria de la región del Mediterráneo. El Sorghum halepense, se conoce vulgarmente con el nombre de sorgo de Alepo, cañota, pasto ruso, pertenece a la familia de las gramíneas (Poaceae), de ciclo de vida perenne, crecimiento primavera, verano, otoño y cuyo periodo de germinación/brotación va de agosto a febrero. Se reproduce por semilla, corona y a partir de rizomas. La fracción aérea no resiste las bajas temperaturas de finales de otoño y del invierno (Mitidieri, 1983). Produce aproximadamente 250 semillas/panoja, de las cuales el $90 \%$ son viables. Los rizomas de sorgo de Alepo constituyen una importante forma de propagación. La producción de rizomas varía en función de los sistemas de cultivo, la densidad de la maleza y el ecotipo, entre otros factores (Mac Worther and Jordan, 1976). Ghersa y Satorre, (1981) establecieron distintos grados de saturación de rizomas en un cultivo de maíz luego de un tratamiento químico fluctuando entre 100 a $4000 \mathrm{~kg}$ $\mathrm{ha}^{-1}$. Ghersa y Soriano (1980), determinaron que un sistema agrícola donde se realizaba monocultivo de maíz, la población de rizomas alcanzó los $834,7 \mathrm{~g} \mathrm{~m}^{-2}$ de rizomas vivos. 
Leguizamón, (2003) menciona que la población de rizomas en un suelo invadido por Sorgo de Alepo puede variar en cuanto a la forma, tamaño y niveles de brotación, señalando que en un sistema ausente de cultivo o con niveles de poblacionales bajos, la tasa de generación de rizomas es la máxima. En un sistema bajo cultivo hace referencia a niveles de $500 \mathrm{~g} \mathrm{~m}^{-2}$ de materia seca de rizomas. Mc Whorter (1981) caracteriza a esta especie como de alta productividad y capacidad de crecimiento, llegando a producir 19 toneladas de rizomas por hectárea. Asimismo Pengue et al., (2009) citan que los rizomas constituyen una fuente importante para la propagación y perpetuación de la especie, indicando que en una temporada, en competencia con un cultivo puede llegar a producir 6 a 8 toneladas de rizomas por hectárea y hasta 40 y 50 toneladas sin competencia de cultivo.

De acuerdo a los datos informados por el Sistema Nacional de Vigilancia y Monitoreo de Plagas, SENASA, la longevidad de los propágalos se estima, para semillas 6 años y para rizomas, 1 año, mientras que 10 macollos. $\mathrm{m}^{-2}$ producen una pérdida de $23 \%$ del rendimiento potencial de soja GM VI (sembrada a una distancia de 0,7 m entre surcos).
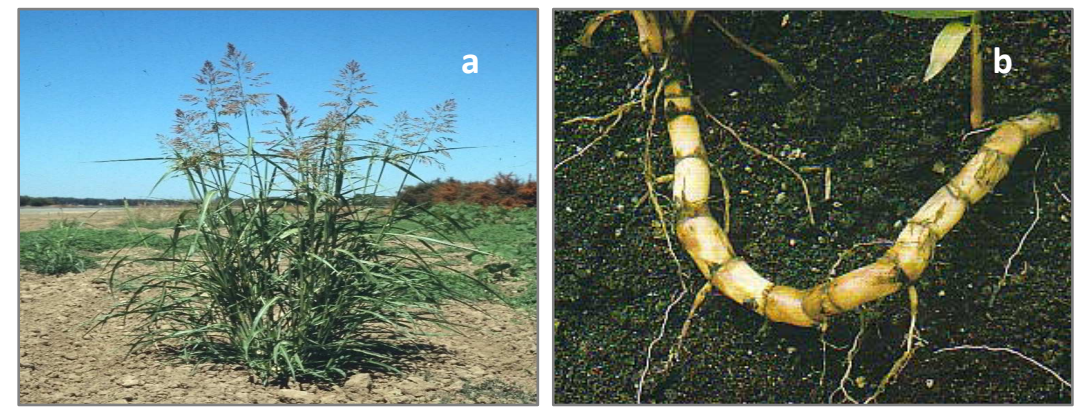

Figura 3. a) Planta entera y b) rizomas de Sorghum halepense (L.) Pers.

La propagación por rizomas resulta eficaz para la persistencia de esta maleza en una gran variedad de agroecosistemas (Leguizamón, 2012), llegando a representar el $30 \%$ de la biomasa total de la planta (Leguizamón 2012). Al mismo tiempo existen evidencias de que los fenómenos alelopáticos pueden contribuir a su establecimiento en nuevos agroecosistemas (Laynez-Garsaball and Méndez-Natera, 2006).

Numerosos estudios han investigado la competitividad de esta maleza en los sistemas agrícolas de la región pampeana argentina, junto con la caracterización ecofisiológicas de esta especie (Bénech-Arnold et al., 1990; Ghersa et al., 1990, 1992). 
Dichos estudios demuestran importantes pérdidas en el rendimiento de los cultivos que variaron entre el 12 y el 95\% en el maíz, de 19 a 99\% en girasol y 18 a 94\% en soja para bajos y altos niveles de infestación de Sorghum halepense, respectivamente (Ghersa et al., 1985, 1993; Ghersa and Martínez-Ghersa, 1991).

El Sorghum halepense además de provocar la disminución del rendimiento de los cultivos por competencia de recursos, también ejerce una importante acción alelopática, producto de sustancias fitotóxicas provenientes de extractos de hojas o rizomas liberados al suelo (Burnside and Wicks, 1965; Friedman and Horowitz, 1970; Abdub Wahab and Rice, 1976; Horowitz, 1973; Beltrano and Montaldi, 1979, 1980, 1982; Lolas and Coble, 1982; Bridges and Chandler, 1987; Beltrano and Caldiz, 1993, Rosales Robles et al., 1999).

En numerosos trabajos se ha demostrado el efecto adverso de las sustancias alelopáticas presentes en el sorgo de Alepo sobre el crecimiento y rendimiento de cultivos de importancia agronómica como el maíz, cebada, soja y trigo (Putman and Weston, 1986; Velu and Rajagopal, 1996; Acciaresi and Asenjo, 2003). Entre los compuestos químicos de acción alelopática identificados, obtenidos a partir de la descomposición de residuos de sorgo de Alepo se encuentran, $p$-benzoquinonas (sorgoleona), glucósidos cianogénicos, taninos y ácidos fenólicos ( $p$-cumárico, ferúlico, vanílico) (Einhellig, 1996; Sene et al., 2001). También se ha estudiado la persistencia en el suelo a lo largo del tiempo de dichos compuestos (Einhellig and Souza, 1992; Anaya, 1999) y la susceptibilidad de los mismos a la degradación microbiana (Blum, 1998, Inderjit, 2005). Einhellig, (1996) establece que, dada la complejidad de los procesos ecológicos, en el estudio de la alelopatía no deben omitirse las interacciones entre el efecto inhibitorio de los aleloquímicos, las condiciones edafoclimáticas, los diferentes biotipos y las distintas alternativas de manejo agronómico.

Asgharipour and Armin, (2010), determinaron el efecto inhibitorio de extractos acuosos obtenidos de raíces y hojas de Sorgo de Alepo sobre la germinación de semillas y el crecimiento de plántulas aromáticas y medicinales como Ocimum basilicum, Negella sativa, Cuminum cyminum, Foeniculum vulgare, Plantago ovata y P. psyllium. Estos autores concluyeron que el efecto alelopático era dependiente de la concentración y del órgano del que provenía el extracto. Sin embargo no se registra información sobre el grado de interferencia del sorgo de Alepo sobre el cultivo de plantas de menta, a pesar que las áreas de su cultivo se superponen con el de esta maleza. 
La alelopatía representa el área de la Bioquímica Ecológica que estudia las interacciones químicas entre plantas (Harborne, 1998). Debido a la dificultad de discernir si el efecto que produce una planta sobre otra se debe a un compuesto químico en particular o a la competencia por recursos, en 1969 Muller introdujo el término de interferencia, para referirse al conjunto de los efectos alelopáticos y también los de competencia por espacio y recursos (agua, nutrientes, luz). Más tarde Rice, (1984) definió la alelopatía como "Cualquier efecto, perjudicial o beneficioso, directo o indirecto, que una planta produce sobre otra (incluyendo los microorganismos) a través de la producción de compuestos químicos liberados al medio". La International Allelopathy Society en el año 1996, define la alelopatía como: "Cualquier proceso que implica metabolitos secundarios producidos por especies exóticas que influyen en el crecimiento y desarrollo de las especies nativas (excluye los animales), comprende efectos positivos y negativos". Luego, la Sociedad de Alelopatía Internacional, amplió esta definición a cualquier proceso que involucre metabolitos secundarios producidos por las plantas, microorganismos, virus y hongos que influyen en el crecimiento y desarrollo de sistemas agrícolas y biológicos. Los compuestos químicos alelopáticos que desencadenan este proceso se denominan compuestos, agentes o sustancias alelopáticas (Rice, 1984; Putnam and Tang, 1986; Inderjit y Dakshini, 1995), los cuales son producidos por una planta donadora hacia una receptora. Estos compuestos son producto del metabolismo secundario y su composición química y concentración varían de acuerdo a las especies, la edad de las plantas y las condiciones climáticas (Dayan, 2006). La acción fitotóxica depende de su concentración, persistencia y destino en el medio donde son liberados (Einhellig, 1995). La actividad alelopática puede ser ejercida por uno o varios compuestos en forma conjunta (Inderjit y Duke, 2003), como así también a una nueva especie química resultante de la descomposición de aleloquímico por microorganismos del suelo (Blum, 1998).

Los compuestos con actividad alelopática pertenecen en general a los denominados metabolitos secundarios, aunque también pueden ser metabolitos primarios (Einhellig, 1995). Estos compuestos presentan diversas estructuras químicas, entre los que se encuentran compuestos fenólicos como flavonoides (Rice, 1984; Stermitz et al., 2003), taninos hidolizables (Rice, 1984), ácidos fenólicos (ácido 
ferúlico) y derivados del fenilpropano (ácido clorogénico, cafeico), (Xuan et al., 2004, Jarchow y Cook, 2009), cumarinas (García et al., 1995), quinonas (juglona, sorgoleona) (Einhellig et al., 1993). Algunos alcaloides también presentan probada acción alelopática como la hordeína (Liu and Lovett, 1993, Ens et al., 2010), terpenoides (Harborne, 1998), etc.

Estos aleloquímicos se los puede encontrar en todos los órganos vegetales (Leicah, 2006). Se sintetizan y almacenan en distintos tipos de células en forma libre o conjugada con otras moléculas y son liberados al entorno en respuesta a distintas situaciones en las que comúnmente están involucradas condiciones de estrés biótico y/o abiótico (Sampietro, 2002). Estos compuestos son liberados al ambiente edáfico a través de cuatro vías principales, dependiendo de la naturaleza química del compuesto, por volatilización desde los tejidos aéreos, lixiviación de sustancias solubles a partir de tallos y hojas, descomposición de residuos o secreción por diferentes partes de la planta como las hojas, tallos, raíces y flores (Rice, 1984, Putnam and Tang, 1986; Inderjit and Dakshini, 1995).

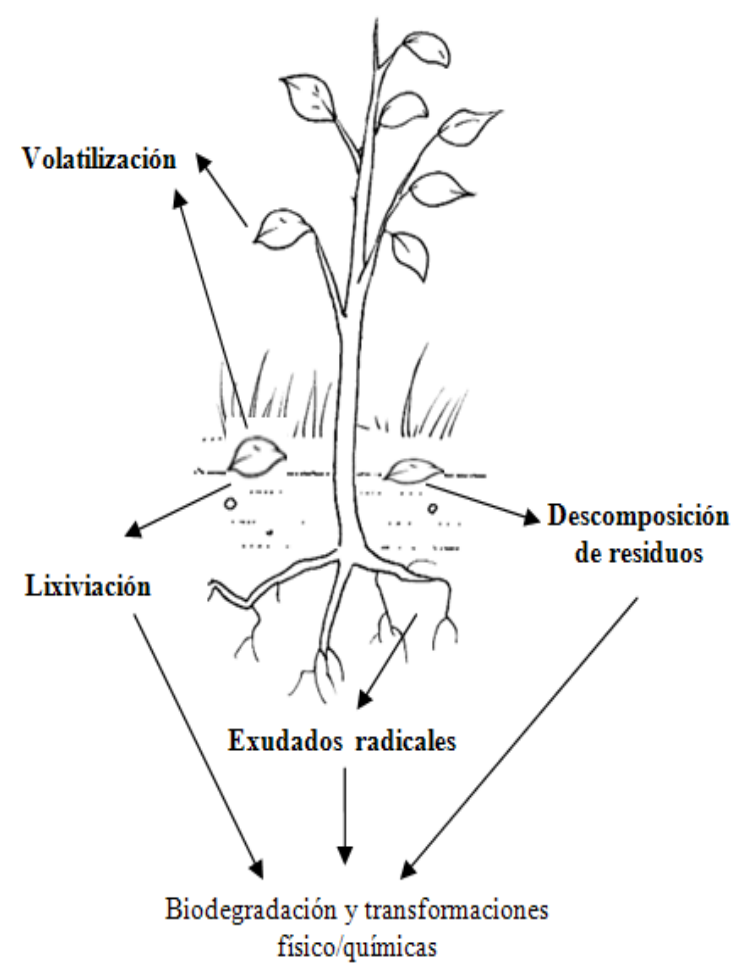

Figura 4. Vías de liberación de aleloquímicos 
Todos los procesos básicos llevados a cabo por el metabolismo vegetal tales como, inhibición de la división celular (Gianfrancisco et al., 1998), síntesis proteica (Zweig et al., 1972), respiración (Putman, 1985), fotosíntesis (Einhellig et al., 1996; Rizvi et al., 1992; Hussain and Reigosa, 2011) síntesis de clorofila (Hussain and Reigosa (2011), permeabilidad de membranas plasmáticas (Macias et al., 2003), balance hormonal (Watanabe et al., 1982, Hollapa and Blum, 1991) absorción de nutrientes y relaciones hídricas pueden ser alteradas por estas sustancias alelopáticas (Yamane et al., 1992). Una de las principales respuestas estudiadas es la inhibición de la germinación de semillas y alteraciones en el crecimiento de las plantas (Lynch, 1980; Putman 1985; Acciaresi and Asenjo, 2003).

Los ácidos benzoico y cinámico en bajas concentraciones pueden inhibir el transporte de electrones en la fase lumínica de la fotosíntesis (Einhellig, 1995). La sorgoleona, presente en exudados radiculares de Sorghum halepense, actúa a nivel del fotosistema II (Einhellig, 1995).

La bibliografía menciona que estos compuestos fitotóxicos son producidos tanto por ciertas especies cultivadas como por especies no cultivadas, entre las cuales se incluyen las malezas (Zamorano, 2006).

\section{Micorrizas arbusculares}

La actividad microbiana del suelo influye sobre sus características físicas, químicas y biológicas, las cuales determinan la fertilidad de los agroecosistemas (Guerra Sierra, 2008).

Los microorganismos benéficos entre los que se destacan los hongos micorrícicos, los microorganismos fijadores de nitrógeno y las rizobacterias promotoras del crecimiento vegetal (PGPR) ejercen un papel fundamental sobre la calidad del suelo (Azcón, 2000).

Las micorrizas arbusculares (HMA) son asociaciones simbióticas mutualistas que se establecen entre ciertos hongos del Phylum Glomeromycota y las raíces de la mayoría de las plantas, siendo considerada como la simbiosis de naturaleza más antigua (Smith and Read, 1997; Schüßler et al., 2001). Aproximadamente un $80 \%$ de las familias de plantas existentes tienen la potencialidad de formar este tipo de asociación 
(Trape, 1987; Schwarzott et al., 2001; Brundrett, 2004). En esta asociación mutualista, el hongo coloniza biotróficamente la corteza de la raíz, sin causar daño a la planta, llegando a ser fisiológica y morfológicamente, parte integrante dicho órgano (Gianinazzi-Pearson, 1996). La planta hospedadora aporta al hongo (heterótrofo) esqueletos carbonados procedentes de la fotosíntesis y un hábitat protegido, mientras que el hongo contribuye, por medio de su red de hifas externas a aumentar la absorción de nutrientes y agua del suelo transfiriéndolos a la planta hospedadora lo que favorece la producción de biomasa (Gange and Ayres, 1999).

\section{Características del proceso de colonización}

El proceso de colonización de los hongos micorrícicos arbusculares comienza con la germinación de las esporas que se encuentran en el suelo o en las raíces de las plantas. En condiciones favorables de humedad y temperatura, las esporas desarrollan uno o varios tubos germinativos formando el micelio externo, que se extiende hasta encontrar la raíz para colonizarla (Giovannetti et al., 1993). Las raíces de las plantas exudan compuestos que intervienen en el reconocimiento planta-hongo (GianinazziPearson et al., 1989; Akiyama et al., 2005), estimulando la germinación de esporas y crecimiento y ramificación de las hifas, que incluyen flavonoides (Vierheilig and Piché, 2002), strigolactona (Akiyama et al., 2005) y auxinas (Podila, 2002).

Cuando una hifa alcanza la superficie de la raíz forma una estructura llamada apresorio, producto de la ramificación y engrosamiento de la pared celular de la hifa. Luego la hifa penetra en la raíz de la planta. El proceso de colonización continúa con la formación de hifas intercelulares que colonizan la corteza radical, dando lugar a las estructuras características de esta simbiosis que son los arbúsculos, ramificaciones dicotómicas repetidas de hifas intracelulares (Smith and Read, 1997). Estas estructuras son las encargadas del intercambio bidireccional de nutrientes y carbono entre el hongo y la planta. 


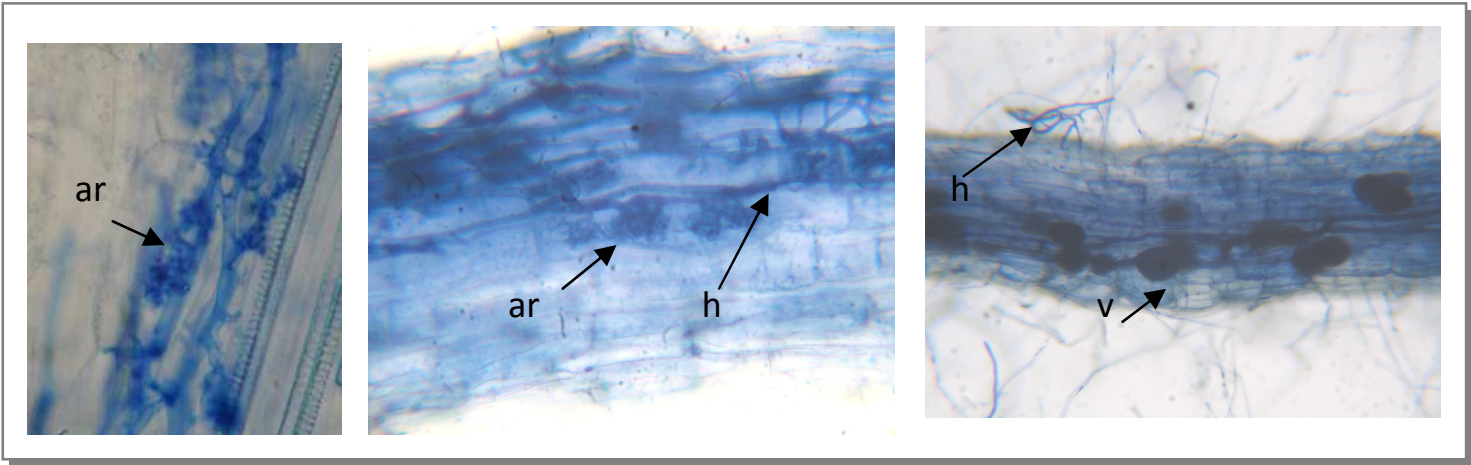

Figura 5. Raíces de plantas de Mentha x piperita L. micorrizadas, inoculadas con Funneliformis mosseae. Se observan, a: arbúsculos, h: hifas, v: vesículas. Fuente propia.

La mayoría de estos hongos forman estructuras denominadas vesículas que funcionan como órganos de reserva de lípidos. Se forman en los extremos de las hifas inter o intracelularmente a medida que progresa la infección (Becard et al., 1993). Algunas vesículas pueden transformarse en esporas para su propagación (Nasim, 2010)

Junto al desarrollo del hongo dentro de la raíz se produce una proliferación de hifas en el suelo lo que constituye el micelio externo o extraradical fundamental para la adquisición de agua y nutrientes por la plantas, ya que permite explorar microhábitats del suelo inaccesibles para las raíces (Barea, 2000).

A través del micelio intraradical el hongo recibe los esqueletos carbonados de la planta hospedadora, aportándole a ésta nutrientes inorgánicos. Este micelio se desarrolla en un ambiente que es controlado por la homeostasis de la planta. El micelio extraradical que se desarrolla en el suelo, cumple con la función de absorber los nutrientes inorgánicos y está expuesto a las variaciones en las condiciones ambientales del suelo tales como pH, disponibilidad de nutrientes, humedad, etc. (Marschner and Dell, 1994). 


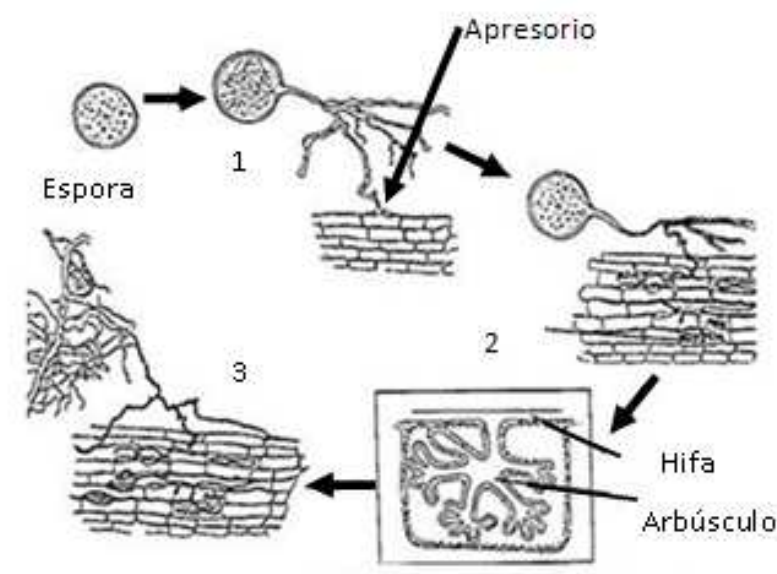

1-Germinación de la espora del hongo en el suelo

2 - Desarrollo del hongo dentro de la raíz

3-Corte transversal de la raíz con hifas y arbúsculos

Figura 6. Ciclo de infección de hongos micorrícicos. Adaptado de Varma A., B., Hock, 1998.

\section{Importancia de las micorrizas arbusculares}

Las micorrizas, permiten aumentar el área potencial de exploración de las raíces en el suelo, permitiendo una mayor absorción de nutrientes y agua. Juegan un papel clave en el reciclaje de nutrientes en el ecosistema, ya que se han demostrado efectos positivos en la absorción de nutrientes, dentro de los cuales el más estudiado ha sido el fósforo (Yao et al., 2003; Garg and Chandel, 2010). Las micorrizas arbusculares favorecen además la absorción otros elementos poco solubles y móviles como el amonio, potasio, cobre, hierro y zinc (Smith and Read, 1997; Zandavalli et al., 2004). Desde el punto de vista nutricional, las plantas micorrizadas se ven beneficiadas debido a un incremento en la absorción de $\mathrm{P}$ cuando este elemento es limitante en el suelo.

Las hifas extra-radicales presentan una estructura extremadamente delgada permitiendo captar nutrientes más allá de la zona de agotamiento (diámetros entre 1 a 3 $\mu$ para hifas delgadas y 5 a $10 \mu$ para las más gruesas). 
Las plantas micotróficas pueden exhibir diferente dependencia micorrícica. Es así que existen plantas que no pueden crecer sin micorrizas aún en suelos fértiles, mientras que otras pueden presentar una respuesta alta o baja a la micorrización, dependiendo de la fertilidad del suelo (Janos, 1980). Las distintas especies de HMA pueden presentar también cierto grado de especificidad con respecto a las plantas hospedadoras y diferir en su capacidad de estimular el crecimiento de las plantas, así como distintas especies vegetales pueden responder diferencialmente a la inoculación con HMA (Vierheiling and Ocampo, 1991). La colonización de las raíces está influenciada por factores bióticos, como las características genéticas de la planta huésped y del organismo colonizador o factores abióticos como el tipo de suelo, humedad, pH y temperatura (Johnson et al., 1991; Matsubara and Harada, 1996).

Entre otras ventajas de esta asociación en los sistemas suelo-planta se ha estudiado la inducción de una mayor tolerancia/resistencia frente a distintos estreses bióticos y abióticos. Las micorrizas pueden conferir tolerancia a patógenos del suelo, ya sea por competencia por los sitios de colonización (Linderman et al., 1992) o por activar mecanismos de defensa en la planta huésped (Cordier et al., 1996). También se ha investigado el incremento de la tolerancia de las plantas al estrés hídrico, salino, por deficiencia de nutrientes, exceso de metales pesados y sustancias fitotóxicas (Barea et al., 2005a; Beltrano and Ronco, 2008; Ruscitti et al., 2011; Kaya et al., 2009; Kohler et al., 2008; Manoharan et al., 2010; Beltrano et al., 2013b). Se ha descrito además que las micorrizas confieren tolerancia a pesticidas (Ocampo, 1993), herbicidas (Ocampo and Barea., 1982; Beltrano et al, 2013a), o residuos de la industria petrolera (Cabello, 1997) Los HMA también contribuyen a la agregación de los suelos mejorando su estructura (Bronick and Lal, 2005; Kohler et al., 2008) y en consecuencia su porosidad y retención de agua.

El desarrollo y la supervivencia de las micorrizas arbusculares pueden ser alteradas por prácticas culturales tales como la fertilización, aplicación de pesticidas, rotaciones de cultivos, desinfección de suelos y factores medioambientales, disminuyendo la población de HMA nativos (Gianinazzi and Schüepp, 1994; Augé, 2001; Moreira and Siquiera, 2006).

La aptitud de estos hongos para favorecer el desarrollo de un cultivo depende de su infectividad (capacidad de penetrar y extenderse en la raíz) y efectividad (capacidad de mejorar el crecimiento y tolerancia a estrés del hospedero) (Sylvia and Williams, 
1992). Se requieren mayores estudios sobre la respuesta a la inoculación, pero se estima, que su introducción pude disminuir los niveles de fertilizantes requeridos sobre todo en la fase de establecimiento de los cultivos. Los hongos micorrícicos arbusculares constituyen un insumo microbiológico promisorio para una agricultura sustentable debido a su papel en el funcionamiento de los ecosistemas y su potencial participación como fertilizantes biológicos (Guerra Sierra, 2008).

\section{Interacción entre la alelopatía y la micorrización}

La alelopatía es una característica distintiva que presentan las malezas o plantas invasoras, que les permite competir por agua, luz solar, nutrientes y dióxido de carbono, al segregar compuestos químicos que afectan el normal crecimiento de otras especies (Inderjit and Dakshini, 1995). Se ha demostrado que las sustancias alelopáticas pueden incrementar la habilidad competitiva de las plantas que las producen ejerciendo un efecto directo sobre los individuos próximos, pero también pueden provocar efectos indirectos al provocar disturbios en las asociaciones benéficas de cierta plantas con HMA y bacterias, disminuyendo su capacidad para obtener recursos tales como el fósforo y el nitrógeno (Koide and Li, 1991). A través de los mecanismos antes mencionados, las plantas invasoras, crean condiciones favorables para su establecimiento (Hierro, 2003). Distintos investigadores estudiaron el efecto de los flavonoides exudados por las raíces de algunas plantas como por ejemplo los provenientes de Allium porrum (Gianinazzi-Pearson et al., 1989), trébol blanco (Scervinio et al., 2005), lupino (Hirosulke et al., 2002) y alfalfa (Tsai and Phillips, 1991), sobre el crecimiento de hongos formadores de micorrizas arbusculares. Los flavonoides pueden estimular o inhibir la germinación de las esporas como así también el crecimiento y ramificación de las hifas (Becard et al., 1992).

Siqueira et al., (1992) encontraron que la aplicación exógena de compuestos fenólicos estimulaba la población de HMA indígenas, provocando un incremento en el crecimiento y rendimiento de los cultivos. Algunos sustancias aleloquímicas pueden afectar en forma adversa la colonización micorrícica de las raíces de las plantas, como es el caso de los extractos de cortezas y hojas de Melia azadarach L (Mushtaq, et al., 1993; Javaid et al., 1995, 1996). Boufalis, (1994) determinó que los compuestos fenólicos reducen el consumo de oxígeno de algunos hongos micorrícicos. 
Investigaciones realizadas con Alliaria petiolata identifican como uno de los mecanismos de competencia de esta especie invasora, la producción de sustancias con propiedades aleloquímicas e inhibitorias sobre la formación de asociaciones micorrícicas (Stinson et al., 2006). Existe poca información en esta área debido principalmente, a la dificultad encontrada en el estudio de las complejas interacciones entre los componentes de la rizosfera en condiciones reales. Bajwa, (2005), determinó que el estrés alelopático afectó en forma negativa la colonización micorrícica en plantas de maíz creciendo en presencia de aleloquímicos provenientes de residuos de Melia azadarach L., sin embargo, las plantas micorrizadas presentaron un crecimiento mayor de tallos y raíces comparadas con las no micorrizadas. Además, se ha demostrado que los HMA permiten soportar el estrés alelopático debido posiblemente a la mejora en el estado de nutrición de las plantas micorrizadas (Javaid, 2007). Bajwa et al., (2000) encontraron que bajo condiciones de estrés alelopático causado por Imperata cilíndrica, los hongos Glomus mosseae y G. fasciculatum mejoraron el rendimiento de plantas de trigo, observándose una respuesta diferencial en función del hongo utilizado. Javaid and Bajwa, (1999) investigaron el efecto de la inoculación con HMA sobre un cultivo de maíz bajo estrés alelopático causado por la incorporación de extractos foliares de Melia azedarach L. y observaron que la inoculación morigeraba en forma significativa los efectos fitotóxicos evidenciado por un mayor desarrollo de aéreo y raíces. No obstante, se plantean incógnitas tales como: velocidad de infestación, actividad y viabilidad de hifas, formación y germinación de esporas y ramificación de hifas en presencia de compuestos alelopáticos y dependencia micorrícica. No se han realizado trabajos que evalúen el potencial alelopático de sorgo de Alepo sobre la asociación micorrícica.

Con respecto al transporte de estos aleloquímicos a través de las hifas existe escasa información. Allen, (1996) determinó que las micorrizas facilitan el transporte de las sustancias aleloquímicas del suelo hacia las plantas, pudiendo alcanzar los niveles de inhibición de crecimiento de las plantas hospedantes más rápidamente. Achatz and Rillig, (2014) demostraron que el micelio desarrollado por los hongos del suelo, como los que forman los HMA, facilitan los procesos de transporte de los aleloquímicos, ampliando la zona de actividad de estos fitotóxicos. Sus resultados demostraron que la juglona acumulada en el suelo, disminuyó el crecimiento de plantas de tomate y que dicha reducción fue mayor en las plantas que estaban micorrizadas. Resultados de experimentos realizados en campo, por los mismos autores (Achatz et al., 2014) apoyan 
la idea que las micorrizas desempeñan un rol importante en la transferencia de aleloquímicos en los entornos naturales, conectando los sistemas radiculares de distintas especies, a través de la formación redes miceliales comunes en el suelo (Giovannetti et al. 2001; Voets et al., 2006).

\section{Micorrización y plantas aromáticas}

Existen antecedentes en lo que hace a la participación de los HMA en especies aromáticas y medicinales, abocados a analizar el incremento de la producción de biomasa y otros pocos trabajos relacionan la interacción de estos hongos con las plantas aromáticas y la producción de aceites esenciales (Kahaliq and Janardhanan, 1997; Abduk-Khaliq et al., 2001; Gupta et al., 2002; Cabello et al., 2005). Sirohi and Singh, (1983) reportaron mayor biomasa y rendimiento de aceite esencial en plantas de Mentha piperita inoculadas con Glomus fasciculatus comparadas con las plantas no inoculadas. Estudios realizados con Mentha arvensis demostraron que la inoculación con HMA incrementó el crecimiento y la producción de aceites esenciales (Freitas et al., 2004; Khaliq and Janardhanan, 1997). Kapoor et al., (2002) obtuvieron resultados similares en Coriandrum sativum y Arango et al., (2006) en Mentha x piperita. Khaosaad et al., (2006) inocularon plantas de Ocimum basilicum con Glomus mosseae las cuales presentaron mayor biomasa y porcentaje de aceites esenciales comparadas con las no inoculadas. Resultados similares fueron encontrados por Copetta el al., (2006); RasouliSadaghiani el al., (2010). Kapoor et al., (2007) también llegaron a los mismos resultados pero en Artemisia annua y Gupta et al., (2002) en plantas de Mentha arvensis inoculadas con G. fasciculatum. Del mismo modo, Freitas et al. (2004) observaron que la inoculación con HMA produjo incrementos de hasta $88 \%$ en el porcentaje de aceites esenciales en relación a las plantas no inoculadas. Karangiannidis et al., (2012), determinaron que plantas de Oreganum vulgare, O. onites, Mentha viridis, M. spicata y M. piperita presentaron aumentos significativos en el peso seco de tallos y raíces como así también en la concentración de nutrientes y aceites esenciales cuando fueron inoculadas con Glomus etunicatum comparadas con las plantas no inoculadas. Shabani et al., (2013) observaron que la inoculación de plantas de Menta spicata con G. mosseae y G. etunicatum, produjeron o aumentos significativos en el peso fresco y seco, contenido de clorofila y nutrientes comparadas con la no inoculadas, y que la respuesta 
dependía del hongo utilizado, siendo en este caso G. etunicatum más eficaz comparado con G. mosseae.

Considerando por una parte la importancia económica del cultivo de menta, la respuesta favorable a la micorrización con HMA y por otro lado los efectos alelopáticos del sorgo de Alepo sobre los cultivos los objetivos planteados en este trabajo fueron:

\section{Objetivo general:}

- Determinar el efecto de los aleloquímicos provenientes de la descomposición de rizomas de Sorghum halepense (L.) Pers. sobre la micorrización, acumulación de materia seca, y aceites esenciales en Mentha x piperita L.

\section{Objetivos particulares:}

- Evaluar el efecto de distintas cantidades de rizomas de S. halepense sobre el crecimiento de plantas de menta mediante determinaciones morfológicas (acumulación de materia seca aérea y de raíz, área foliar, relación tallo/hoja), fisiológicas (fotosíntesis y transpiración) y bioquímicas (clorofila, proteínas, ALP)

- Analizar el efecto los aleloquímicos provenientes de los de rizomas de S. halepense sobre la producción de aceites esenciales en el cultivo de menta.

- Analizar el efecto de los los aleloquímicos provenientes de de rizomas de S. halepense presentes en el suelo sobre la micorrización de plantas de menta.

- Evaluar la presencia, viabilidad y actividad de los hongos formadores de micorrizas arbusculares en suelos bajo la presencia de compuestos liberados por los rizomas de $S$. halepense.

- Determinar si las micorrizas arbusculares contribuyen a mejorar el crecimiento y producción de materia seca de plantas de menta piperita en presencia de aleloquímicos de S. halepense. 
- Estudiar la eficiencia comparativa de diferentes HMA en respuesta al estrés alelopático causado por los aleloquímicos liberados por los rizomas de $S$. halepense en el cultivo de menta, cuantificada a través de la producción de materia seca y de aceites esenciales.

\section{$\underline{\text { Hipótesis }}$}

- La liberación de sustancias alelopáticas por los rizomas de sorgo de Alepo produce efectos fitotóxicos afectando, la micorrización de las raíces, el crecimiento y la producción de materia seca y aceites esenciales de la menta. Esta fitotoxicidad afecta la simbiosis, dando como resultado una menor absorción de agua y nutrientes, fundamentales para el crecimiento y desarrollo de las planta.

- La inoculación de la menta con micorrizas específicas reduce el efecto negativo de los aleloquímicos provenientes de la descomposición de rizomas de sorgo de Alepo. 
Capítulo 2

Materiales y Métodos 
Los ensayos se realizaron en el Instituto de Fisiología Vegetal (INFIVE), de la Facultad de Ciencias Agrarias y Forestales (UNLP-CONICET) en la ciudad de La Plata (latitud $34^{\circ} \mathrm{S}$, longitud $58^{\circ} \mathrm{O}$ ), y en el Laboratorio de Bioquímica y Fitoquímica de la Facultad de Ciencias Agrarias y Forestales (UNLP), entre los años 2011 y 2012.

\section{Material Biológico}

\section{Material vegetal}

Los experimentos se llevaron a cabo con plantas de Mentha x piperita L. obtenidas de parcelas experimentales pertenecientes al Laboratorio de Bioquímica y Fitoquímica, implantadas en la Estación Experimental J. Hirschhorn de la Facultad de Ciencias Agrarias y Forestales (UNLP).

Los rizomas de sorgo de Alepo (Sorghum halepense (L.) Pers.) se recolectaron de plantas provenientes de infestaciones espontáneas de la misma Estación Experimental.

\section{Material fúngico, preparación del inóculo}

Los hongos micorrícicos arbusculares (HMA) que componen el inóculo utilizado en los ensayos, fueron las siguientes especies identificadas taxonómicamente como Glomus intraradices cepa $\mathrm{B}_{1}$ (IB1), actualmente denominado Rhizophagus irregularis o Rhizophagus intraradices ((Błaszk., Wubet, Renker \& Buscot) C. Walker \& A. Schüßler comb. nov.; Stockinger et al., 2009), proveniente del Banco in vitro de Glomeromycota, BGI, Bs. As., Argentina y Glomus mosseae (IM) aislado SB1, de la Colección del Instituto Spegazzini, UNLP, actualmente denominado Funneliformis mosseae ((T.H. Nicolson \& Gerd.) C. Walker \& A. Schuessler 2010)). Dicho inóculo se multiplicó en terrinas, utilizando como sustrato una mezcla estéril de arena:perlita:vermiculita (1:1:1 v/v) y trébol blanco (Trifolium repens L.) como planta trampa. Las plantas de trébol crecieron en condiciones controladas en cámaras de cultivo. Al cabo de tres meses posteriores a la inoculación, se suspendió el riego, 
dejando secar las plantas para luego eliminar la parte aérea. Las raíces se cortaron en fragmentos pequeños mezclándolas en forma homogénea con el sustrato.

El inóculo estaba constituido por una mezcla de sustrato, hifas, fragmentos de raíces de trébol (Trifolium repens L.) micorrizadas en un $90 \%$ y una densidad de 60 esporas $\mathrm{g}^{-1}$ de sustrato seco.

\section{Experimento $N^{\circ}$ 1: Evaluación de distintas concentraciones de extracto acuoso de rizomas de sorgo de Alepo sobre la micorrización y parámetros de crecimiento de plántulas de Mentha $x$ piperita $\mathrm{L}$.}

Material vegetal

Se utilizaron trozos de estolones de plantas de Mentha x piperita de $33 \pm 2 \mathrm{~mm}$ de longitud y $5 \pm 1 \mathrm{~mm}$ de diámetro, con un nudo sin brotes.

Preparación del extracto acuoso de rizomas de sorgo de Alepo

La preparación del extracto acuoso se realizó a partir de rizomas de sorgo de Alepo. Los rizomas recolectados se lavaron con agua y desinfectaron con una solución de hipoclorito de sodio al 10\% durante 10 minutos, posteriormente se enjuagaron con agua destilada estéril tres veces y se dejaron secar a temperatura ambiente $\left(25^{\circ} \mathrm{C}\right)$ por tres días. Luego se procedió a molerlos utilizando una procesadora. A partir de este material se preparó una solución madre de extracto con $25 \mathrm{~g}$ de rizomas en $100 \mathrm{~mL}$ de agua destilada estéril (Javaid and Anjum, 2006), la que se dejó macerar durante 72 hs en cámara fría a $4^{\circ} \mathrm{C}$. El macerado se filtró con una doble tela de queso y el producto del filtrado se centrifugó a $4000 \mathrm{rpm}$ por 30 minutos. El sobrenadante se guardó a $4^{\circ} \mathrm{C}$ hasta el momento de su utilización.

A partir de la solución madre de extracto acuoso de rizomas se realizaron las siguientes diluciones utilizando solución nutritiva Hoagland: 
S0: solución Hoagland 100\%

S1: 5\% extracto acuoso de rizomas de sorgo de Alepo $+95 \%$ solución Hoagland

S2: $10 \%$ extracto acuoso de rizomas de sorgo de Alepo $+90 \%$ solución Hoagland

S3: $15 \%$ extracto acuoso de rizomas de sorgo de Alepo $+85 \%$ solución Hoagland

S4: $25 \%$ extracto acuoso de rizomas de sorgo de Alepo $+75 \%$ solución Hoagland

Para cada concentración de extracto se determinó:

- $p H$ : se utilizó un peachímetro marca Methler (Tabla 1).

- Conductividad eléctrica: se utilizó un conductímetro marca Jenco 3173 (Tabla 1).

- Contenido compuestos fenólicos totales: El contenido de compuestos fenólicos totales se determinó por el método colorimétrico que emplea el reactivo de Folin-Ciocalteu (Singleton y Rossi, 1965), con ligeras modificaciones.

Una muestra de $25 \mu \mathrm{L}$ de extracto diluido (1:1) fue transferida a un tubo que contenía $1775 \mu \mathrm{L}$ de agua bidestilada, luego se añadieron $400 \mu \mathrm{L}$ de $\mathrm{Na}_{2} \mathrm{CO}_{3} 20 \%$ (p/v) en $\mathrm{NaOH} 0,1 \mathrm{~N}$ y $200 \mu \mathrm{L}$ de reactivo Folin-Ciocalteau diluido en agua destilada (1:1).

La absorbancia de la solución se midió a $760 \mathrm{~nm}$ al completar $90 \mathrm{~min}$ de reacción. Las determinaciones se realizaron en un espectrofotómetro Shimadzu UV$160 \mathrm{~A}$.

La concentración de fenoles totales fue calculada usando una curva de calibración con ácido gálico. Los resultados se expresaron como $\mu \mathrm{g}$ de ácido gálico por $\mathrm{mL}$ de extracto. Las determinaciones se realizaron por triplicado. (Tabla 2).

\section{Solución nutritiva Hoagland}

La composición de la solución nutritiva utilizada se presenta en la Tabla 1. 
Tabla 1. Fórmula de la solución nutritiva de Hoagland

\begin{tabular}{|l|c|}
\hline Solución madre de macronutrientes & $\mathrm{mL} /$ litro \\
\hline $\mathrm{KH}_{2} \mathrm{PO}_{4} 1 \mathrm{M}$ & 1 \\
\hline $\mathrm{KNO}_{3} 1 \mathrm{M}$ & 5 \\
\hline $\mathrm{Ca}\left(\mathrm{NO}_{3}\right)_{2} 4 \mathrm{H}_{2} \mathrm{O} 1 \mathrm{M}$ & 5 \\
\hline $\mathrm{MgSO}_{4} 7 \mathrm{H}_{2} \mathrm{O} 1 \mathrm{M}$ & 2 \\
\hline EDTA-Fe & 1 \\
\hline Soluciones madres de micronutrientes & $\mathrm{g} /$ litro \\
\hline $\mathrm{H}_{3} \mathrm{BO}_{3}$ & 2,86 \\
\hline $\mathrm{MnCl}_{2} 4 \mathrm{H}_{2} \mathrm{O}$ & 1,81 \\
\hline $\mathrm{ZnCl}_{2}$ & 0,11 \\
\hline $\mathrm{CuCl}_{2} 2 \mathrm{H}_{2} \mathrm{O}$ & 0,05 \\
\hline $\mathrm{Na}_{2} \mathrm{MoO}_{4} 2 \mathrm{H}_{2} \mathrm{O}$ & 0,025 \\
\hline
\end{tabular}

*EDTA-Fe (Sal sódica del ácido etilendiamino tetracético y $\mathrm{FeSO}_{4} 7 \mathrm{H}_{2} \mathrm{O}$ )

La conductancia eléctrica de la solución Hoagland fue de $1,77 \mathrm{mS} \mathrm{cm}^{-1}$ y el pH 5,47 .

Tabla 2. Conductividad eléctrica $\left(\mathrm{mS} \mathrm{cm}^{-1}\right), \mathrm{pH}$ y fenoles totales ( $\mu \mathrm{g}$ de ácido gálico $\mathrm{mL}^{-1}$ ) de las distintas concentraciones de los extractos preparados a partir de rizomas de Sorgo de Alepo.

\begin{tabular}{|c|c|c|c|}
\hline $\begin{array}{c}\text { Concentración de } \\
\text { Extracto de sorgo de Alepo } \\
(\%)\end{array}$ & $\begin{array}{l}\text { Conductividad } \\
\text { eléctrica } \\
\left(\mathrm{mS} \mathrm{cm}^{-1}\right)\end{array}$ & $\mathrm{pH}$ & $\begin{array}{l}\text { Compuestos fenólicos } \\
\left(\mu \mathrm{g} \text { de ag } \mathrm{mL}^{-1}\right)\end{array}$ \\
\hline 25 & 2,75 & 3,8 & 157,83 \\
\hline 15 & 2,54 & 4,4 & 113,72 \\
\hline 10 & 2,33 & 4,4 & 70,76 \\
\hline 5 & 2,27 & 4,4 & 51,3 \\
\hline
\end{tabular}

Condiciones de crecimiento

El ensayo se desarrolló en invernáculo con condiciones de fotoperiodo y temperatura correspondiente para la ciudad de La Plata.

Se colocaron estolones de menta piperita en bandejas sobre un sustrato de arena:perlita:vermiculita $(1: 1: 1 \mathrm{v} / \mathrm{v})$ al cual se le incorporó un $10 \%$ de inóculo Rhizophagus intraradices cepa B1). A las bandejas no inoculados (NI) se les agregó la 
misma cantidad inóculo previamente autoclavado (inactivado), a fin de uniformar las condiciones de crecimiento.

A los 30 días, los estolones enraizados, se trasplantaron a speedling de 72 celdas (capacidad de cada celda $43 \mathrm{~cm}^{3}$ ). A partir del trasplante, los estolones se regaron semanalmente con solución nutritiva Hoagland junto con los extractos de SA hasta capacidad de campo.

\section{Tratamientos}

Los tratamientos realizados fueron el resultado de la combinación de 5 (cinco) concentraciones de extractos de rizomas de sorgo de Alepo 0\% (S0), 5\% (S1), 10\% (S2), 15\% (S3) y 25\% (S4) y la inoculación o no con hongos micorrícicos, Rhizophagus intraradices B1 (IB1). De ese modo resultaron 10 tratamientos, los cuales se detallan en la tabla 3. Los tratamientos sin agregado de extracto (S0) y sin inocular (NI) constituyeron los testigos (Tabla 3 ).

Tabla 3. Tratamientos correspondientes al experimento $\mathrm{N}^{\circ} 1$

NI: plantas no inoculadas, IB1: planas inoculadas con $R$. intraradices $\mathrm{B} 1$ : S0: riego con Hoagland sin extracto; S1: riego con extracto al 5\%, S2: riego con extracto al 10\%; S3: riego con extracto al 15\%; S4; riego con extracto al $25 \%$.

\begin{tabular}{|c|c|}
\hline TRATAMIENTO & TRATAMIENTO \\
\hline NI S0 & IB1 S0 \\
\hline NI S1 & IB1S1 \\
\hline NI S2 & IB1S2 \\
\hline NI S3 & IB1 S3 \\
\hline NI S4 & IB1 S4 \\
\hline
\end{tabular}

Las plantas se cultivaron durante 60 días a partir del trasplante. A los 30 y 60 días después del trasplante, se realizaron las siguientes determinaciones: 
Análisis de la infectividad de los hongos micorrícicos arbusculares

La infectividad micorrícica se evaluó a través de la colonización fúngica según Trouvelot et al. (1986) y se expresó como el porcentaje de micorrización (M\%).

\section{Tinción de raíces micorrizadas}

Se seleccionaron en forma aleatoria fracciones de raíces no lignificadas y se procedió a clarificar y teñir según la técnica de Phillips \& Hayman (1970). Las raíces se aclararon con $\mathrm{KOH}$ al $10 \%(\mathrm{p} / \mathrm{v})\left(10 \mathrm{~min} ., 100^{\circ} \mathrm{C}\right)$. Luego se lavaron tres veces con agua y se aplicó una solución de $\mathrm{HCl} 0,1 \mathrm{~N}$ (5 min. a $\mathrm{T}^{\mathrm{a}}$ ambiente). Finalmente se tiñeron con azul de tripán $\left(5 \mathrm{~min}\right.$. a $\left.95^{\circ} \mathrm{C}\right)$. El colorante tiñe de color azul las estructuras del hongo que contienen quitina, principal componente de las paredes celulares de los hongos micorrícicos arbusculares (HMA). Luego las raíces se conservaron en una solución de lacto-fenol.

\section{Porcentaje de micorrización y eficiencia de la colonización micorrícica}

Fragmentos de raíces teñidas, de aproximadamente $1 \mathrm{~cm}$ de longitud, se montaron en portaobjetos añadiendo gotas de ácido láctico y se cubrieron con un cubreobjeto observándose al microscopio óptico. Se realizaron 3 repeticiones de cada tratamiento, cada una de 10 fragmentos de raíz.

De cada muestra se observó la presencia de campos negativos (sin presencia de estructuras fúngicas) y positivos (con presencia de estructuras fúngicas). En los campos positivos se tuvo en cuenta el tipo de estructuras (arbúsculos, vesículas, hifas) presente dentro de la raíz. El porcentaje de micorrización (M\%) se calculó como la proporción de raíces infectadas sobre el número total de fragmentos de raíz observados, calculando también el porcentaje de arbúsculos $(\% \mathrm{Ar})$ y vesículas $(\% \mathrm{~V})$.

La eficiencia de la colonización micorrícica fue estimado por la dependencia micorrícica (DM) de acuerdo a Plenchette et al., (1983), que relaciona la materia seca de 
las plantas inoculadas con la de las plantas no inoculadas cultivadas bajo las mismas condiciones; se calculó como:

$\mathrm{DM}=\underline{\text { PST de plantas micorrizadas }- \text { PST de plantas no micorrizadas }} \times 100$ PST de plantas micorrizadas

$\mathrm{PST}=$ peso seco total

Parámetros de crecimiento:

- Altura de la planta $(\mathrm{cm})$ : Se realizó con una regla, desde la base hasta el ápice.

- Peso seco aéreo (de hojas y tallos) (g planta ${ }^{-1}$ ): fueron obtenidos por secado del material en estufa a $80^{\circ} \mathrm{C}$ hasta peso constante.

-Peso seco de raíz (g planta $\left.{ }^{-1}\right)$ : fueron obtenidos por secado del material en estufa a $80^{\circ} \mathrm{C}$ hasta peso constante.

- Longitud de raíz (cm): se midió con una regla graduada en mm, desde el cuello hasta el ápice de la raíz de mayor longitud.

\section{Análisis estadístico}

El diseño experimental fue completamente aleatorizado en un factorial de $2 \mathrm{x}$ 5 , con dos niveles de micorrización (NI; IB1) y cinco niveles de extracto acuoso de sorgo de Alepo (S0: libre de extracto; S1: extracto al 5\%; S2: extracto al 10\%; S3: extracto al $15 \%$ y S4: extracto al 25\%). Los datos fueron sometidos a análisis de la varianza y las medias comparadas por el test de LSD al 5\% (Statgraphics Centurion). Los datos porcentuales de micorrización se transformaron previamente en arcoseno para su análisis estadístico.

El número de repeticiones (n) en cada tratamiento dependió de la variable en estudio ( $n=4$ para parámetros de crecimiento $\mathrm{y} n=3$ para micorrización).

Experimento $N^{\circ}$ 2: Evaluación del efecto de extractos acuosos de rizomas de sorgo de Alepo sobre la micorrización, crecimiento, parámetros fisiológicos y bioquímicos de plantas de Mentha $x$ piperita $\mathrm{L}$. 


\section{Material vegetal}

Se seleccionaron estacas apicales de Mentha $x$ piperita $\mathrm{L}$ de $5 \mathrm{~cm}$ de longitud con dos nudos y dos pares de hojas.

\section{Condiciones de crecimiento}

El experimento se llevó a cabo en invernáculo, en condiciones naturales de luz y temperatura para la ciudad de La Plata durante los meses de noviembre a enero.

Las estacas se desinfectaron con una solución al $0,5 \%$ de hipoclorito de sodio durante $10 \mathrm{~min}$, se enjuagaron tres veces con agua estéril y se colocaron en bandejas de plástico con perlita:vermiculita (1:1) como sustrato, para su enraizamiento. Al cabo de 10 días se realizó el trasplante de las estacas enraizadas a speedling de $250 \mathrm{~cm}^{3} \mathrm{de}$ capacidad con un sustrato constituido por una mezcla esterilizada de perlita:vermiculita:arena $(1: 1: 1(\mathrm{v} / \mathrm{v}))$ al cual se le incorporó $12 \mathrm{~g}$ de inóculo micorrícico por celda (F. mosseae (IM) o R. intraradices B1 (IB1)). A las celdas no inoculadas (NI) se les incorporaron $12 \mathrm{~g}$ de una mezcla autoclavada de los dos inóculos (inóculo inactivado), a fin de uniformar las condiciones de crecimiento. A partir del trasplante las estacas se regaron semanalmente hasta capacidad de campo, con solución de Hoagland y las diluciones al $0,5,10$ y $15 \%$ del extracto obtenido a partir de los rizomas de sorgo de Alepo.

\section{Tratamientos}

En este ensayo se eliminó la concentración de S4 (25\% de extracto) porque en los experimentos previos resultó inhibitoria del crecimiento y se incorporó otra cepa de hongos micorrícicos para evaluar el comportamiento diferencial de distintos inóculos. Los tratamientos realizados fueron 12 resultado de una combinación de distintas concentraciones de extractos de sorgo de Alepo 0\% (S0), 5\% (S1), 10\% (S2) y 15\% (S3) y la inoculación con hongos micorrícicos, F. mosseae (IM) y $R$. intraradices B1 (IB1), los que se presentan en la tabla 4. Los tratamientos sin agregado de extracto (S0) y sin inocular (NI) constituyeron los testigos (Tabla 4). 
Tabla 4. Tratamientos correspondientes al experimento $\mathrm{N}^{\circ} 2$. NI: plantas no inoculadas, IB1: plantas inoculadas con $R$. intraradices B1, IM: plantas inoculadas con $F$. mosseae: S0: riego sin extracto; S1: riego con extracto al 5\%, S2: riego con extracto al 10\%; S3: riego con extracto al $15 \%$.

\begin{tabular}{|c|c|c|}
\hline TRATAMIENTO & TRATAMIENTO & TRATAMIENTO \\
\hline NI S0 & IM S0 & IB1 S0 \\
\hline NI S1 & IM S1 & IB1 S1 \\
\hline NI S2 & IM S2 & IB1 S2 \\
\hline NI S3 & IM S3 & IB1 S3 \\
\hline
\end{tabular}

El extracto de rizomas de sorgo de Alepo y la solución de Hoagland utilizado en este ensayo fueron preparados en las mismas condiciones indicadas para el experimento $\mathrm{N}^{\circ} 1$.

Las plantas se cultivaron durante 60 días en invernáculo.

Análisis de la infectividad y eficiencia de la colonización micorrícica

Se determinó a los 30 y 60 días después del trasplante (Idem experimento $\mathrm{N}^{\circ}$ 1)

Viabilidad de las estructuras fúngicas (SDH)

La determinación de la viabilidad de las estructuras fúngicas se determinó a los 60 DDT, evaluando la actividad de la enzima succinato deshidrogenasa (\% SDH), basada en el porcentaje de micorrización, de acuerdo al procedimiento descrito por Smith and Gianinazzi-Pearson (1990). Las raíces se colocaron en una solución 0,2 M de Tris-HCL, $\mathrm{pH} 7 ; 2,5 \mathrm{M}$ de succinato de sodio. $6 \mathrm{H}_{2} \mathrm{O} ; 5 \mathrm{mM}$ de $\mathrm{MgCl}_{2}$ y $4 \mathrm{mg} / \mathrm{mL}$ de nitroblue tetrazolium. Los fragmentos de raíces se tiñeron en oscuridad durante $18 \mathrm{hs}$ a temperatura ambiente, y luego se aclararon con una solución de hidrato de cloral al $75 \%$. Finalmente se tiñeron con una solución de fuccina-ácida al 0,01\% en ácido láctico durante 8 min a $90{ }^{\circ} \mathrm{C}$. Los fragmentos de raíces teñidos con fuccina ácida, se 
dispusieron en portaobjetos de la misma manera que aquellos teñidos con azul de tripán, y se cuantificó el \% de raíces que presentaban actividad observándose las estructuras del hongo coloreadas de azul.

\section{Parámetros de crecimiento}

Altura de plantas de Mentha x piperita al comienzo de los tratamientos con extractos de $S A$

Se realizaron cinco mediciones de la altura de las plantas de menta a partir de los siete días de comenzado el riego con el con el extracto acuoso de rizomas de SA y cada 3 días.

A los 30 días después del trasplante se registró:

- Área foliar por planta $\left(\mathrm{cm}^{2}\right)$ : con un medidor de área foliar (LICOR, Li 3000 Lincoln, NE, EE.UU.).

- Peso seco de hojas, tallos y raíces y longitud de raíz. (Idem experimento $\left.\mathrm{N}^{\circ} 1\right)$

A los 60 días después del trasplante se registró:

- Área foliar por planta $\left(\mathrm{cm}^{2}\right)$, altura, peso seco de hojas, tallos y raíces y longitud de raíz, $\mathrm{N}^{\circ}$ hojas de los tallos (Idem experimento $\mathrm{N}^{\circ} 1$ )

- Volumen de raíz $\left(\mathrm{cm}^{3}\right)$ : Las raíces se lavaron, se eliminó el exceso de agua y se introdujeron en una probeta graduada, el volumen desplazado se tomo como volumen radical (O-Quezada et al., 2011).

Determinación de la actividad de la enzima fosfatasa alcalina (ALP)

La actividad de la enzima fosfatasa alcalina (ALP) en las raíces se determinó utilizando un el kit del Laboratorio Wiener (Rosario, Argentina). Las raíces se lavaron con agua destilada en frio para remover las partículas de sustrato y se almacenaron a $4^{\circ} \mathrm{C}$ hasta el momento de ser analizadas. Las raíces se molieron en mortero con nitrógeno líquido con el agregado de buffer $\mathrm{pH} 10$ de 4-aminoantipirine (29 $\mathrm{mM}$ ) en 3- amino-metilpropanol y se incubaron a $37^{\circ} \mathrm{C}$ por $10 \mathrm{~min}$. Luego se agregó ferrocianuro de K (10 mM) y se centrifugó a 2000 x g durante $10 \mathrm{~min}$, se separó el sobrenadante y se determinó la absorbancia a $520 \mathrm{~nm}$. Los resultados se expresan como 
$\mathrm{mU} \mathrm{mL}^{-1}$ de extracto de raíces. Una unidad (U) de ALP equivale a la cantidad de enzima que permite la formación de $1 \mu$ mol de producto por minuto bajo las condiciones de ensayo.

Determinación de la conductividad relativa de membranas celulares en hojas y raices

La conductividad relativa de las membranas celulares de hoja y raíz (CR) se evaluó a partir de $500 \mathrm{mg}$ de hoja o raíz por tratamiento. Se determinó de acuerdo a Lutts et al., (1996) con algunas modificaciones, utilizando un conductímetro Jenco 3173 .

La CR se determinó de acuerdo a la siguiente ecuación:

$$
\mathrm{CR}=\frac{\mathrm{C} 1}{\mathrm{C} 2} \times 100
$$

Donde

C1 y C2 representan la pérdida de electrolitos, expresada como la conductividad eléctrica $\left(\mathrm{dS} \mathrm{m} \mathrm{m}^{-1}\right)$, medida después de $4 \mathrm{~h}$ de incubación a $25{ }^{\circ} \mathrm{C}(\mathrm{C} 1)$ y luego de autoclavar el material a $120^{\circ} \mathrm{C}$ durante $20 \mathrm{~min}(\mathrm{C} 2)$.

Determinación de la fotosintesis neta, transpiración y conductancia estomática

La fotosíntesis neta (PN), transpiración (E) y conductancia estomática (CS) se determinaron a los 60 DDT, utilizando un analizador de gases infrarrojos portátil (modelo CIRAS-2®, PP Systems), que estima la asimilación neta de $\mathrm{CO}_{2}$ expresada en $\mu \mathrm{mol} \mathrm{CO}_{2} \mathrm{~m}^{-2} \mathrm{~s}^{-1}$. Las mediciones fueron realizadas a $25^{\circ} \mathrm{C}$ con una concentración de $\mathrm{CO}_{2}$ externo de $360 \mathrm{ppm}, 1000 \mu \mathrm{mol} \mathrm{m} \mathrm{m}^{-2}$.

Estimación del contenido de clorofila y carotenoides.

El contenido de clorofila y carotenoides se determinó a partir de un disco de hoja de $1 \mathrm{~cm}$ de diámetro. Se utilizó N, N-Dimetilformamida como solvente de extracción, determinando la absorbancia de la solución a las longitudes de onda 647, 664 y 480 nm, en un espectrofotómetro Shimadzu UV 160 A. El cálculo del contenido de pigmentos se realizó de acuerdo a Wellburn (1994) en las siguientes ecuaciones: 
Clorofila a $\left(\mu \mathrm{g} \mathrm{cm}^{-2}\right)=12$ x Ab663.8 - 3.11xAb646.8

Clorofila $\mathrm{b}\left(\mu \mathrm{g} \mathrm{cm}^{-2}\right)=20.78 \times \mathrm{Ab} 646,-4.88 \times \mathrm{Ab} 663.8$

$\mathrm{C}$ total $\mathrm{a}+\mathrm{b}\left(\mu \mathrm{g} \mathrm{cm}^{-2}\right)=17.67 \times \mathrm{Ab} 646.8+7.12 \times \mathrm{Ab} 663.8$

Carotenoides $\left(\mu \mathrm{g} \mathrm{cm}^{-2}\right)=(1000 \times \mathrm{Ab} 480-1.12 \mathrm{Ca}-34.07 \mathrm{Cb}) / 245$

\section{Determinación del contenido de proteinas solubles en hojas}

El contenido de proteínas solubles se determinó de acuerdo al método de Bradford en 4 discos de hoja de $1 \mathrm{~cm}$ de diámetro. La curva patrón se realizó con albúmina de suero bovino (BSA, Sigma Chemical Co).

\section{Análisis estadístico}

El diseño experimental fue completamente aleatorizado, en un factorial de $3 \mathrm{x}$ 4, con tres niveles de micorrización (NI; IB1; IM) y cuatro niveles de extracto acuoso de sorgo de Alepo (S0: libre de extracto; S1: extracto al 5\%; S2: extracto al 10\%; S3: extracto al 15\%). Los datos fueron sometidos a análisis de la varianza y las medias comparadas por el test de LSD al 5\% (Statgraphics Centurion). Los datos porcentuales de micorrización y de actividad de SDH se transformaron previamente en arcoseno para su análisis estadístico.

El número de repeticiones (n) en cada tratamiento dependió de la variable en estudio $(n=4$ para parámetros de crecimiento, $n=3$ para las determinaciones bioquímicas y fisiológicas, y \% de micorrización, \% SDH y ALP).

Experimento $N^{\circ}$ 3. Efecto de los aleloquímicos provenientes de los rizomas de sorgo de Alepo sobre la micorrización, la materia seca, parámetros fisiológicos y bioquímicos y aceites esenciales de plantas de Mentha $\mathrm{x}$ piperita $\mathrm{L}$.

\section{Material vegetal}

Se seleccionaron plantines de Menta piperita enraizados de $15 \mathrm{~cm}$ de longitud provenientes de las parcelas experimentales pertenecientes al Laboratorio de Bioquímica y Fitoquímica implantadas en la Estación Experimental J. Hirschhorn (EEJH). 
Los rizomas de Sorghum halepense, se recolectaron de un lote de maíz de la (EEJH), se lavaron con agua y desinfectaron con una solución de hipoclorito de sodio al $10 \%$ durante 10 minutos, posteriormente se enjuagaron con agua destilada estéril tres veces y se dejaron secar a temperatura ambiente $\left(25^{\circ} \mathrm{C}\right)$ durante tres días. Dichos rizomas se cortaron en trozos de $1 \mathrm{~cm}$ de longitud y se mezclaron con el sustrato a utilizar en tres proporciones, calculadas teniendo en cuenta valores de materia seca de rizomas de sorgo de Alepo encontrados en distintos sistemas de producción citados en la bibliografía, (Ghersa y Soriano, 1980; Ghersa y Satorre, 1981; Mc Whorter, 1981).

\section{Condiciones de crecimiento}

El experimento se condujo durante los meses de octubre a mediados de enero en las condiciones naturales de luz y temperatura de la ciudad de La Plata. Se utilizaron macetas plásticas de $3 \mathrm{~kg}$ de capacidad. El sustrato con el que se llenaron las macetas fue una mezcla de tierra negra tamizada y arena $(1: 1 \mathrm{v} / \mathrm{v})$. El suelo utilizado fue un argiudol vértico: $\mathrm{pH}$ : 5,5; CE: $0,91 \mathrm{mmhos}^{-\mathrm{cm}^{-1}}$; $\mathrm{P}: 10 \mathrm{mg} \mathrm{kg}^{-1}$; materia orgánica: 3,5\% and total N: 0,24\%, procedente de las proximidades del INFIVE. Dado que la rizosfera puede contener una microflora específica capaz de degradar los aleloquímios (Inderjit, 2005), se tomó la precaución de que en tiempos recientes en dicho suelo no hubiese crecido sorgo de Alepo.

A cada maceta se le agregaron distintas cantidades de rizomas de Sorghum halepense correspondientes a los distintos tratamientos, los cuales fueron mezclados con el sustrato a utilizar. (Tabla 5).

Seis días después de la preparación del sustrato con los rizomas, se colocaron los plantines enraizados de Mentha x piperita en los recipientes junto con el agregado de $40 \mathrm{~g}$ de inóculo micorrícico por maceta. El ensayo se desarrolló bajo cubierta de polietileno transparente (200 $\mu \mathrm{m}$ de espesor) para evitar las precipitaciones.

Los hongos micorrícicos arbusculares (HMA) del inóculo utilizado fueron Rhizophagus intraradices cepa $\mathrm{B}_{1}$ (IB1) y Funneliformis mosseae (IM) aislado SB1, los mismos utilizados en el ensayo 2. El riego se realizó con agua corriente hasta capacidad de campo. 


\section{Tratamientos}

Los tratamientos realizados fueron 12 resultado de la combinación de tres proporciones de rizomas de sorgo de Alepo: R0, sin la incorporación de rizomas, R1: 10 $\mathrm{g}$ de rizomas por maceta, equivalentes a $250 \mathrm{~g} \mathrm{~m}^{-2} \mathrm{MS}$, R2: $20 \mathrm{~g}\left(500 \mathrm{~g} \mathrm{~m}^{-2} \mathrm{MS}\right)$, y R3: $32 \mathrm{~g}$ (800 $\left.\mathrm{g} \mathrm{m}^{-2} \mathrm{MS}\right)$. La inoculación se realizó con los hongos micorrícicos, Funneliformis mosseae (IM) y Rhizophagus intraradices B1 (IB1). Los tratamientos sin agregado de rizomas (R0) y sin inocular (NI) constituyeron los testigos. A las macetas no inoculados (NI) se les agregó la misma cantidad inóculo a fin de uniformar las condiciones de crecimiento (Tabla 5).

Tabla 5. Tratamientos correspondientes al experimento $\mathrm{N}^{\circ} 3$. NI: plantas no inoculadas; IM: plantas inoculadas con F. mosseae; IB1: plantas inoculadas con $R$. intraradices, R0: $0 \mathrm{~g}$ de rizomas $\left(0 \mathrm{~g} \mathrm{~m}^{-2}\right), \mathrm{R} 1: 10 \mathrm{~g}$ de rizomas, $\mathrm{R} 2: 20 \mathrm{~g}$ de rizomas y R3: $32 \mathrm{~g}$ de rizomas, cantidades equivalentes a 250, 500 y $800 \mathrm{~g} \mathrm{~m}^{2} \mathrm{MS}$ de rizomas respectivamente.

\begin{tabular}{|c|c|c|}
\hline TRATAMIENTO & TRATAMIENTO & TRATAMIENTO \\
\hline NI R0 & IM R0 & IB1 R0 \\
\hline NI R1 & IM R1 & IB1 R1 \\
\hline NI R2 & IM R2 & IB1 R2 \\
\hline NI R3 & IM R3 & IB1 R3 \\
\hline
\end{tabular}

Las plantas se cultivaron durante 90 días cosechándose en estado de floración.

Análisis de la infectividad y eficiencia de la colonización micorrícica.

El análisis de la infectividad de los hongos micorrícicos, viabilidad de las estructuras fúngicas (SDH) y dependencia micorrícica (DM) se determinaron a los 90 días después de la plantación (Idem experimento $\mathrm{N}^{\circ} 2$ ). 
Determinación de parámetros de crecimiento:

A partir de los 30 días después de la plantación de los plantines se registraron datos de altura de planta cada 10 días durante 30 días.

El ensayo culminó con la cosecha de las plantas 90 días después de la plantación, realizando las siguientes determinaciones.

De las plantas cosechadas se separó la parte aérea de la radical y se determinó

- Altura de la planta (Alt) cm,

- Área foliar total (AF) $\mathrm{cm}^{2}$,

- Peso seco de hojas (PSH) g,

- Peso seco de tallo (PST) g,

- Peso seco de raíz (PSR) g,

El peso seco de hojas y tallos se realizó pesando el material secado en estufa a $40^{\circ} \mathrm{C}$ hasta peso constante, ya que este material se utilizó también para cuantificar el porcentaje de aceites esenciales (AE).

- Determinación de la fotosíntesis neta y conductancia estomática Idem experimento $\mathrm{N}^{\circ} 2$

-Estimación del contenido de clorofila y carotenoides Idem experimento $\mathrm{N}^{\circ} 2$

-Determinación del contenido de proteínas solubles de hojas Idem experimento $\mathrm{N}^{\circ} 2$

-Determinación de la conductividad relativa de hojas y raíces. Idem experimento $\mathrm{N}^{\circ} 2$

-Extracción y cuantificación de aceites esenciales

Para la extracción de los aceites esenciales se utilizó un equipo de hidrodestilación a escala de laboratorio. 
El equipo consta de un balón de destilación de vidrio de $5 \mathrm{~L}$, una trampa graduada Clevenger de $10 \mathrm{~mL}$ para aceites menos densos que el agua y un condensador encamisado.

Se pesaron $250 \mathrm{~g}$ de material vegetal (hojas y tallos) secado a $40^{\circ} \mathrm{C}$ y se colocaron dentro del balón cubriéndolo con agua destilada. El tiempo de destilación fue de 3 horas. La lectura del contenido de aceite esencial se realizó directamente sobre la porción graduada de la trampa una vez separada la emulsión agua-aceite esencial. El rendimiento de aceite esencial se calculó como $\mathrm{mL}$ en $100 \mathrm{~g}$ de materia seca.

Las determinaciones correspondientes a cuantificación del contenido de aceite esencial, se realizaron por triplicado.
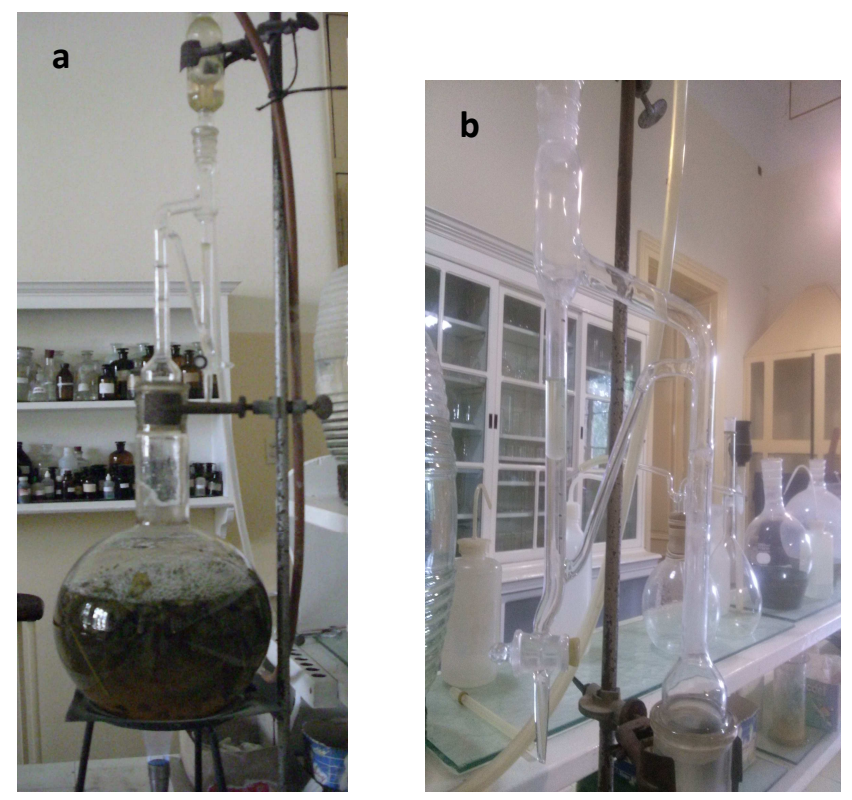

Figura 7. a) Destilador de aceites esenciales de laboratorio. b) Trampa Clevenger de vidrio para aceites esenciales de menor densidad que el agua.

\section{Análisis estadístico}

El diseño experimental fue completamente aleatorizado, en un factorial de $3 \mathrm{x}$ 4, con tres niveles de micorrización (NI; IB1; IM) y cuatro niveles de concentración de rizomas de sorgo de Alepo (R0: libre de rizomas; R1: $250 \mathrm{~g} \mathrm{~m}^{2}, \mathrm{R} 2,500 \mathrm{~g} \mathrm{~m}^{-2}$ y R3 800 $\mathrm{g} \mathrm{m}^{-2} \mathrm{MS}$ de rizomas respectivamente. Los datos fueron sometidos a análisis de la varianza y las medias comparadas por el test de LSD al 5\% (Statgraphics Centurion). 
Los datos porcentuales de micorrización y de actividad de SDH se transformaron previamente en arcoseno para su análisis estadístico.

El número de repeticiones (n) en cada tratamiento dependió de la variable en estudio ( $\mathrm{n}=4$ para parámetros de crecimiento, $\mathrm{n}=3$ para determinaciones bioquímicas $\mathrm{y}$ fisiológicas \% de micorrización, \% SDH y porcentaje de aceites esenciales). 
Capítulo 3

Resultados 
Los resultados obtenidos, se presentan a continuación ordenados por experimentos.

\subsection{Experimento 1}

\section{Evaluación del efecto de extractos acuosos de rizomas de sorgo de Alepo sobre la micorrización y el crecimiento de plantas de Mentha $\mathbf{x}$ piperita $\mathrm{L}$.}

\section{Colonización micorrícica y dependencia micorrícica}

El porcentaje de micorrización $(\% \mathrm{M})$ con el hongo micorrícico Rhizophagus intraradices determinado a los 30 días después del trasplante de los estolones fue de $30 \%, 40 \%$ y $6 \%$ para las concentraciones de extracto de sorgo de Alepo S0, S1 y S2 respectivamente, mientras en S3 y S4 no se observó invasión del hongo dentro de la raíz.

El análisis de la colonización micorrícica determinada a los 60 días posteriores al trasplante, se presenta en la Tabla 6 . El \% de micorrización aumentó con respecto al evaluado a los 30 días, en todas las concentraciones de extracto, también se observó un menor porcentaje de micorrización con el aumento de la concentración de extracto aplicado. Para S2, S3 y S4 se registraron diferencias significativas con respecto a S0 y $\mathrm{S} 1$. E1 \% de arbúsculos y vesículas disminuyó significativamente a partir de S1, siendo en $\mathrm{S} 4$ de $2 \%$ y 3\% respectivamente. La dependencia micorrícica (DM) no mostró diferencias significativas.

Tabla 6. Colonización micorrícica $(\% \mathrm{M})$, arbúsculos $(\% \mathrm{Ar})$, vesículas $(\% \mathrm{~V})$ y dependencia micorrícica (\%DM), en plantas de Mentha $x$ piperita L. inoculadas con Rhizophagus intraradices (IB1) que crecieron con diferentes concentraciones de extracto de rizomas de SA. Mediciones registradas a los 60 días después del trasplante (60 DDT). Referencias: S0: 0\%; S1: 5\%; S2: 10\%; S3: 15\%; S4: 25\%.

\begin{tabular}{ccccc}
\hline Tratamientos & $\% \mathrm{M}$ & $\% \mathrm{Ar}$ & $\% \mathrm{~V}$ & $\% \mathrm{DM}$ \\
\hline S0 & $97,3 \mathrm{a}$ & $93 \mathrm{a}$ & $95 \mathrm{a}$ & $18,1 \mathrm{a}$ \\
S1 & $81,5 \mathrm{a}$ & $71 \mathrm{~b}$ & $60 \mathrm{~b}$ & $15,1 \mathrm{a}$ \\
S2 & $66 \mathrm{~b}$ & $60 \mathrm{~b}$ & $33 \mathrm{c}$ & $10,7 \mathrm{a}$ \\
S3 & $51 \mathrm{~b}$ & $48 \mathrm{c}$ & $46 \mathrm{c}$ & $13,9 \mathrm{a}$ \\
S4 & $10 \mathrm{c}$ & $2 \mathrm{~d}$ & $3 \mathrm{~d}$ & $11,8 \mathrm{a}$ \\
\hline
\end{tabular}

Letras distintas en cada columna indican diferencias significativas entre las medias $(p<0,05)$. 
Parámetros de crecimiento registrados a los 30 días después del trasplante.

Las mediciones realizadas 30 DDT (días después del trasplante), mostraron diferencias significativas tanto para la micorrización como para las concentraciones de extracto de SA (Tabla 7). La interacción $\mathrm{H}$ x S no fue significativa para Alt ni Long raíz. La altura de las plantas fue mayor en las inoculadas siendo las diferencias significativas en S0 y S1. Las NI redujeron significativamente la altura en S4 y las inoculadas en $\mathrm{S} 2$.

Para el PSA, la interacción $\mathrm{H}$ x S no fue estadísticamente significativa. En las NI la disminución del PSA fue significativa en S4, mientras que en las inoculadas con IB1 el PSA mostró una disminución significativa a partir de S3.

En cuanto a la longitud de raíz, la interacción H x S fue significativa $(p<0,05)$. Las plantas inoculadas presentaron mayor longitud de raíz en S0 comparadas con las NI. Las mayores concentraciones de extracto, a partir de S2, redujeron la longitud de las raíces en las plantas inoculadas.

Tabla 7. Efecto de los extractos de rizomas de SA sobre la altura de planta (Alt) peso seco aéreo (PSA), longitud de raíz (Long raíz) en plantas de Mentha x piperita L. no inoculadas (NI) o inoculadas con Rhizophagus intraradices (IB1). Mediciones registradas a los 30 días después del trasplante (30 DDT). Referencias: S0: 0\%; S1: 5\%; S2: 10\%; S3: 15\%; S4: 25\%. H: micorrización, S: extracto de rizomas de SA.

\begin{tabular}{|c|c|c|c|c|c|c|}
\hline \multirow{2}{*}{ Tratamiento } & \multicolumn{2}{|c|}{ Alt $(\mathrm{cm})$} & \multicolumn{2}{|c|}{$\operatorname{PSA}\left(\mathrm{g} \mathrm{pl}^{-1}\right)$} & \multicolumn{2}{|c|}{ Long raíz $(\mathrm{cm})$} \\
\hline & NI & IB1 & NI & IB1 & NI & IB1 \\
\hline S0 & $4,33 \mathrm{aB}$ & $5,97 \mathrm{aA}$ & $0,023 \mathrm{aA}$ & $0,033 \mathrm{aA}$ & $3,83 \mathrm{aB}$ & $7,30 \mathrm{aA}$ \\
\hline S1 & $4,34 \mathrm{aB}$ & $5,91 \mathrm{aA}$ & 0,022 a A & $0,029 \mathrm{abA}$ & 3,83 aA & $5,50 \mathrm{abA}$ \\
\hline S2 & $4,08 \mathrm{aA}$ & $4,40 \mathrm{bA}$ & $0,021 \mathrm{abA}$ & 0,023 abcA & $4,16 \mathrm{aA}$ & $3,66 \mathrm{bcA}$ \\
\hline S3 & 3,63 abA & $4,05 \mathrm{bcA}$ & $0,015 \mathrm{abA}$ & $0,020 \mathrm{bcA}$ & $1,76 \mathrm{bA}$ & $2,86 \mathrm{cA}$ \\
\hline S4 & $2,82 \mathrm{bA}$ & $3,13 \mathrm{cA}$ & $0,012 \mathrm{bA}$ & $0,014 \mathrm{dA}$ & $2,62 \mathrm{abA}$ & $2,03 \mathrm{cA}$ \\
\hline $\mathrm{H}$ & \multicolumn{2}{|c|}{$<0,001$} & \multicolumn{2}{|c|}{$<0,05$} & \multicolumn{2}{|c|}{$<0,05$} \\
\hline S & \multicolumn{2}{|c|}{$<0,001$} & \multicolumn{2}{|c|}{$<0,05$} & \multicolumn{2}{|c|}{$<0,001$} \\
\hline $\mathrm{H} \times \mathrm{S}$ & \multicolumn{2}{|c|}{ ns } & \multicolumn{2}{|c|}{ ns } & \multicolumn{2}{|c|}{$<0,05$} \\
\hline
\end{tabular}

Letras distintas, minúscula en cada columna y mayúsculas en cada fila indican diferencias significativas entre las medias para cada parámetro evaluado $(p<0,05)$. ns: no significativo. 
Parámetros de crecimiento registrados a los 60 días después del trasplante.

En las mediciones del crecimiento, realizadas a los 60 DDT, se observaron diferencias significativas para los tratamientos de micorrización y las concentraciones de extracto (Tabla 8). La interacción $\mathrm{H}$ x S fue significativa para Alt y longitud de raíz. El extracto acuoso de rizomas de sorgo de Alepo produjo una inhibición del crecimiento, reflejada en la altura, peso seco aéreo y peso seco de raíz. En las plantas NI y IB1 la altura disminuyó significativamente a partir de S1 y S2 respectivamente, y no se observaron diferencias entre las plantas inoculadas y no inoculadas en S4. Una tendencia similar se observó en el peso seco aéreo, el cual también se vio afectado por los extractos acuosos. En cuanto al peso seco de raíz, las NI mostraron ser menos afectadas comparadas con las plantas inoculadas con $R$. intraradices. En las plantas NI, para S3 y S4 la disminución fue del $21 \%$ y $22,4 \%$ respectivamente con respecto a S0, para las IB1 la reducción del peso seco de raíces para esas mismas concentraciones fue de $49 \%$ y $58 \%$ con respecto a S0. La longitud de la raíz en las IB1 disminuyó significativamente en $\mathrm{S} 4$ con respecto al resto de los tratamientos, mientras que las NI se vieron afectadas a partir de S1.

Tabla 8. Efecto de los extractos de rizomas de SA sobre la altura de planta (Alt) peso seco aéreo (PSA), longitud de raíz (Long. raíz) y peso seco de raíz (PSR) en plantas de Mentha x piperita L. no inoculadas (NI) o inoculadas con Rhizophagus intraradices (IB1). Mediciones registradas a los 60 días después del trasplante (60 DDT). Referencias: S0: 0\%; S1: 5\%; S2: 10\%; S3: 15\%; S4: 25\%. H: micorrización, S: extracto de rizomas de SA.

\begin{tabular}{|c|c|c|c|c|c|c|c|c|}
\hline \multirow{2}{*}{ Trat. } & \multicolumn{2}{|c|}{ Alt $(\mathrm{cm})$} & \multicolumn{2}{|c|}{$\operatorname{PSA}\left(\mathrm{g} \mathrm{pl}^{-1}\right)$} & \multicolumn{2}{|c|}{ Long. raíz $(\mathrm{cm})$} & \multicolumn{2}{|c|}{$\operatorname{PSR}\left(\mathrm{g} \mathrm{pl}^{-1}\right)$} \\
\hline & $\mathrm{NI}$ & IB1 & $\mathrm{NI}$ & IB1 & $\mathrm{NI}$ & IB1 & $\mathrm{NI}$ & IB1 \\
\hline S0 & $12,12 \mathrm{aB}$ & $14,45 \mathrm{aA}$ & $0,343 \mathrm{aA}$ & $0,412 \mathrm{aA}$ & $22,50 \mathrm{aA}$ & $20,37 \mathrm{aA}$ & $0,051 \mathrm{aA}$ & $0,087 \mathrm{aA}$ \\
\hline $\mathrm{S} 1$ & $8,97 \mathrm{bB}$ & $13,75 \mathrm{aA}$ & $0,277 \mathrm{abA}$ & $0,340 \mathrm{aA}$ & $17,62 \mathrm{bB}$ & $20,75 \mathrm{aA}$ & $0,060 \mathrm{abA}$ & $0,064 \mathrm{abA}$ \\
\hline $\mathrm{S} 2$ & $8,16 \mathrm{bcA}$ & $10,37 \mathrm{bA}$ & $0,195 \mathrm{bcA}$ & $0,225 \mathrm{bA}$ & $11,50 \mathrm{cB}$ & $18,62 \mathrm{aA}$ & $0,040 \mathrm{abA}$ & $0,054 \mathrm{bA}$ \\
\hline S3 & 7,37A cdA & $8,25 \mathrm{bcA}$ & $0,202 \mathrm{bcA}$ & $0,247 \mathrm{bcA}$ & $12,37 \mathrm{cB}$ & $20,25 \mathrm{aA}$ & $0,040 \mathrm{abB}$ & $0,044 \mathrm{bA}$ \\
\hline $\mathrm{S} 4$ & $6,50 \mathrm{dA}$ & $6,50 \mathrm{dA}$ & $0,143 \mathrm{cB}$ & $0,165 \mathrm{cA}$ & $7,01 \mathrm{~dB}$ & $13,85 \mathrm{bA}$ & $0,034 \mathrm{bB}$ & $0,036 \mathrm{bA}$ \\
\hline $\mathrm{H}$ & \multicolumn{2}{|c|}{$<0,001$} & \multicolumn{2}{|c|}{$<0,05$} & \multicolumn{2}{|c|}{$<0,001$} & \multicolumn{2}{|c|}{$<0,05$} \\
\hline $\mathrm{S}$ & \multicolumn{2}{|c|}{$<0,001$} & \multicolumn{2}{|c|}{$<0,001$} & \multicolumn{2}{|c|}{$<0,001$} & \multicolumn{2}{|c|}{$<0,05$} \\
\hline $\mathrm{H} \times \mathrm{S}$ & \multicolumn{2}{|c|}{$<0,05$} & \multicolumn{2}{|c|}{ ns } & \multicolumn{2}{|c|}{$<0,001$} & \multicolumn{2}{|c|}{ ns } \\
\hline
\end{tabular}

Letras distintas, minúscula en cada columna y mayúsculas en cada fila indican diferencias significativas entre las medias para cada parámetro evaluado $(p<0,05)$. ns: no significativo. 


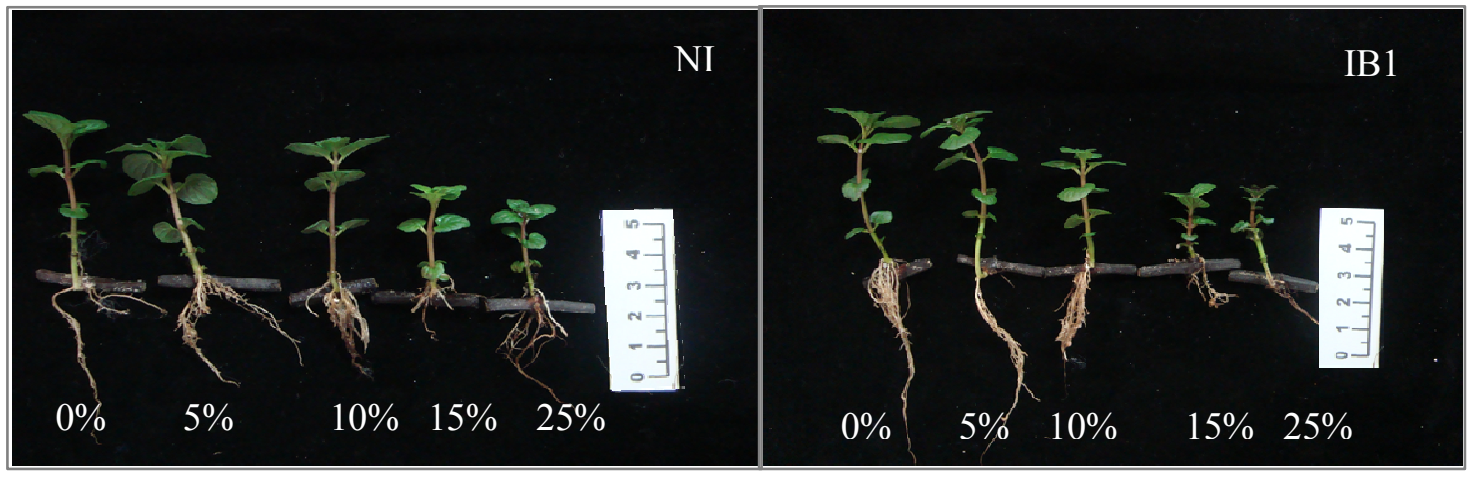

Figura 8. Plantas de Mentha x piperita a los 30 días después del trasplante que crecieron con distintas concentraciones de extracto de sorgo de Alepo.

\subsection{Experimento 2}

Evaluación del efecto de extractos acuosos de rizomas de sorgo de Alepo sobre la micorrización, parámetros morfológicos, fisiológicos y bioquímicos de plantas de

\section{Mentha $\mathbf{x}$ piperita $\mathbf{L}$.}

\section{Colonización micorrícica y dependencia micorrícica}

La colonización micorrícica se analizó en dos momentos del cultivo, a los 30 días después del trasplante (30 DDT) y a los 60 días después del trasplante (60 DDT).

El porcentaje de micorrización a los 30 DDT se presenta en la tabla 9. Ambos inóculos disminuyeron significativamente el \% $\mathrm{M}$ a partir de $\mathrm{S} 1$. La interacción $\mathrm{H}$ x S fue significativa $(p<0.001)$. Se observó abundancia de arbúsculos y vesículas en las raíces de las plantas inoculadas con ambos hongos. El \%Ar y \%V disminuyó también a partir de S1. No se observaron diferencias con respecto a los tratamientos para la dependencia micorrícica en IM, siendo dichos valores inferiores a los determinados para IB1. No obstante la DM fue elevada para la combinación menta y ambos hongos. 
Tabla 9. Colonización micorrícica $(\% \mathrm{M})$, arbúsculos $(\% \mathrm{Ar})$, vesículas $(\% \mathrm{~V})$ y dependencia micorrícica (\%DM), en plantas de Mentha x piperita L. inoculadas con Funneliformis mosseae (IM) y Rhizophagus intraradices (IB1) que crecieron con diferentes concentraciones de extracto de rizomas de SA. Referencias: S0: 0\%; S1: 5\%; S2: 10\%; S3: 15\%. Registros a los 30 días después del trasplante (30 DDT). H: micorrización, S: extracto de rizomas de SA.

\begin{tabular}{|c|c|c|c|c|c|c|c|c|}
\hline \multirow{2}{*}{$\begin{array}{c}\text { Extracto de } \\
\text { Sorgo de Alepo }\end{array}$} & \multicolumn{2}{|c|}{$\% \mathrm{M}$} & \multicolumn{2}{|c|}{$\% \mathrm{Ar}$} & \multicolumn{2}{|c|}{$\% \mathrm{~V}$} & \multicolumn{2}{|c|}{$\% \mathrm{DM}$} \\
\hline & IM & IB1 & IM & IB1 & IM & IB1 & IM & IB1 \\
\hline S0 & $92 \mathrm{a}$ & $89 a$ & $89 \mathrm{a}$ & $83 \mathrm{a}$ & $83 \mathrm{a}$ & $86 a$ & $55,2 \mathrm{a}$ & $67,6 \mathrm{a}$ \\
\hline S1 & $74 \mathrm{~b}$ & $70 \mathrm{~b}$ & $61 \mathrm{~b}$ & $60 \mathrm{~b}$ & $60 \mathrm{~b}$ & $58 \mathrm{~b}$ & $33 \mathrm{a}$ & $59,8 \mathrm{ab}$ \\
\hline S2 & $81 \mathrm{~b}$ & $65 \mathrm{c}$ & $50 \mathrm{c}$ & $55 \mathrm{c}$ & $55 \mathrm{~b}$ & $53 \mathrm{c}$ & $41,8 \mathrm{a}$ & $68,3 \mathrm{a}$ \\
\hline S3 & $54 \mathrm{c}$ & $63 \mathrm{~b}$ & $48 \mathrm{c}$ & $59 \mathrm{bc}$ & $49 \mathrm{c}$ & $55 \mathrm{bc}$ & $49,2 \mathrm{a}$ & $51,5 \mathrm{~b}$ \\
\hline $\mathrm{H}$ & \multicolumn{2}{|c|}{$<0,05$} & \multicolumn{2}{|c|}{ ns } & \multicolumn{2}{|c|}{$\mathrm{ns}$} & \multicolumn{2}{|c|}{$<0,05$} \\
\hline $\mathrm{S}$ & \multicolumn{2}{|c|}{$<0,001$} & \multicolumn{2}{|c|}{$<0,001$} & \multicolumn{2}{|c|}{$<0,001$} & \multicolumn{2}{|c|}{ ns } \\
\hline $\mathrm{H} \times \mathrm{S}$ & \multicolumn{2}{|c|}{$<0,001$} & \multicolumn{2}{|c|}{$<0,001$} & \multicolumn{2}{|c|}{$<0,05$} & \multicolumn{2}{|c|}{ ns } \\
\hline
\end{tabular}

Letras distintas en cada columna indican diferencias significativas entre las medias $(p<0,05)$. ns: no significativo.

El análisis de la micorrización registrada a los 60 DDT se presenta en la Tabla 10. El porcentaje de micorrización fue significativamente disminuido a partir de S1 para IM y a partir de S2 para IB1. La interacción $\mathrm{H}$ x S resultó no significativa para el \%M, Al finalizar el ensayo, en S0 el porcentaje de micorrización fue de $87 \%$ y $92 \%$ para $F$. mosseae y $R$. intraradices respectivamente y disminuyó a $65 \%$ y $79 \%$ con S3.

Se observó un menor \% de arbúsculos y vesículas en las raíces colonizadas por las dos especies de hongos micorrícicos al aumentar la concentración de extracto. El porcentaje de arbúsculos y vesículas disminuyó a partir de S1 para ambos inóculos. En S3 la disminución en el \%Ar fue del 62\% y 59\% para IM e IB1 respectivamente y para el \%V la reducción fue del 34\% y 30\% para IM e IB1 respectivamente comparados con S0 (Tabla 5). La viabilidad de las estructuras fúngicas SDH), disminuyó con el aumento de las concentraciones de extracto en ambos inóculos observándose una interacción significativa $\mathrm{H}$ x S. En $F$. mosseae disminuyó significativamente a partir de $\mathrm{S} 2$, mientras que en $R$. intraradices, en S3.

En este estado de desarrollo la DM aumentó significativamente en S2 y S3 con respecto a $\mathrm{S} 0$ y $\mathrm{S} 1$. Los valores fueron más elevados comparados con los observados a los 30 DDT (Tabla 10). 
Tabla 10. Colonización micorrícica $(\% \mathrm{M})$, arbúsculos $(\% \mathrm{Ar})$, vesículas $(\% \mathrm{~V})$ y dependencia micorrícica (\%DM) en plantas de Mentha x piperita L. inoculadas con Funneliformis mosseae (IM) y Rhizophagus intraradices (IB1) que crecieron con diferentes concentraciones de extracto de rizomas de SA. Referencias: S0: 0\%; S1: 5\%; S2: 10\%; S3: 15\%. Registros a los 60 días después del trasplante (60 DDT). H: micorrización, S: extracto de rizomas de SA.

$\begin{array}{lllll}\text { Extracto de } & \% \mathrm{M} & \% \mathrm{Ar} & \% \mathrm{~V} & \% \mathrm{SDH}\end{array}$

Sorgo de Alepo

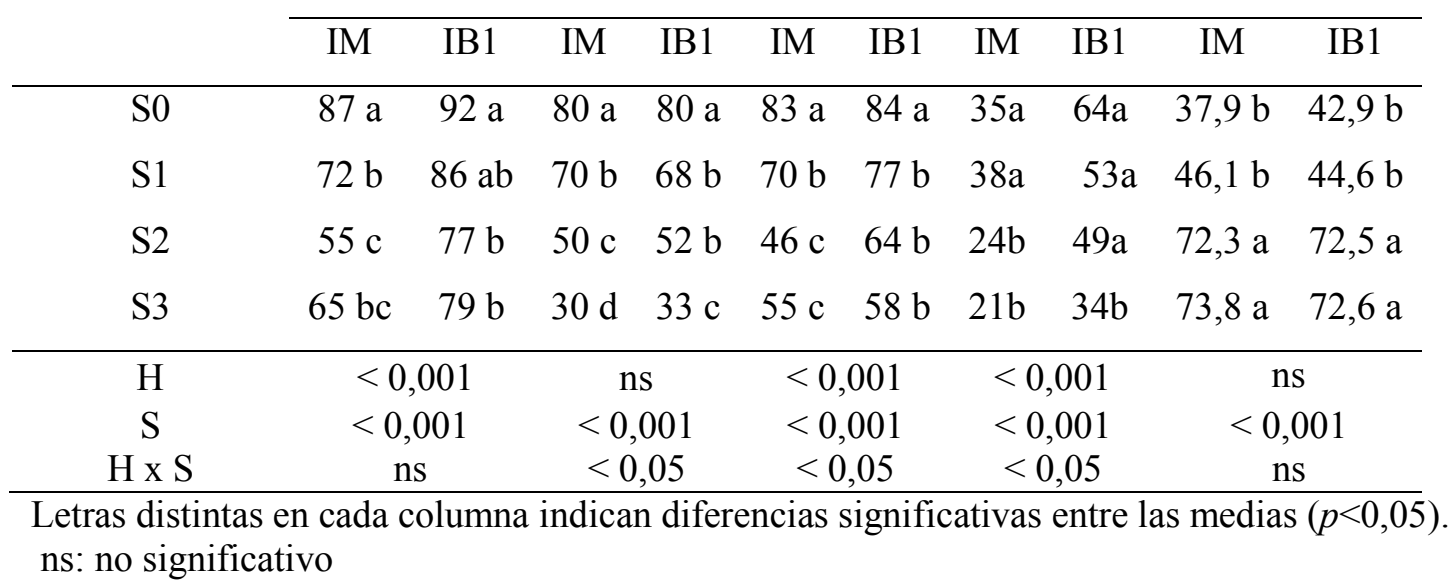

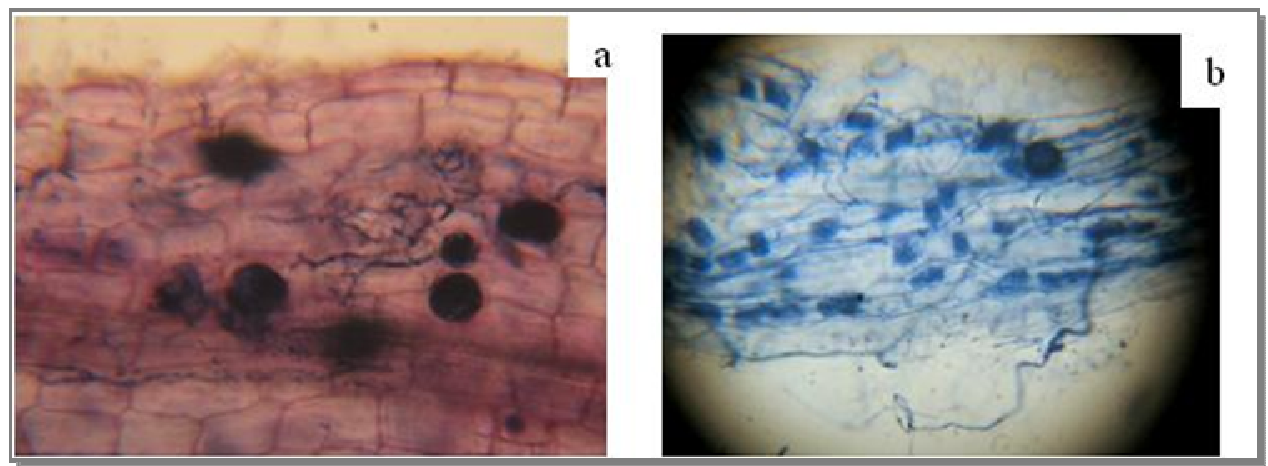

Figura 9: a) Tinción de succinato deshidrogenasa (SDH): se observan hifas y vesículas teñidas de azul indicando actividad. b) tinción de hifas, vesículas y arbúsculos con azul de tripán.

Actividad de la enzima fosfatasa alcalina en raíces

La actividad de la enzima fosfatasa alcalina se determinó al culminar en ensayo (60 DDT). Los extractos de rizomas de sorgo de Alepo afectaron significativamente la actividad de esta enzima en las plantas inoculadas con $R$. intraradices. La interacción micorrización $\mathrm{x}$ extracto fue significativa $(p<0,001)$. Las plantas no inoculadas y las inoculadas con F. mosseae no presentaron incrementos significativos con el extracto, 
mientras que las inocouladas con $R$. intraradices incrementaron significativamente la actividad de la enzima a partir de S1. En S2 y S3 los aumentos fueron del 144\% con respecto a los testigos sin extracto (Figura 10).

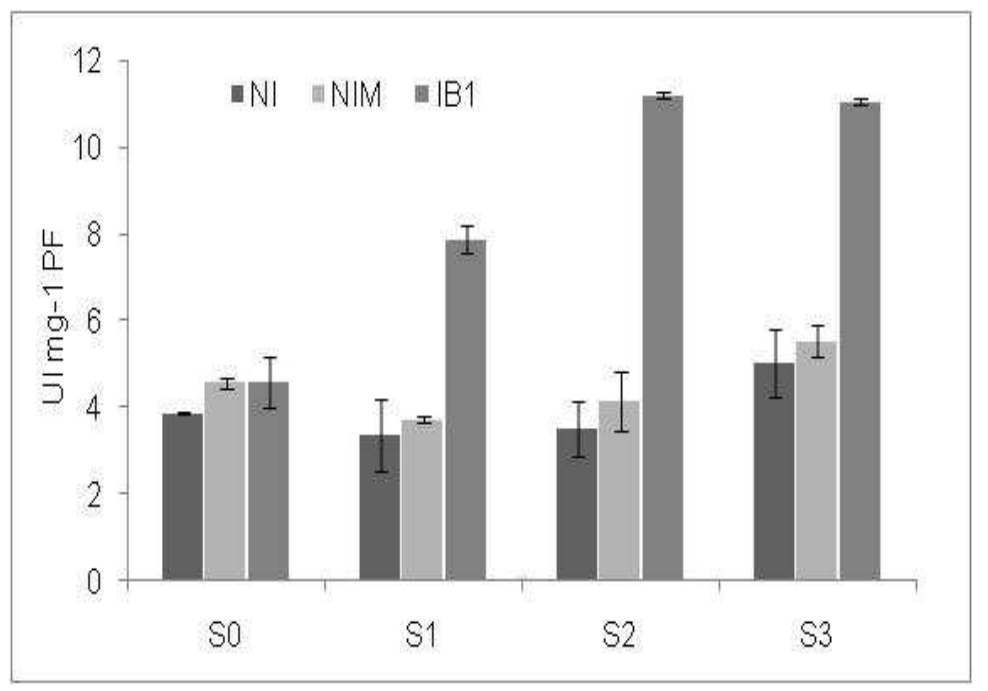

Figura 10. Efecto de los extractos de rizomas de SA sobre la actividad de la enzima fosfatasa alcalina de raíces de plantas de Mentha x piperita L. no inoculadas (NI) o inoculadas con Funneliformis mosseae (IM) y Rhizophagus intraradices (IB1). Referencias: S0: 0\%; S1: 5\%; S2: $10 \%$; S3: $15 \%$.

Tabla 11. Análisis de Varianza de los efectos de la micorrización (NI, IM e IB1) y el extracto acuoso de rizomas de SA (S0, S1, S2 y S3) y su interacción sobre la Fosfatasa alcalina (UI $\mathrm{mg}^{1}$ ). Referencias: H: micorrización; S: extracto de rizomas de SA.

\begin{tabular}{llll}
\hline Fuente de variación & Gl & CM & Valor-P \\
\hline H: Micorrización & 2 & 80,4806 & $<0,001$ \\
S:Extracto de SA & 3 & 14,8671 & $<0,001$ \\
Interacciones H x S & 6 & 9,04785 & $<0,001$ \\
\hline
\end{tabular}

Gl: grados de libertad; CM: cuadrado medio; P: valor de probabilidad de la prueba de F

Parámetros de crecimiento

El crecimiento se expresó como peso seco por planta, peso seco de hojas, tallos y raíces y se determinó en dos períodos, a los 30 DDT y al finalizar el ensayo 60 DDT. Al finalizar el ensayo se determinó además la longitud y el volumen de la raíz.

Altura de plantas de Mentha x piperita al comienzo de los tratamientos con extractos de $S A$. 
Se tomaron registros de altura de plantas de Mentha x piperita $\mathrm{L}$ a partir de los 7 días después del primer riego con extracto acuoso de rizomas de Sorgo de Alepo y cada 3 días (DDE) (Figura 11). La presencia del extracto y la inoculación modificaron el crecimiento en altura de las plantas desde el inicio del ensayo. Se observó una interacción significativa $\mathrm{H}$ x S y S x F (fecha de registro de altura) (Tabla 12) No se observaron diferencias significativas entre los tratamientos de inoculación en las concentraciones $\mathrm{S} 0$ y S1. En S2 tanto IM como IB1 registraron mayor altura a los $10 \mathrm{y}$ 13 DDE. Con la concentración S3, la altura de las plantas inoculadas con $R$. intraradices mostraron diferencias significativas con respecto a las NI y IM a partir de los 10 DDE. A los 19 DDE las plantas inoculadas con ambos inóculos, presentaron mayor altura respecto a las NI.
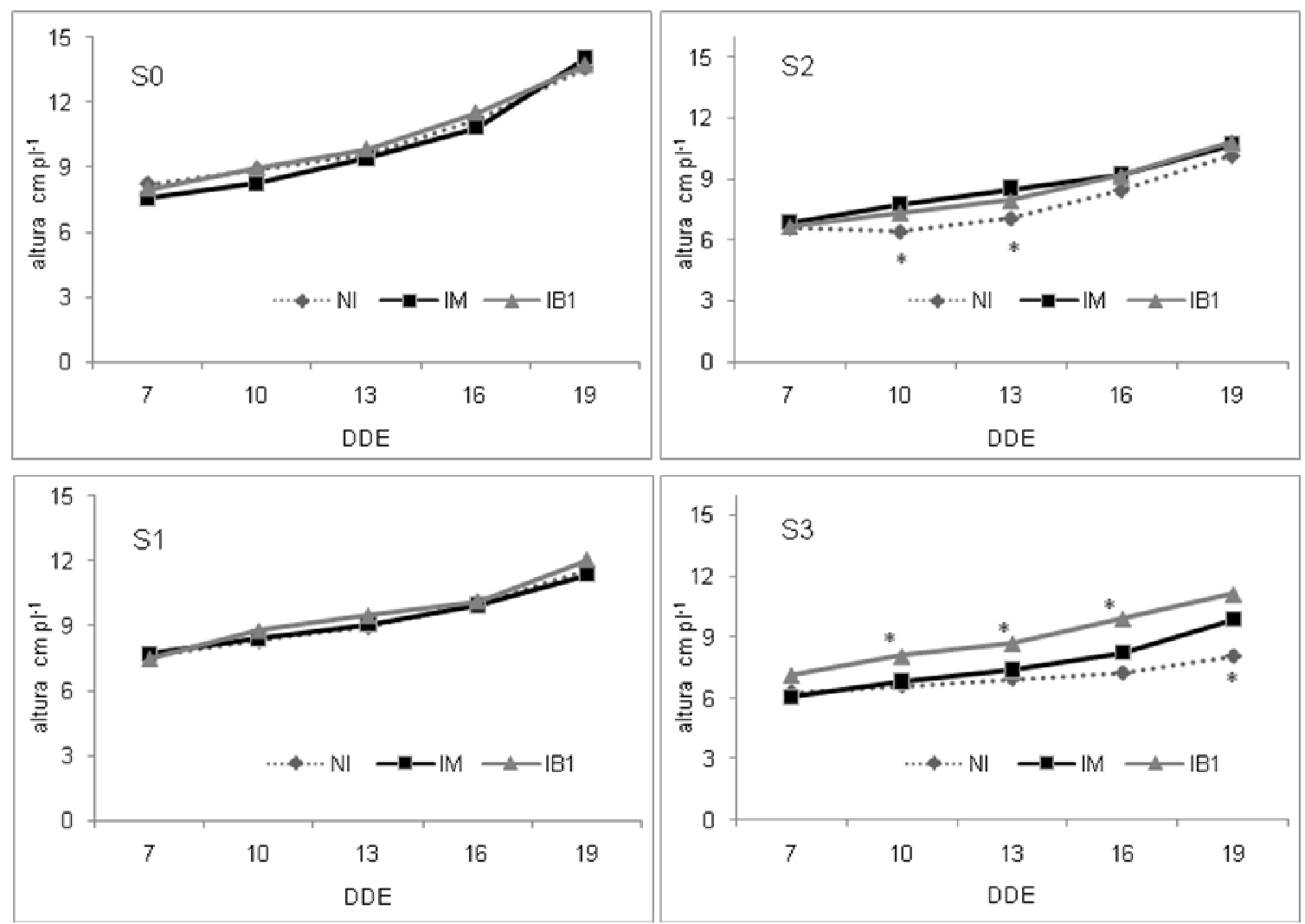

Figura 11. Altura de plantas de Mentha x piperita $\mathrm{L}$ tomados a partir de los 7 días después del primer riego con extracto acuoso de rizomas de Sorgo de Alepo (DDE) y cada 3 días, no inoculadas (NI), inoculadas con Funneliformis mosseae (IM) y Rhizophagus intraradices (IB1). Referencias: S0: 0\%; S1: 5\%; S2: 10\%; S3: 15\%.

(*) Diferencias significativas entre las medias $(p<0,05)$. 
Tabla 12. Análisis de Varianza de los efectos de la micorrización (NI, IM e IB1), el extracto acuoso de rizomas de SA (S0, S1, S2 y S3) y la fecha de registro de altura (7, 10, 13, 16 y 19 DDE) y sus interacciones sobre la altura de plantas. H: micorrización; S: extracto de rizomas de SA; F: fecha de registro de altura.

\begin{tabular}{lcll}
\hline \multicolumn{1}{c}{ Fuente de variación } & Gl & CM & Valor-P \\
\hline H: Micorrización & 2 & 25,7893 & $<0,001$ \\
S: Extracto de SA & 3 & 87,6107 & $<0,001$ \\
F: Fecha registro de altura & 4 & 193,915 & $<0,001$ \\
Interacciones & & & \\
H x S & 6 & 5,27046 & $<0,001$ \\
H x F & 8 & 0,909656 & 0,3442 \\
S x F & 12 & 4,458 & $<0,001$ \\
H x S x F & 24 & 0,804693 & 0,4690 \\
\hline
\end{tabular}

Gl: grados de libertad; CM: cuadrado medio; P: valor de probabilidad de la prueba de F

Parámetros de crecimiento medidos a los 30 días después del trasplante

La altura de las plantas medida a los 30 DDT (Tabla 13) se vio significativamente afectada por la inoculación y los extractos de sorgo de Alepo. Las plantas inoculadas presentaron mayor altura en todos los tratamientos, las inoculadas con $R$. intraradices superaron a las inoculadas con $F$. mosseae. La aplicación o el riego con extractos disminuyó significativamente la altura, en las NI a partir de S1, en las IB1 en S3 y en las IM la disminución no fue significativa.

El área foliar fue también significativamente mayor en las plantas inoculadas en todas las concentraciones. Este parámetro se vio afectado en forma negativa por el agregado de extracto, disminuyendo a partir de S1.Comparando los dos inóculos utilizados, las plantas inoculadas con IB1 mostraron mayor AF. Las diferencias entre inoculadas y no inoculadas fueron estadísticamente significativas $(p<0,05)$ y también fueron afectados por el extracto. Con altas concentraciones de extracto (S3) no hubo diferencias entre los inóculos.

El peso seco de hojas y tallos fue afectado significativamente por la micorrización y el extracto de sorgo de Alepo. Para estos parámetros se observó una interacción significativa $\mathrm{H}$ x S $(p<0,001)$. Las plantas inoculadas acumularon mayor PSH y PST que las NI en todos los tratamientos, siendo las IB1 las que presentaron los mayores valores. E1 PSH fue disminuido significativamente a partir de S2 en las plantas NI y a partir de S1 en las inoculadas. En cuanto al peso seco de raíz, el análisis de la varianza mostró diferencias estadísticamente significativas para la $\mathrm{H}$ y los $\mathrm{S}$, 
observándose una interacción entre $\mathrm{H}$ x $\mathrm{S}(p<0,001)$. La mayor acumulación de PSR se observó en las plantas inoculadas en todos los tratamientos, con diferencias significativas a favor de las inoculadas con IB1 con respecto a IM en los tratamientos con extracto.

La longitud de raíz no mostró diferencias significativas en los tratamientos sin extracto entre plantas inoculadas y no inoculadas. Las plantas inoculadas con $F$. mosseae y las NI disminuyeron estadísticamente este parámetro en $\mathrm{S} 3$, mientras que no hubo diferencias con el agregado de distintas concentraciones de extracto en las IB1 (Tabla 13).

Tabla 13. Efecto de los extractos de rizomas de SA sobre la altura de planta (Alt) área foliar (AF), peso seco de hojas (PSH), tallos (PST) y raíces (PSR) y longitud de raíz (Long raíz) en plantas de Mentha x piperita L. no inoculadas (NI) o inoculadas con Funneliformis mosseae (IM) y Rhizophagus intraradices (IB1). Referencias: S0: 0\%; S1: 5\%; S2: 10\%; S3: 15\%. Registros realizados a los 30 días después del trasplante (30 DDT). H: micorrización; S: extracto de rizomas de SA.

\begin{tabular}{cccccccc}
\hline $\begin{array}{c}\text { Hongos } \\
\text { Micorrícicos }\end{array}$ & $\begin{array}{c}\text { Extracto } \\
\text { de Sorgo } \\
\text { de Alepo }\end{array}$ & $\begin{array}{c}\text { Alt } \\
\left(\mathrm{cm} \mathrm{pl}^{-1}\right)\end{array}$ & $\begin{array}{c}\text { AF } \\
\left(\mathrm{cm}^{2} \mathrm{pl}^{-1}\right)\end{array}$ & $\begin{array}{c}\text { PSH } \\
\left(\mathrm{g} \mathrm{pl}^{-1}\right)\end{array}$ & $\begin{array}{c}\text { PST } \\
\left(\mathrm{g} \mathrm{pl}^{-1}\right)\end{array}$ & $\begin{array}{c}\text { PSR } \\
\left(\mathrm{g} \mathrm{pl}^{-1}\right)\end{array}$ & Long raíz $\left(\mathrm{cm} \mathrm{pl}^{-1}\right)$ \\
\hline \multirow{2}{*}{$\mathrm{NI}$} & $\mathrm{S} 0$ & $16,03 \mathrm{a}$ & $60,10 \mathrm{a}$ & $0,160 \mathrm{a}$ & $0,064 \mathrm{a}$ & $0,113 \mathrm{a}$ & $20,33 \mathrm{a}$ \\
& $\mathrm{S} 1$ & $12,60 \mathrm{~b}$ & $47,56 \mathrm{~b}$ & $0,169 \mathrm{a}$ & $0,049 \mathrm{~b}$ & $0,099 \mathrm{ab}$ & $20,66 \mathrm{a}$ \\
& $\mathrm{S} 2$ & $10,86 \mathrm{bc}$ & $26,06 \mathrm{c}$ & $0,122 \mathrm{~b}$ & $0,030 \mathrm{c}$ & $0,081 \mathrm{~b}$ & $16,50 \mathrm{a}$ \\
& $\mathrm{S} 3$ & $9,00 \mathrm{c}$ & $16,98 \mathrm{~d}$ & $0,074 \mathrm{c}$ & $0,022 \mathrm{~d}$ & $0,074 \mathrm{~b}$ & $9,00 \mathrm{~b}$ \\
& & & & & & & \\
$\mathrm{IM}$ & $\mathrm{S} 0$ & $19,60 \mathrm{a}$ & $137,14 \mathrm{a}$ & $0,356 \mathrm{a}$ & $0,175 \mathrm{a}$ & $0,228 \mathrm{a}$ & $21,16 \mathrm{a}$ \\
& $\mathrm{S} 1$ & $16,10 \mathrm{a}$ & $88,84 \mathrm{~b}$ & $0,208 \mathrm{~b}$ & $0,115 \mathrm{~b}$ & $0,139 \mathrm{~b}$ & $21,83 \mathrm{a}$ \\
& $\mathrm{S} 2$ & $18,50 \mathrm{a}$ & $81,03 \mathrm{~b}$ & $0,199 \mathrm{~b}$ & $0,066 \mathrm{c}$ & $0,148 \mathrm{ab}$ & $21,50 \mathrm{a}$ \\
& $\mathrm{S} 3$ & $15,66 \mathrm{a}$ & $64,06 \mathrm{~b}$ & $0,232 \mathrm{~b}$ & $0,059 \mathrm{c}$ & $0,089 \mathrm{~b}$ & $13,33 \mathrm{~b}$ \\
& & & & & & & \\
$\mathrm{IB} 1$ & $\mathrm{~S} 0$ & $24,20 \mathrm{a}$ & $175,07 \mathrm{a}$ & $0,519 \mathrm{a}$ & $0,241 \mathrm{a}$ & $0,291 \mathrm{a}$ & $21,75 \mathrm{a}$ \\
& $\mathrm{S} 1$ & $20,76 \mathrm{a}$ & $130,90 \mathrm{~b}$ & $0,349 \mathrm{~b}$ & $0,176 \mathrm{~b}$ & $0,289 \mathrm{a}$ & $25,33 \mathrm{a}$ \\
& $\mathrm{S} 2$ & $20,23 \mathrm{a}$ & $125,19 \mathrm{~b}$ & $0,392 \mathrm{~b}$ & $0,162 \mathrm{~b}$ & $0,205 \mathrm{~b}$ & $23,33 \mathrm{a}$ \\
& $\mathrm{S} 3$ & $14,26 \mathrm{~b}$ & $53,75 \mathrm{c}$ & $0,203 \mathrm{c}$ & $0,058 \mathrm{c}$ & $0,104 \mathrm{c}$ & $17,33 \mathrm{a}$ \\
\hline $\mathrm{H}$ & & $<0,001$ & $<0,001$ & $<0,001$ & $<0,001$ & $<0,001$ & $<0,05$ \\
$\mathrm{~S}$ & & $<0,001$ & $<0,001$ & $<0,001$ & $<0,001$ & $<0,001$ & $<0,001$ \\
$\mathrm{H}$ H S & & $\mathrm{ns}$ & $<0,001$ & $<0,001$ & $<0,001$ & $<0,05$ & $\mathrm{~ns}$ \\
\hline
\end{tabular}

Letras distintas en cada columna indican diferencias significativas entre las medias de distintas concentraciones de extracto para cada tratamiento de inoculación $(p<0.05)$. ns: no significativo 
La altura de las plantas se vio significativamente disminuida por el extracto acuoso de sorgo de Alepo, con una interacción H x S significativa $(p<0,001)$. Las plantas NI vieron reducida su altura a partir de S2, mientras que las IB1 lo hicieron en S1 y las IM en S3. Las plantas inoculadas superaron en altura a las NI en S2 aproximadamente en 50\% (Tabla 14).

El área foliar disminuyó en forma significativa en S2 y S3 comparada con S0 en las plantas no inoculadas, mientras que en las inoculadas la disminución fue significativa en S2 y S3 para IB1 y solo en S3 para IM. Se observó una interacción significativa $\mathrm{H} x \mathrm{~S}$ para este parámetro $(p<0,001)$, siendo las plantas inoculadas las que evidenciaron un mejor comportamiento en presencia del extracto de sorgo de Alepo (Tabla 14)

Las plantas inoculadas alcanzaron una mayor acumulación de materia seca, determinada por el PSH y PST, comparadas con las no inoculadas en todas las concentraciones de extracto de SA, con diferencias estadísticamente significativas ( $p$ $<0,001)$. En este caso, no se observaron diferencias significativas entre los inóculos utilizados. Los tratamientos S2 y S3 redujeron significativamente estos parámetros en las inoculadas y las NI. El peso seco de hojas y tallos disminuyó un 62\% y $66 \%$ en las plantas no inoculadas en S2 y S3 respectivamente en las mediciones registradas al finalizar el ensayo. En las plantas inoculadas el peso seco de disminuyó un 8\% y 21\% en las IM y $19 \%$ y $23 \%$ en IB1, respectivamente, comparadas con S0. Las plantas inoculadas también mostraron mayor cantidad de hojas por planta, siendo las IM las que presentaron los valores más elevados. Los extractos redujeron este parámetro en NI y en IM en S3 y S2 respectivamente.

La inoculación incrementó el peso seco y volumen de las raíces en forma significativa en todos tratamientos de extracto. No hubo diferencias entre los inóculos ensayados. Las plantas inoculadas con IB1 redujeron significativamente el PSR en S2 y $\mathrm{S} 3$, mientras que las inoculadas con F. mosseae lo hicieron en $\mathrm{S} 3$. El volumen no se vio afectado en las plantas inoculadas pero si en las NI con una reducción de 9,5\% y 14\% en S2 y S3 respectivamente comparado con S0 (Tabla 15). 
Tabla 14. Efecto de los extractos de rizomas de SA sobre la altura de planta (Alt) área foliar (AF), peso seco de hojas (PSH), tallos (PST) en plantas de Mentha x piperita L. no inoculadas (NI) o inoculadas con Funneliformis mosseae (IM) y Rhizophagus intraradices (IB1). Referencias: S0: 0\%; S1: 5\%; S2: 10\%; S3: 15\%. Registros a los 60 días después del trasplante (60 DDT). H: micorrización; S: extracto de rizomas de SA.

\begin{tabular}{ccccccc}
\hline $\begin{array}{c}\text { Hongos } \\
\text { Micorrícicos }\end{array}$ & $\begin{array}{c}\text { Extracto de } \\
\text { Sorgo de } \\
\text { Alepo }\end{array}$ & $\begin{array}{c}\text { Alt } \\
\left(\mathrm{cm} \mathrm{pl}^{-1}\right)\end{array}$ & $\begin{array}{c}\text { AF } \\
\left(\mathrm{cm}^{2} \mathrm{pl}^{-1}\right)\end{array}$ & $\begin{array}{c}\text { PSH } \\
\left(\mathrm{g} \mathrm{pl}^{-1}\right)\end{array}$ & $\mathrm{N}^{\circ}$ hojas & $\begin{array}{c}\text { PST } \\
\left(\mathrm{g} \mathrm{pl}^{-1}\right)\end{array}$ \\
\hline NI & $\mathrm{S} 0$ & $61,37 \mathrm{a}$ & $295,17 \mathrm{a}$ & $1,111 \mathrm{a}$ & $62,0 \mathrm{a}$ & $0,759 \mathrm{a}$ \\
& $\mathrm{S} 1$ & $55,00 \mathrm{a}$ & $309,25 \mathrm{a}$ & $0,993 \mathrm{a}$ & $71,6 \mathrm{ab}$ & $0,717 \mathrm{a}$ \\
& $\mathrm{S} 2$ & $42,83 \mathrm{~b}$ & $113,50 \mathrm{~b}$ & $0,414 \mathrm{~b}$ & $44,2 \mathrm{~b}$ & $0,283 \mathrm{~b}$ \\
& $\mathrm{~S} 3$ & $25,25 \mathrm{c}$ & $67,75 \mathrm{c}$ & $0,427 \mathrm{~b}$ & $23,5 \mathrm{c}$ & $0,181 \mathrm{~b}$ \\
$\mathrm{IM}$ & $\mathrm{S} 0$ & $62,37 \mathrm{ab}$ & $412,00 \mathrm{a}$ & $1,626 \mathrm{a}$ & $119,2 \mathrm{a}$ & $1,213 \mathrm{ab}$ \\
& $\mathrm{S} 1$ & $64,00 \mathrm{a}$ & $451,50 \mathrm{a}$ & $1,860 \mathrm{a}$ & $128,5 \mathrm{a}$ & $1,310 \mathrm{a}$ \\
& $\mathrm{S} 2$ & $60,62 \mathrm{ab}$ & $418,50 \mathrm{a}$ & $1,586 \mathrm{~b}$ & $109,0 \mathrm{ab}$ & $1,079 \mathrm{ab}$ \\
& $\mathrm{S} 3$ & $55,75 \mathrm{~b}$ & $322,75 \mathrm{~b}$ & $1,324 \mathrm{~b}$ & $82,0 \mathrm{~b}$ & $0,900 \mathrm{~b}$ \\
$\mathrm{IB} 1$ & $\mathrm{~S} 0$ & $71,12 \mathrm{a}$ & $433,50 \mathrm{a}$ & $1,803 \mathrm{a}$ & $77,2 \mathrm{a}$ & $1,324 \mathrm{a}$ \\
& $\mathrm{S} 1$ & $60,75 \mathrm{~b}$ & $425,50 \mathrm{a}$ & $1,870 \mathrm{a}$ & $92,2 \mathrm{a}$ & $1,091 \mathrm{ab}$ \\
& $\mathrm{S} 2$ & $61,00 \mathrm{~b}$ & $389,00 \mathrm{~b}$ & $1,395 \mathrm{~b}$ & $88,5 \mathrm{a}$ & $1,205 \mathrm{bc}$ \\
& $\mathrm{S} 3$ & $50,70 \mathrm{c}$ & $406,00 \mathrm{~b}$ & $1,137 \mathrm{~b}$ & $94,2 \mathrm{a}$ & $0,966 \mathrm{c}$ \\
\hline H & & $<0,001$ & $<0,001$ & $<0,001$ & $<0,001$ & $<0,001$ \\
Sn & & $<0,001$ & $<0,001$ & $<0,001$ & $<0,001$ & $<0,001$ \\
H x S & & $<0,001$ & $<0,001$ & ns & $<0,05$ & $<0,05$ \\
\hline
\end{tabular}

Letras distintas en cada columna indican diferencias significativas entre las medias de distintas concentraciones de extracto para cada tratamiento de inoculación $(p<0.05)$.

** Indican diferencias significativas entre las medias $(p<0.001)$. ns: no significativa. 
Tabla 15. Efecto de los extractos de rizomas de SA sobre el peso seco de raíces (PSR), longitud de raíz (Long raíz) y volumen de raíz (Vol. raíz) en plantas de Mentha x piperita L. no inoculadas (NI) o inoculadas con Funneliformis mosseae (IM) y Rhizophagus intraradices (IB1). Registros a los 60 días después del trasplante (60 DDT). Referencias: S0: 0\%; S1: 5\%; S2: 10\%; S3: 15\%. H: micorrización; S: extracto de rizomas de SA.

\begin{tabular}{ccccc}
\hline $\begin{array}{c}\text { Hongos } \\
\text { micorrí́cicos }\end{array}$ & $\begin{array}{c}\text { Extracto } \\
\text { de Sorgo } \\
\text { de Alepo }\end{array}$ & $\begin{array}{c}\text { PSR } \\
\left(\mathrm{g} \mathrm{pl}^{-1}\right)\end{array}$ & $\begin{array}{c}\text { Long raíz } \\
\left(\mathrm{cm} \mathrm{pl}^{-1}\right)\end{array}$ & $\begin{array}{c}\text { Vol. raíz } \\
\left(\mathrm{cm}^{3}\right)\end{array}$ \\
\hline NI & S0 & $0,205 \mathrm{~b}$ & $27,37 \mathrm{a}$ & $18,37 \mathrm{a}$ \\
& $\mathrm{S} 1$ & $0,273 \mathrm{a}$ & $29,12 \mathrm{a}$ & $18,66 \mathrm{a}$ \\
& $\mathrm{S} 2$ & $0,127 \mathrm{c}$ & $20,12 \mathrm{~b}$ & $16,62 \mathrm{~b}$ \\
& $\mathrm{~S} 3$ & $0,065 \mathrm{~d}$ & $16,37 \mathrm{~b}$ & $15,75 \mathrm{c}$ \\
$\mathrm{IM}$ & $\mathrm{S} 0$ & $0,566 \mathrm{a}$ & $22,87 \mathrm{a}$ & $44,75 \mathrm{a}$ \\
& $\mathrm{S} 1$ & $0,564 \mathrm{a}$ & $24,75 \mathrm{a}$ & $45,12 \mathrm{a}$ \\
& $\mathrm{S} 2$ & $0,322 \mathrm{~b}$ & $26,50 \mathrm{a}$ & $43,12 \mathrm{a}$ \\
& $\mathrm{S} 3$ & $0,411 \mathrm{ab}$ & $28,37 \mathrm{a}$ & $44,12 \mathrm{a}$ \\
$\mathrm{IB} 1$ & $\mathrm{~S} 0$ & $0,493 \mathrm{~b}$ & $28,12 \mathrm{a}$ & $43,75 \mathrm{a}$ \\
& $\mathrm{S} 1$ & $0,624 \mathrm{a}$ & $24,00 \mathrm{~b}$ & $43,87 \mathrm{a}$ \\
& $\mathrm{S} 2$ & $0,483 \mathrm{~b}$ & $25,00 \mathrm{ab}$ & $44,75 \mathrm{a}$ \\
& $\mathrm{S} 3$ & $0,385 \mathrm{~b}$ & $21,62 \mathrm{~b}$ & $44,50 \mathrm{a}$ \\
\hline $\mathrm{H}$ & & $<0,001$ & $\mathrm{~ns}$ & $<0,001$ \\
$\mathrm{~S}$ & & $<0,001$ & $\mathrm{~ns}$ & $<0,05$ \\
$\mathrm{H}$ x S & & ns & $<0,05$ & $<0,05$ \\
\hline
\end{tabular}

Letras distintas en cada columna indican diferencias significativas entre las medias de distintas concentraciones de extracto para cada tratamiento de inoculación $(p<0.05)$.

ns: no significativo.

\section{Contenido de proteínas solubles en hojas}

Los valores de proteínas de hojas fueron significativamente más elevados en las plantas inoculadas para todos los tratamientos, observándose una interacción micorrización $\mathrm{x}$ extracto significativa $(p<0,001)$. Se observó una disminución significativa del contenido proteico a partir de S2 en las plantas NI y las IM, mientras que para IB1 el descenso se observó en S3. La disminución en S2 y S3 fue de 22\% y $33 \%$ respectivamente para las NI, mientras que las IM presentaron una disminución del $32 \%$ y $33 \%$ respectivamente para las mismas concentraciones. Los valores de proteínas expresados en $\mu \mathrm{g} \mathrm{g}^{-1} \mathrm{PF}$ fueron mayores en las inoculadas con $F$. mosseae en S0 y S1 (Figura 12). 


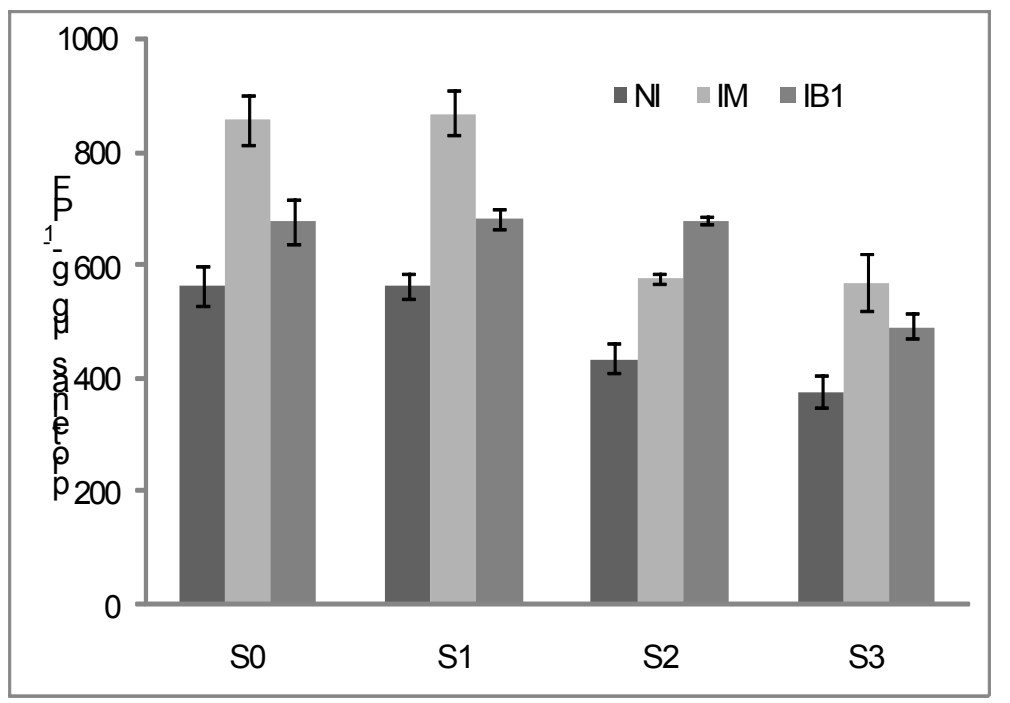

Figura 12. Efecto de los extractos de rizomas de sorgo de Alepo sobre el contenido de proteínas solubles de hojas plantas de Mentha x piperita L. no inoculadas (NI) o inoculadas con Funneliformis mosseae (IM) y Rhizophagus intraradices (IB1). Referencias: S0: 0\%; S1: 5\%; S2: $10 \%$; S3: $15 \%$.

Tabla 16. Análisis de Varianza de los efectos de la micorrización (NI, IM e IB1) y el extracto acuoso de rizomas de SA (S0, S1, S2 y S3) y su interacción sobre la concentración de proteínas solubles de hoja ( $\left.\mu \mathrm{g} \mathrm{g}^{-1} \mathrm{PF}\right)$. Referencias: H: micorrización; S: extracto de rizomas de SA.

\begin{tabular}{llll}
\hline Fuente de variación & Gl & CM & Valor-P \\
\hline H: Micorrización & 2 & 225007, & $<0,001$ \\
S:Extracto de SA & 3 & 143275, & $<0,001$ \\
Interacción H x S & 6 & 20275,0 & $<0,001$ \\
\hline
\end{tabular}

Gl: grados de libertad; CM: cuadrado medio; P: valor de probabilidad de la prueba de F

\section{Contenido de clorofila total y carotenoides}

El contenido de clorofila total expresado en $\mu \mathrm{g} \mathrm{cm}^{-2}$ mostró diferencias significativas entre las concentraciones de extracto y la micorrización (Figura 13). La interacción micorrización $\mathrm{x}$ extracto fue significativa $(p<0,001)$. Las concentraciones S2 y S3 disminuyeron el contenido de clorofila en las plantas NI. En S2 y S3 el porcentaje de disminución fue de 38\% y 54\% para las NI, $0 \%$ y $12,7 \%$ para IM y $8 \%$ y $30 \%$ IB1 respectivamente.

Las plantas inoculadas registraron los valores más elevados de clorofila con diferencias significativas en S2 y S3 respecto a las NI. En S2 y S3 el contenido de clorofila de IM fue $71 \%$ y $100 \%$ superior a las plantas NI respectivamente y las 
inoculadas con IB1 $81 \%$ y $86 \%$ respecto a los mismos tratamientos. El contenido de carotenoides expresado por $\mu \mathrm{g} \mathrm{cm}^{-2}$, (Figura 14) siguió la misma tendencia que el observado para el contenido de clorofila en las mayores concentraciones de extracto (S3 y S2), donde las inoculadas presentaron mayor concentración de estos pigmentos comparadas con las NI.

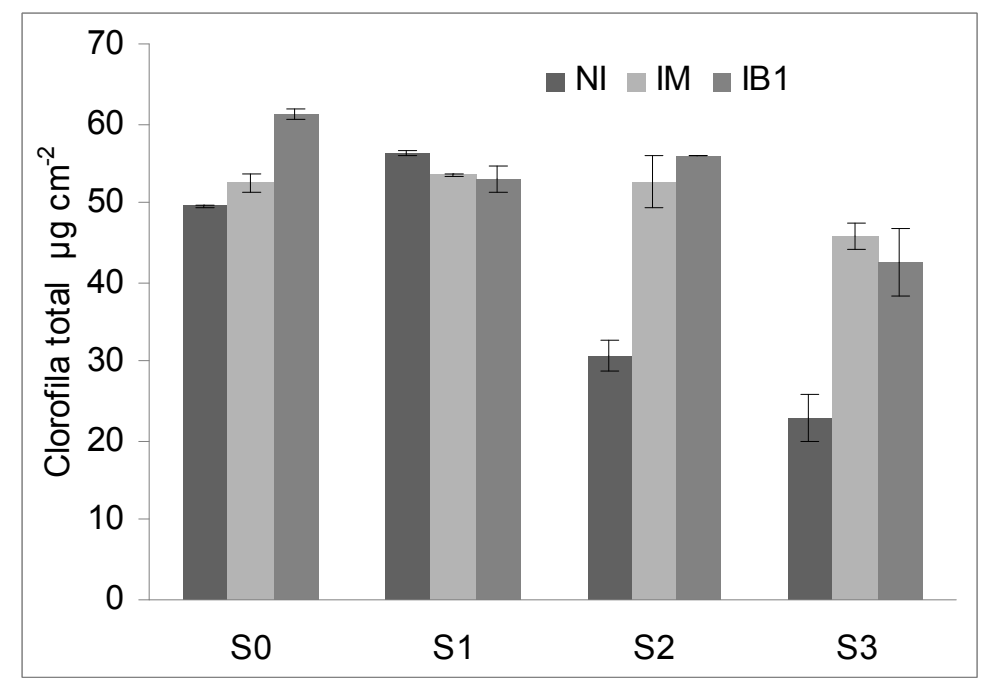

Figura 13. Efecto de los extractos de rizomas de sorgo de Alepo sobre la concentración de clorofila total de plantas de Mentha x piperita L. no inoculadas (NI) o inoculadas con Funneliformis mosseae (IM) y Rhizophagus intraradices (IB1). Referencias: S0: 0\%; S1: 5\%; S2: $10 \%$; S3: $15 \%$.

Tabla 17. Análisis de Varianza de los efectos de la micorrización (NI, IM e IB1) y el extracto acuoso de rizomas de SA (S0, S1, S2 y S3) y su interacción sobre la concentración de clorofila total $\left(\mu \mathrm{g} \mathrm{cm}^{-2}\right)$. Referencias: H: micorrización; S: extracto de rizomas de SA.

\begin{tabular}{llcl}
\hline Fuente de variación & Gl & CM & Valor-P \\
\hline H: Micorrización & 2 & 820,042 & $<0,001$ \\
S:Extracto de SA & 3 & 810,079 & $<0,001$ \\
Interacción H x S & 6 & 233,238 & $<0,001$ \\
\hline
\end{tabular}

Gl: grados de libertad; CM: cuadrado medio; P: valor de probabilidad de la prueba de F 


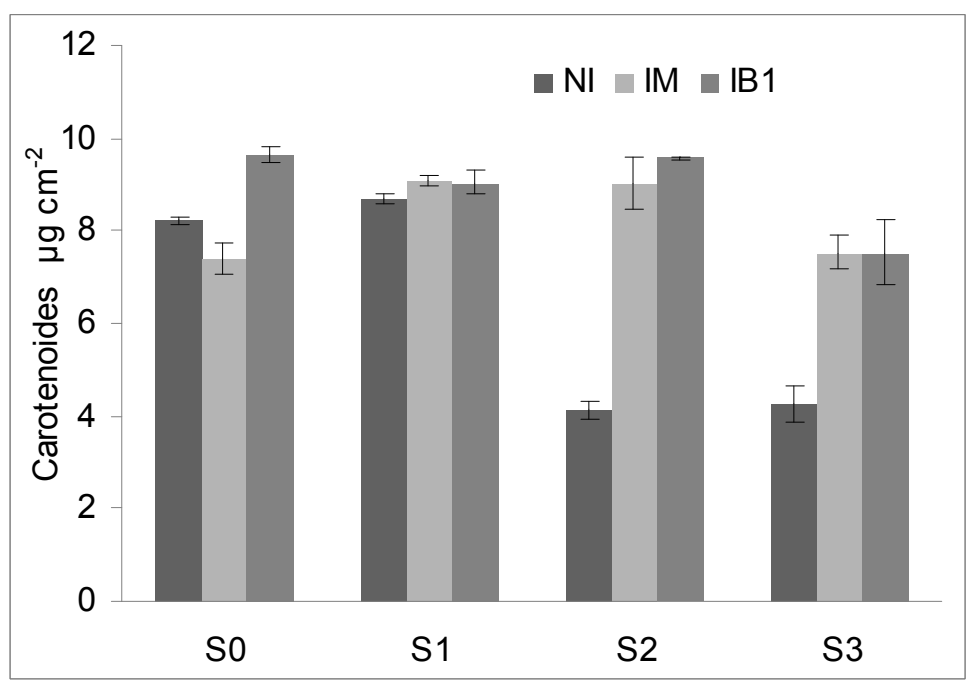

Figura 14. Efecto de los extractos de rizomas de sorgo de Alepo sobre la concentración de carotenoides de plantas de Mentha x piperita L. no inoculadas (NI) o inoculadas con Funneliformis mosseae (IM) y Rhizophagus intraradices (IB1). Referencias: S0: 0\%; S1: 5\%; S2: $10 \%$; S3: 15\%.

Tabla 18. Análisis de Varianza de los efectos de la micorrización (NI, IM e IB1) y el extracto acuoso de rizomas de SA (S0, S1, S2 y S3) y su interacción sobre la concentración de carotenoides $\left(\mu \mathrm{g} \mathrm{cm}^{-2}\right)$. Referencias: H: micorrización; S: extracto de rizomas de SA.

\begin{tabular}{llll}
\hline Fuente de variación & Gl & CM & Valor-P \\
\hline H: Micorrización & 2 & 29,6932 & $<0,001$ \\
S:Extracto de SA & 3 & 14,2511 & $<0,001$ \\
Interacción H x S & 6 & 8,62249 & $<0,001$ \\
\hline
\end{tabular}

Gl: grados de libertad; CM: cuadrado medio; P: valor de probabilidad de la prueba de F

Fotosintesis neta (PN)

En S0 las plantas micorrizadas con ambos inóculos presentaron mayores valores de PN, con diferencias significativas para las inoculadas con $R$. intraradices. La interacción $\mathrm{H} \times \mathrm{S}$ fue no significativa $(p>0,05)$. Las NI registraron una disminución significativa en S2 y S3 en tanto que en las inoculadas el descenso se produjo solo en S3.

Las plantas NI, IM e IB1 disminuyeron la PN en $65 \%$, 9\% y $16,9 \%$ en $\mathrm{S} 3$ con respecto a S0 (Figura 15). 


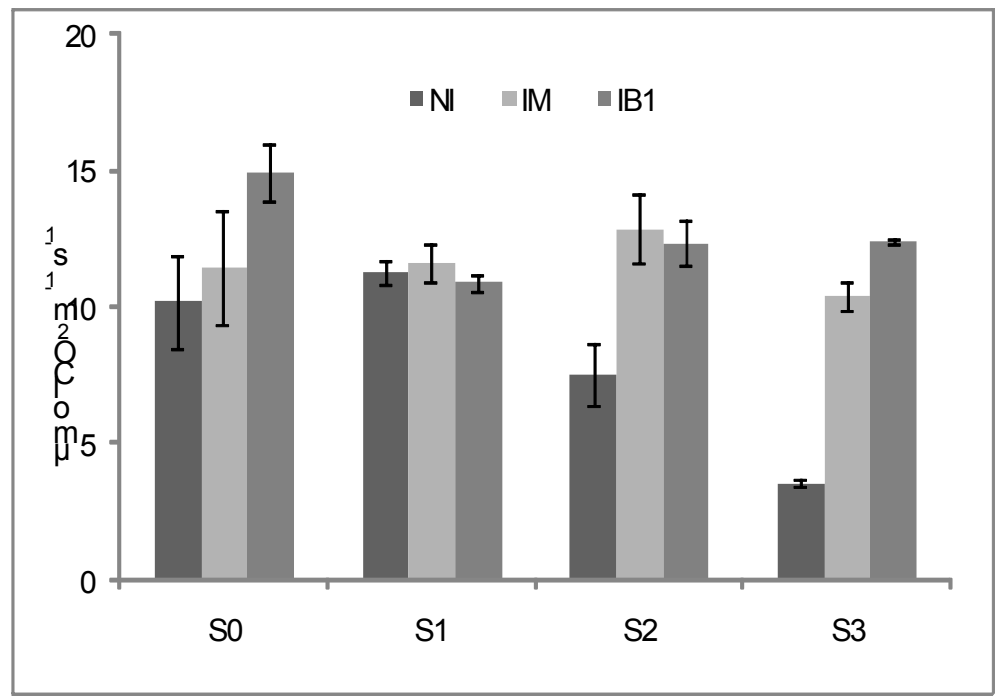

Figura 15. Efecto de los extractos de rizomas de sorgo de Alepo sobre la Fotosíntesis neta (PN) de plantas de Mentha x piperita L. no inoculadas (NI) o inoculadas con Funneliformis mosseae (IM) y Rhizophagus intraradices (IB1). Referencias: S0: 0\%; S1: 5\%; S2: 10\%; S3: 15\%.

Tabla 19. Análisis de Varianza de los efectos de la micorrización (NI, IM e IB1) y el extracto acuoso de rizomas de SA (S0, S1, S2 y S3) y su interacción sobre la Fotosíntesis neta (PN). Referencias: H: micorrización; S: extracto de rizomas de SA.

\begin{tabular}{llll}
\hline Fuente de variación & Gl & CM & Valor-P \\
\hline H: Micorrización & 2 & 88,6775 & $<0,001$ \\
S:Extracto de SA & 3 & 25,0377 & 0,0733 \\
Interacción H x S & 6 & 18,9139 & 0,1069 \\
\hline
\end{tabular}

Gl: grados de libertad; CM: cuadrado medio; P: valor de probabilidad de la prueba de F

\section{Transpiración (E)}

Los valores de E mostraron diferencias significativas tanto para micorrización como para las concentraciones de extracto. La interacción micorrización x extracto no fue significativa $(p>0,05)$. Las plantas inoculadas con $R$. intraradices mostraron los mayores valores de $\mathrm{E}$ en $\mathrm{S} 0$ con respecto a las inoculadas con $F$. mosseae y las NI. Todos los tratamientos de inoculación disminuyeron los valores de E con el agregado de extracto. En S3 las plantas inoculadas con ambos hongos micorrícicos mostraron valores de E significativamente mayores a los registrados en las plantas no inoculadas (Figura 16). 


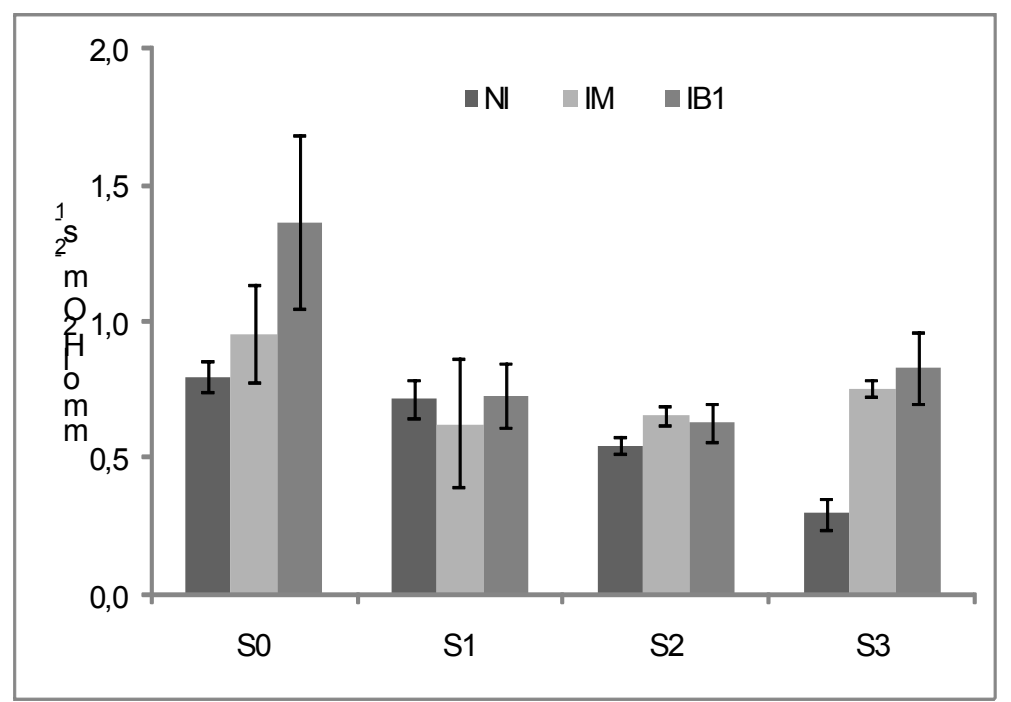

Figura 16. Efecto de los extractos de rizomas de sorgo de Alepo sobre la transpiración (E) de plantas de Mentha x piperita L. no inoculadas (NI) o inoculadas con Funneliformis mosseae (IM) y Rhizophagus intraradices (IB1). Referencias: S0: 0\%; S1: 5\%; S2: 10\%; S3: 15\%.

Tabla 20. Análisis de Varianza de los efectos de la micorrización (NI, IM e IB1) y el extracto acuoso de rizomas de SA (S0, S1, S2 y S3) y su interacción sobre la transpiración (E). Referencias: H: micorrización; S: extracto de rizomas de SA.

\begin{tabular}{llcl}
\hline Fuente de variación & Gl & CM & Valor-P \\
\hline H: Micorrización & 2 & 0,26724 & 0,0221 \\
S:Extracto de SA & 3 & 0,362564 & 0,0031 \\
Interacción H x S & 6 & 0,0868692 & 0,2344 \\
\hline
\end{tabular}

Gl: grados de libertad; CM: cuadrado medio; P: valor de probabilidad de la prueba de F

\section{Conductancia estomática (CS)}

Las plantas inoculadas registraron valores más elevados de CS que las plantas no inoculadas, siendo estas diferencias significativas en S0, S2 y S3 (Figura 17). No hubo interacción $\mathrm{H} x \mathrm{~S}$ significativa $(p>0,05)$.

La concentración S3 de extracto de rizomas produjo un cierre de los estomas más pronunciado en las plantas no inoculadas con diferencias significativas con respecto a S0 y para la misma concentración con respecto a las plantas inoculadas. Las plantas inoculadas se mantuvieron más estables con respecto a los valores de $\mathrm{E}$. 


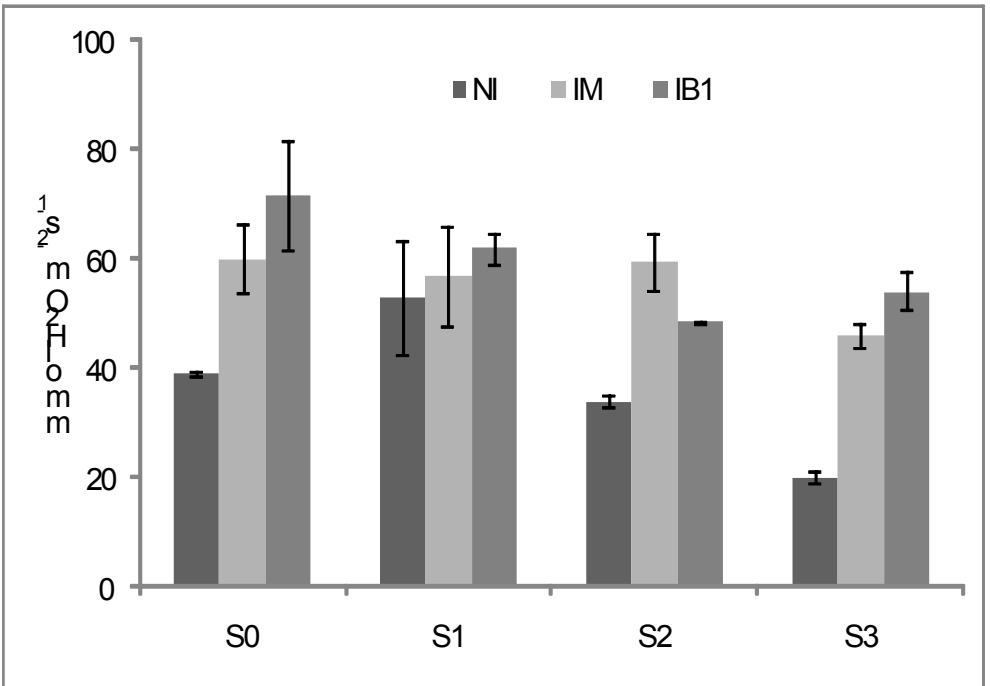

Figura 17. Efecto de los extractos de rizomas de sorgo de Alepo sobre la conductancia estomática (CS) de plantas de Mentha x piperita L. no inoculadas (NI) o inoculadas con Funneliformis mosseae (IM) y Rhizophagus intraradices (IB1). Referencias: S0: 0\%; S1: 5\%; S2: $10 \%$; S3: $15 \%$.

Tabla 21. Análisis de Varianza de los efectos de la micorrización (NI, IM e IB1) y el extracto acuoso de rizomas de SA (S0, S1, S2 y S3) y su interacción sobre la conductancia estomática (CS). Referencias: H: micorrización; S: extracto de rizomas de SA.

\begin{tabular}{llcl}
\hline Fuente de variación & Gl & CM & Valor-P \\
\hline H: Micorrización & 2 & 1679,12 & $<0,001$ \\
S:Extracto de SA & 3 & 708,64 & 0,0012 \\
Interacción H x S & 6 & 172,952 & 0,1448 \\
\hline
\end{tabular}

Gl: grados de libertad; CM: cuadrado medio; P: valor de probabilidad de la prueba de F

\section{Conductividad relativa de raices}

Las plantas micorrizadas mostraron menor conductividad relativa de los tejidos de la raíz para todos los tratamientos comparadas con las NI. La interacción $\mathrm{H}$ x S fue significativa $(p<0,001)$. El aumento en la CRR de las plantas no inoculadas fue significativo en S3, con un incremento del 85\%. Las plantas inoculadas no presentaron diferencias significativas con los extractos. (Figura 18). 


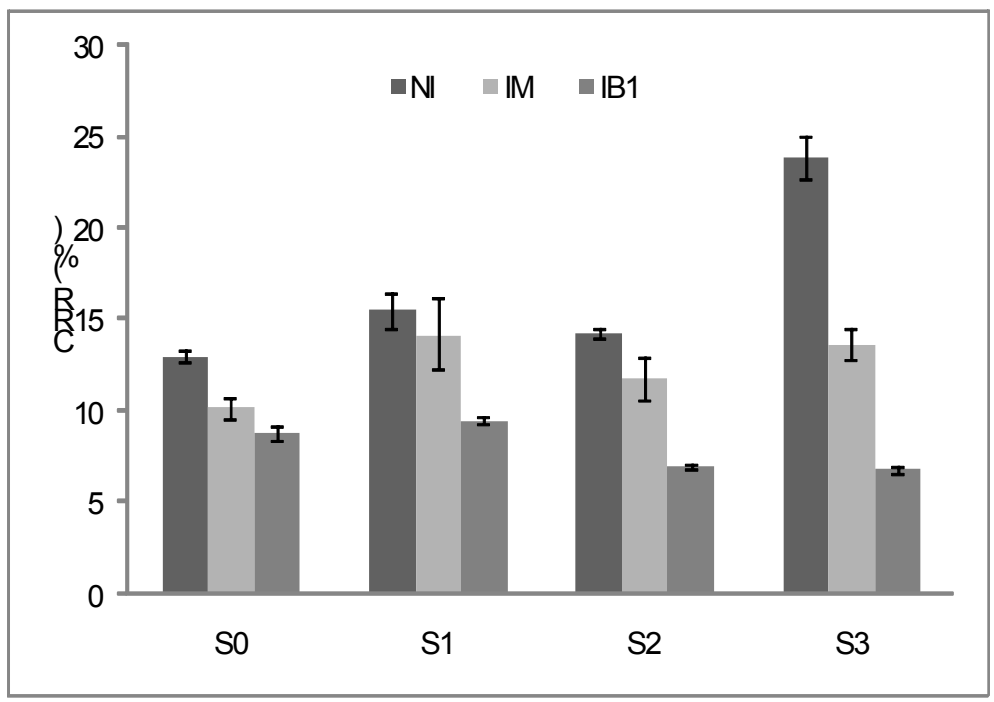

Figura 18. Efecto de los extractos de rizomas de sorgo de Alepo sobre la conductividad relativa (CRR) de raíces de plantas de Mentha x piperita L. no inoculadas (NI) o inoculadas con Funneliformis mosseae (IM) y Rhizophagus intraradices (IB1). Referencias: S0: 0\%; S1: 5\%; S2: $10 \%$; S3: $15 \%$.

Tabla 22. Análisis de Varianza de los efectos de la micorrización (NI, IM e IB1) y el extracto acuoso de rizomas de SA (S0, S1, S2 y S3) y su interacción sobre la conductividad relativa (CRR) de raíces. Referencias: H: micorrización; S: extracto de rizomas de SA.

\begin{tabular}{llll}
\hline Fuente de variación & Gl & CM & Valor-P \\
\hline H: Micorrización & 2 & 309,055 & $<0,001$ \\
S:Extracto de SA & 3 & 44,5962 & 0,0013 \\
Interacción H x S & 6 & 35,9257 & $<0,001$ \\
\hline
\end{tabular}

Gl: grados de libertad; CM: cuadrado medio; P: valor de probabilidad de la prueba de F

\section{Conductividad relativa de membranas de hojas}

En hojas el daño sobre las membranas celulares solo aumentó significativamente en S3 tanto en las NI como en las inoculadas. La interacción micorrización x extracto no fue significativa. Los valores registrados de $\mathrm{CRH}$ en general fueron bajos, comparados con los observados en las raíces en altas concentraciones de extracto (Figura 19). 


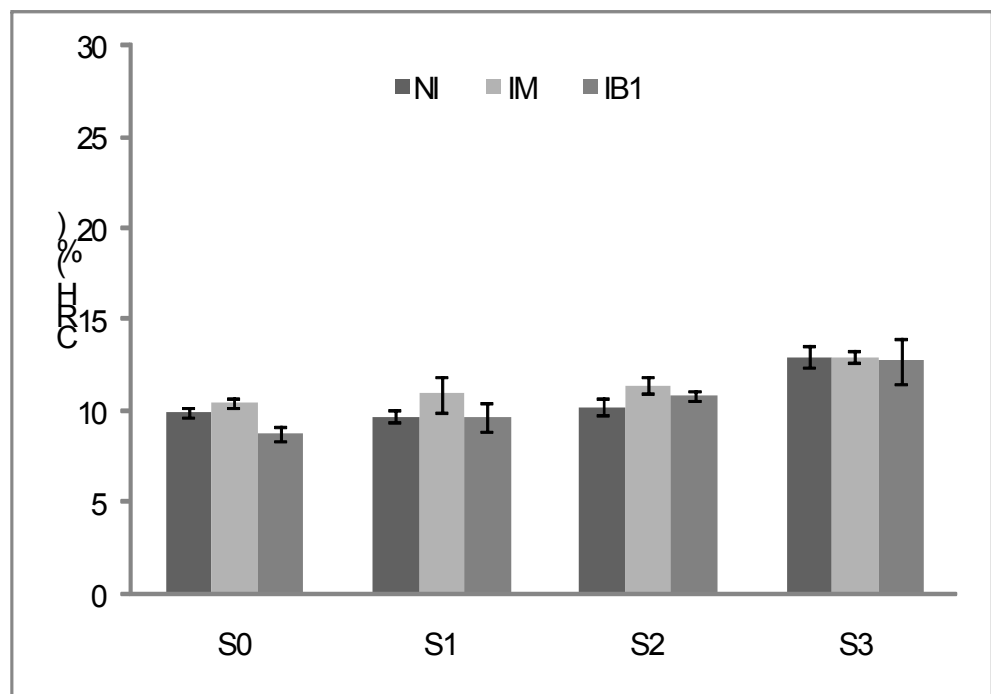

Figura 19. Efecto de los extractos de rizomas de sorgo de Alepo sobre la conductividad relativa (CRH) de hojas de plantas de Mentha x piperita L. no inoculadas (NI) o inoculadas con Funneliformis mosseae (IM) y Rhizophagus intraradices (IB1). Referencias: S0: 0\%; S1: 5\%; S2: $10 \%$; S3: $15 \%$.

Tabla 23. Análisis de Varianza de los efectos de la micorrización (NI, IM e IB1) y el extracto acuoso de rizomas de SA (S0, S1, S2 y S3) y su interacción sobre la conductividad relativa (CRH) de hojas de plantas. Referencias: H: micorrización; S: extracto de rizomas de SA.

\begin{tabular}{llll}
\hline Fuente de variación & Gl & CM & Valor-P \\
\hline H: Micorrización & 2 & 7,90686 & 0,0602 \\
S:Extracto de SA & 3 & 49,5071 & $<0,001$ \\
Interacción H x S & 6 & 1,77256 & 0,6889 \\
\hline
\end{tabular}

Gl: grados de libertad; CM: cuadrado medio; P: valor de probabilidad de la prueba de F 

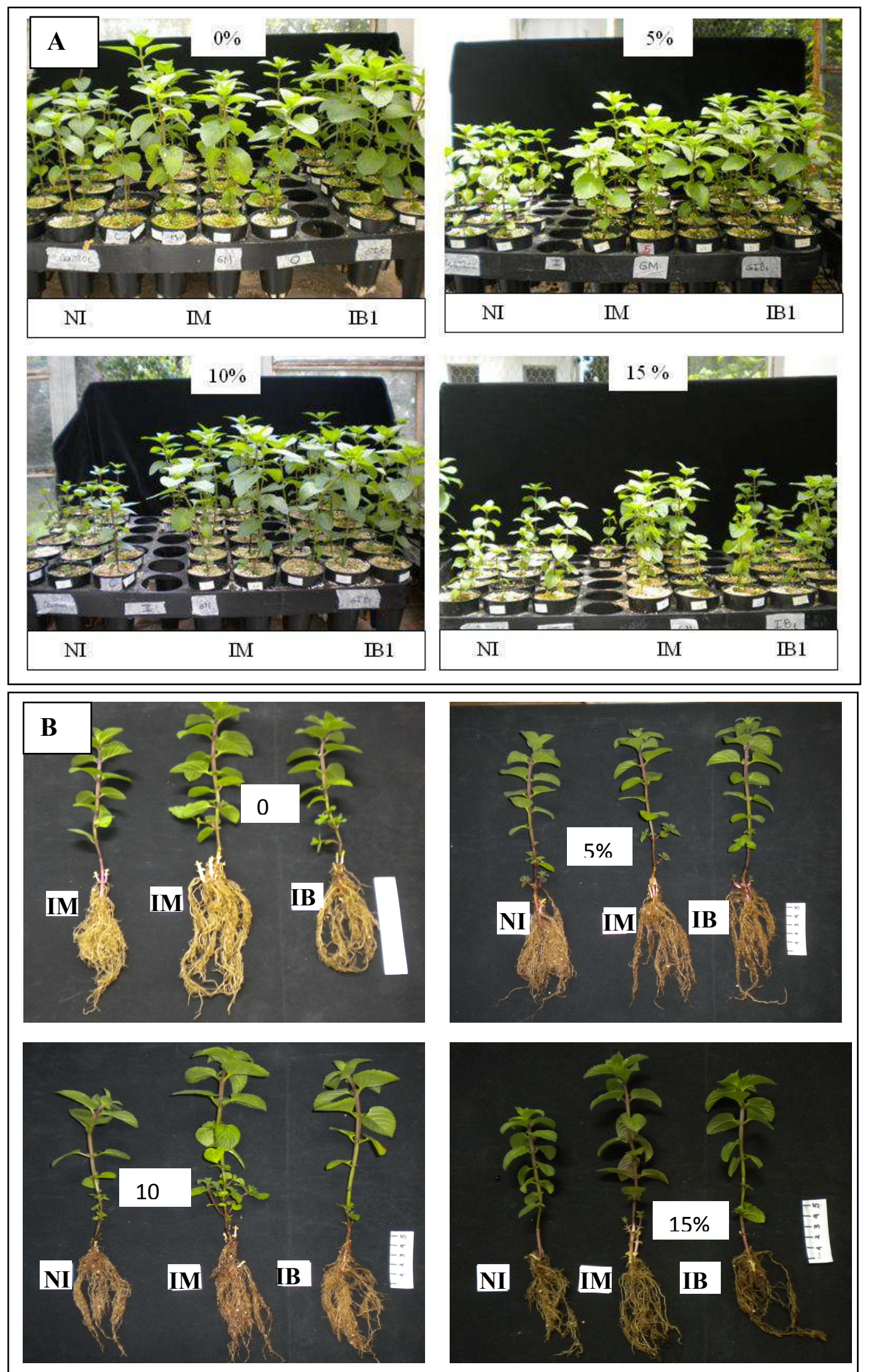

Figura 20. Speedling (A) y plantas (B) de plantas de Menta piperita 30 DDT. Referencias: $0 \%, 5 \%, 10 \%$ y $15 \%$, concentraciones de extracto de rizomas de Sorgo de Alepo. NI: no inoculadas, IM: inoculadas con F. mosseae; IB1: inoculadas con $R$. intraradices. 


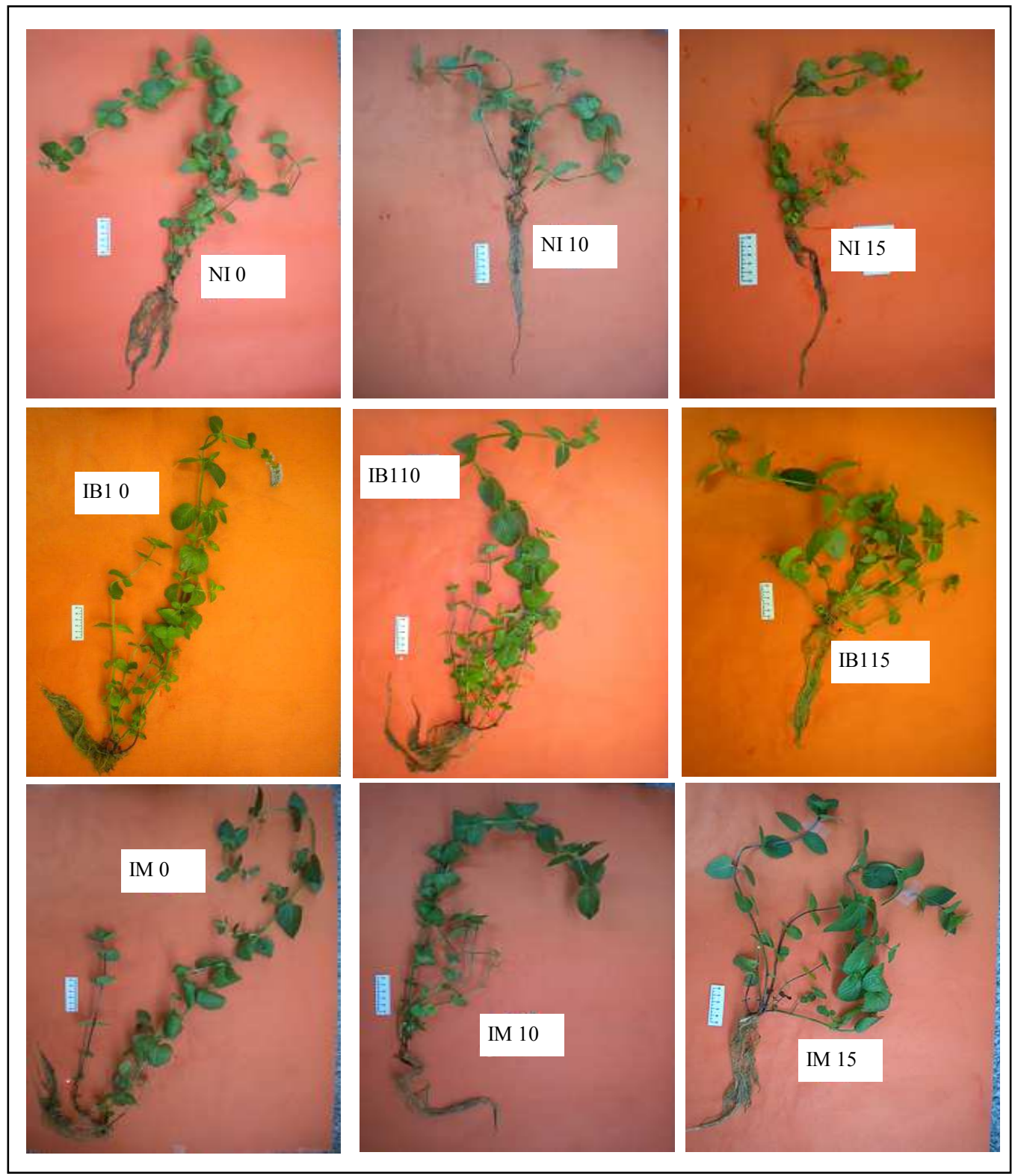

Figura 21. Plantas de Menta piperita. 60 días después del trasplante. Referencias: 0\%, $5 \%, 10 \%$ y $15 \%$, concentraciones de extracto de rizomas de Sorgo de Alepo. NI: no inoculadas, IM: inoculadas con $F$. mosseae; IB1: inoculadas con $R$. intraradices. 


\subsection{Experimento 3}

Efecto de aleloquímicos provenientes de los rizomas de sorgo de Alepo sobre la micorrización, la materia seca, parámetros fisiológicos y bioquímicos y aceites esenciales de plantas de Mentha $\mathbf{x}$ piperita $\mathrm{L}$.

\section{Colonización micorrícica y dependencia micorrícica}

Tabla 24. Colonización micorrícica $(\% \mathrm{M})$, arbúsculos $(\% \mathrm{Ar})$, vesículas $(\% \mathrm{~V})$ y dependencia micorrícica $(\% \mathrm{DM})$ en plantas de Mentha x piperita L. inoculadas con Funneliformis mosseae (IM) y Rhizophagus intraradices (IB1) o no inoculadas, que crecieron con diferentes cantidades de rizomas de sorgo de Alepo. Referencias: R0: $0 \mathrm{~g} \mathrm{~m}^{-2} \mathrm{MS}$ de rizomas, R1: $250 \mathrm{~g} \mathrm{~m}^{-2} \mathrm{MS}$ de rizomas, R2: $500 \mathrm{~g} \mathrm{~m}^{-2} \mathrm{MS}$ de rizomas, $\mathrm{R} 3: 800 \mathrm{~g} \mathrm{~m}^{-2} \mathrm{MS}$ de rizomas.

\begin{tabular}{cccccc}
\hline $\begin{array}{c}\text { Hongos } \\
\text { micorrícicos }\end{array}$ & SORG & $\% \mathrm{M}$ & $\% \mathrm{Ar}$ & $\% \mathrm{~V}$ & $\% \mathrm{DM}$ \\
& & & & & \\
\hline & $\mathrm{R} 0$ & $43,3 \mathrm{ab}$ & $35,0 \mathrm{a}$ & $12,0 \mathrm{~b}$ & \\
$\mathrm{NI}$ & $\mathrm{R} 1$ & $46,6 \mathrm{ab}$ & $34,5 \mathrm{a}$ & $14,9 \mathrm{~b}$ & \\
& $\mathrm{R} 2$ & $49,8 \mathrm{a}$ & $39,9 \mathrm{a}$ & $28,4 \mathrm{a}$ & \\
& $\mathrm{R} 3$ & $38,0 \mathrm{~b}$ & $6,3 \mathrm{~b}$ & $8,5 \mathrm{c}$ & \\
& & & & & \\
& $\mathrm{R} 0$ & $78,1 \mathrm{a}$ & $73,3 \mathrm{a}$ & $41,0 \mathrm{a}$ & $34,5 \mathrm{a}$ \\
$\mathrm{IM}$ & $\mathrm{R} 1$ & $56,5 \mathrm{~b}$ & $39,0 \mathrm{c}$ & $38,3 \mathrm{a}$ & $17,2 \mathrm{~b}$ \\
& $\mathrm{R} 2$ & $46,4 \mathrm{c}$ & $44,0 \mathrm{bc}$ & $25,0 \mathrm{~b}$ & $23,3 \mathrm{ab}$ \\
& $\mathrm{R} 3$ & $50,4 \mathrm{c}$ & $49,7 \mathrm{~b}$ & $14,7 \mathrm{c}$ & $34,8 \mathrm{a}$ \\
& & & & & \\
& $\mathrm{R} 0$ & $72,3 \mathrm{a}$ & $43,3 \mathrm{a}$ & $63,7 \mathrm{a}$ & $36,8 \mathrm{a}$ \\
$\mathrm{IB} 1$ & $\mathrm{R} 1$ & $51,0 \mathrm{~b}$ & $22,5 \mathrm{~b}$ & $45,0 \mathrm{~b}$ & $30,1 \mathrm{~b}$ \\
& $\mathrm{R} 2$ & $54,6 \mathrm{~b}$ & $39,3 \mathrm{a}$ & $47,0 \mathrm{~b}$ & $43,6 \mathrm{a}$ \\
& $\mathrm{R} 3$ & $56,2 \mathrm{~b}$ & $20,0 \mathrm{~b}$ & $48,7 \mathrm{~b}$ & $41,9 \mathrm{a}$ \\
\hline H & & $<0,001$ & $<0,001$ & $<0,001$ & $<0,001$ \\
$\mathrm{R}$ & & $<0,001$ & $<0,001$ & $<0,001$ & $<0,05$ \\
Interacción H x R & & $<0,001$ & $<0,001$ & $<0,001$ & $\mathrm{~ns}$ \\
& & & &
\end{tabular}

Letras distintas en cada columna indican diferencias significativas entre las medias de distintas cantidades de rizomas de SA para cada tratamiento de inoculación $(p<0.05)$. ns: no significativo.

Debido a que la tierra utilizada en el ensayo no fue tindalizada las plantas no inoculadas mostraron, al analizar sus raices, la inoculación por la presencia de hongos micorrícicos nativos presentes. E1 \% de micorrización de las plantas no inoculadas fue 
inferior al de las inoculadas, independientemente del inóculo utilizado, en el tratamiento sin agregado de rizomas de sorgo de Alepo. El \%M para las micorrizadas con hongos nativos fue de 43,3\% y el de aquellas a las que se le incorporó el inóculo seleccionado fue en promedio de $75 \%$. La interacción $\mathrm{H}$ x R fue significativa. Los aleloquímicos provenientes de rizomas de sorgo de Alepo afectaron negativamente la micorrización. Las plantas inoculadas con IM e IB1 disminuyeron el \%M a partir de R1, alcanzando valores similares a las NI. Sin embargo en S3 el \% de micorrización de IM e IB1 fue $32 \%$ y $47,8 \%$ mayor que el registrado en las NI respectivamente (Tabla 24).

El \% de arbúsculos disminuyó con la presencia de alelquímicos en el suelo, en las NI la reducción fue significativa en R3, mientras que en las inoculadas con IM o IB1 lo fue a partir de R1. Con la mayor cantidad de rizomas las IM mostraron el mayor \% de arbúsculos $(49,7 \%)$ y las NI el menor porcentaje $(6,3 \%)$. Con respecto al porcentaje de vesiculas, las inoculadas presentaron valores superiores con respecto a las NI en R0 y $\mathrm{R} 1$. En las concentraciones mas altas de rizomas de SA, $R$. intraradices mostró un \% de vesículas superior a las NI y las IM (Tabla 23).

La dependencia micorrícia (DM) disminuyó en R1 sin diferencias significtivas en el resto de las concentraciones. Las plantas de menta mostraron mayor dependencia del hongo $R$. intraradices.

\section{Parámetros de crecimiento}

Altura de plantas de Mentha x piperita registrados a partir de los 30 días después de la plantación.

La de altura de las plantas tomadas a partir de los 30 días después de la plantación (DDP) varió significativamente dependiendo de la interacción micorrización $\mathrm{x}$ rizomas $\mathrm{x}$ fecha de registro de altura (Tabla 25). Las plantas inoculadas con IB1 superaron a las NI e IM en R0, R1 y R2. La cantidad más alta (R3), afectó el crecimiento de las inoculadas con IB1, con diferencias significativas a los 30 y 50 DDP $(p<0,05)$ no diferenciándose de las IM y NI a los 60 días DDP $(p>0,05)$. Con $800 \mathrm{~g} \mathrm{~m}^{-2}$ MS de rizomas (R3) en la medición realizada a los 60 DDP, las IB1 redujeron su altura en un $29 \%$ con respecto a R0 $(p<0,001)$, mientras que las IM y las NI no se vieron afectadas $(p<0,05)$ (Figura 22$)$. 

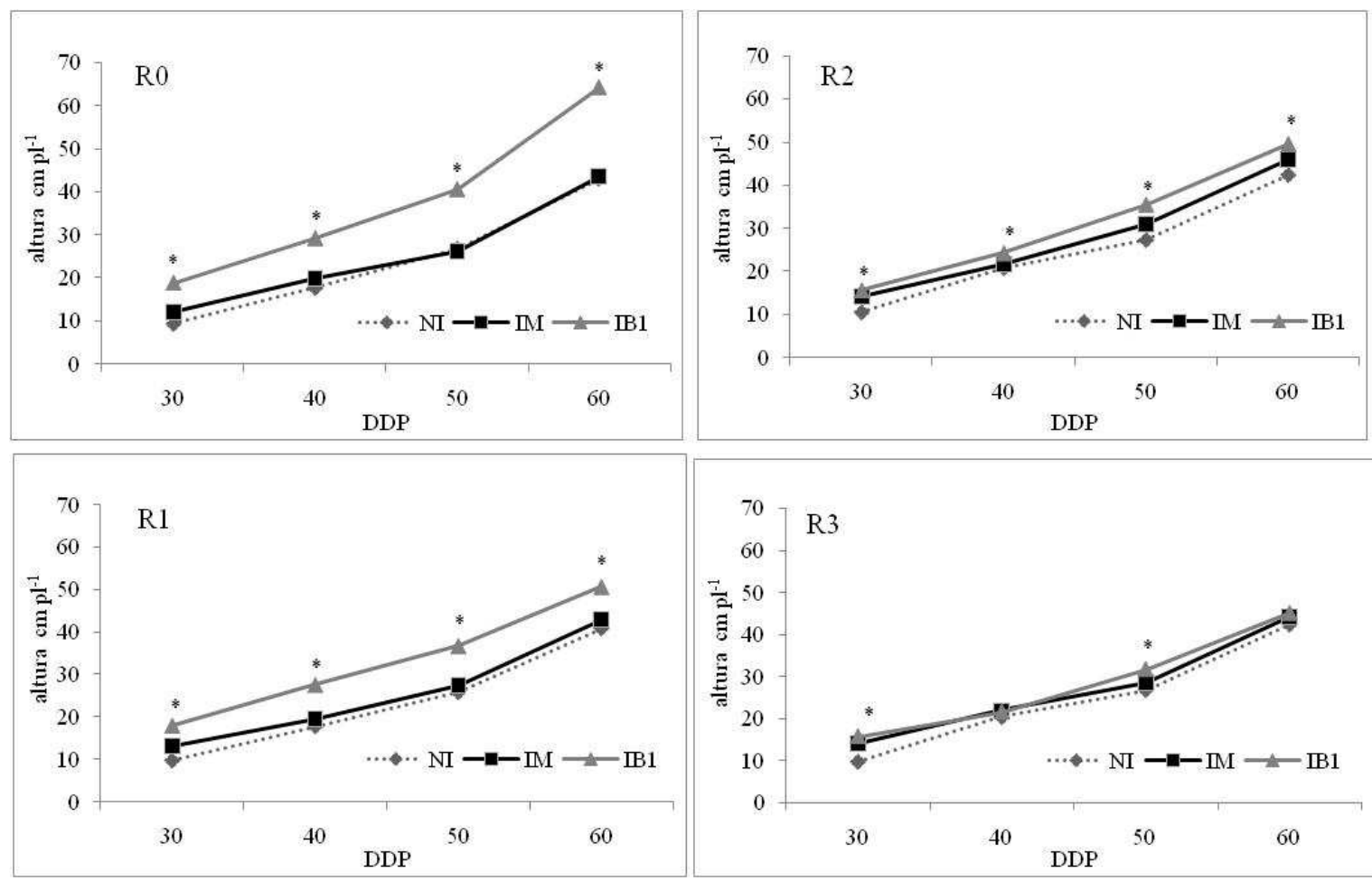

Figura 22. Altura de plantas de Mentha x piperita L registrados a partir de los 30 días después de la plantación y durante 30 días, inoculadas con Funneliformis mosseae (IM) y Rhizophagus intraradices (IB1) en respuesta a los diferentes tratamientos con rizomas de sorgo de Alepo.

$\left(^{*}\right)$ Diferencias significativas entre las medias $(p<0,05)$.

Tabla 25. Análisis de Varianza de los efectos de la micorrización (NI, IM e IB1), rizomas de SA (R0, R1, R2 y R3) y la fecha de registro de altura (7, 10, 13, 16 y 19 DDE) y sus interacciones sobre la altura de plantas. H: micorrización; R: rizomas de SA; F: fecha de registro de altura $(30,40,50$ y 60 DDP).

\begin{tabular}{|l|c|c|c|}
\hline \multicolumn{1}{|c|}{ Fuente de variación } & Gl & CM & Valor-P \\
\hline H:Micorrización & 2 & 2927,1 & $<0,001$ \\
\hline R:Rizomas & 3 & 113,244 & $<0,001$ \\
\hline F:Fecha de registro de altura & 3 & 23672,4 & $<0,001$ \\
\hline Interacciones & & & \\
\hline H x R & 6 & 325,95 & $<0,001$ \\
\hline H x F & 6 & 59,145 & $<0,001$ \\
\hline R x F & 9 & 47,7492 & $<0,001$ \\
\hline H x R x F & 18 & 30,0211 & $<0,001$ \\
\hline
\end{tabular}

Gl: grados de libertad; CM: cuadrado medio; P: valor de probabilidad de la prueba de F 
El area foliar mostró diferencias significativas para la micorriación y los rizomas. La interacción $\mathrm{H} \times \mathrm{R}$ fue significativa $(p<0,05)$. Las plantas inoculadas con IB1 presentaron los mayores valores para todos los tratamientos con respecto a las NI y a partir de R1 con respecto a las IM. En R0 el AF de las plantas IM y IB1, fue de 64\% y $33 \%$ superior a las NI respectivamente y en R3 la diferencia fue de $25 \%$ y $54 \%$ (Tabla 26).

Como resultado del análisis de ANOVA multifactorial, el peso seco de las hojas mostró diferencias significativas entre los tratamientos de inoculación, sin diferencias significativas para los rizomas y la interacción $\mathrm{H}$ x R (Tabla 26). Las plantas inoculadas con IB1 registraron un PSH superior a las NI en todas las cantidades de rizomas y a partir de R2 a las IM. El peso seco de los tallos fue superior en la IB1 a partir de R1 con respecto a IM y en todas las cantidades de rizomas con respecto a las NI. Las IM se diferenciaron significativamente de las NI a partir de R2 (Tabla 26).

Tabla 26. Efecto de los de rizomas de SA sobre el Área foliar (AF), Peso seco de hojas (PSH) y Peso seco e tallos (PST) de plantas de Mentha x piperita L. no inoculadas (NI) o inoculadas con Funneliformis mosseae (IM) y Rhizophagus intraradices (IB1). Referencias: R0: $0 \mathrm{~g} \mathrm{~m}^{-2} \mathrm{MS}$ de rizomas, R1: $250 \mathrm{~g} \mathrm{~m}^{-2}$ MS de rizomas, R2: $500 \mathrm{~g} \mathrm{~m}^{-2}$ MS de rizomas, R3: $800 \mathrm{~g} \mathrm{~m}^{-2} \mathrm{MS}$ de rizomas.

\begin{tabular}{|c|c|c|c|c|c|c|c|c|c|}
\hline \multirow[t]{2}{*}{ Tratamiento } & \multicolumn{3}{|c|}{$\mathrm{AF}(\mathrm{cm})$} & \multicolumn{3}{|c|}{ PSH $\left(\mathrm{g} \mathrm{pl}^{-1}\right)$} & \multicolumn{3}{|c|}{$\operatorname{PST}\left(\mathrm{g} \mathrm{pl}^{-1}\right)$} \\
\hline & NI & IM & IB1 & NI & IM & IB1 & NI & IM & IB1 \\
\hline R0 & $610,7 \mathrm{aB}$ & $1000,0 \mathrm{aA}$ & $890,0 \mathrm{aA}$ & $4,99 \mathrm{aB}$ & $6,83 \mathrm{aA}$ & 7,79aA & $6,08 \mathrm{aB}$ & $8,96 \mathrm{aA}$ & 9,70a A \\
\hline R1 & $572,5 \mathrm{aC}$ & $725,0 \mathrm{bB}$ & $893,3 \mathrm{aA}$ & $5,31 \mathrm{aB}$ & $6,84 \mathrm{aA}$ & $7,68 \mathrm{aA}$ & $6,87 \mathrm{abB}$ & 7,41aB & $9,76 \mathrm{aA}$ \\
\hline $\mathrm{R} 2$ & $615,7 \mathrm{aB}$ & $640,0 \mathrm{bB}$ & $860,0 \mathrm{aA}$ & $4,62 \mathrm{aB}$ & $5,69 \mathrm{aB}$ & 7,72aA & $5,19 \mathrm{bC}$ & 7,11aB & $9,68 \mathrm{aA}$ \\
\hline R3 & $587,5 \mathrm{aC}$ & $735,0 \mathrm{bB}$ & 906,0 aA & $4,66 \mathrm{aB}$ & $5,91 \mathrm{aB}$ & $6,76 \mathrm{aA}$ & $4,89 \mathrm{bC}$ & $7,65 \mathrm{aB}$ & 9,89aA \\
\hline $\mathrm{H}$ & & $<0,001$ & & & $<0,001$ & & & $<0,001$ & \\
\hline $\mathrm{R}$ & & $<0,05$ & & & $\mathrm{~ns}$ & & & $\mathrm{~ns}$ & \\
\hline $\mathrm{H} \times \mathrm{R}$ & & $<0,05$ & & & $\mathrm{~ns}$ & & & $\mathrm{~ns}$ & \\
\hline
\end{tabular}

Letras distintas, minúscula en cada columna y mayúsculas en cada fila indican diferencias significativas entre las medias para cada parámetro evaluado $(p<0,05)$. ns: no significativo. 
La inoculación con hongos micorrícicos favoreció el crecimiento de las plantas, observándose diferencias en materia seca aérea estadísticamente significativa con respecto a las NI $(p>0,001)$. Las plantas inoculadas con IB1 mostraron un mejor comportamiento comparado con las inoculadas con $F$. mosseae. La materia seca aérea se mantuvo constante en IB1 ante la presencia de rizomas en el sustrato, mientras que en las IM se redujo a partir de R2 (Figura 23).

Las plantas inoculadas con F. mosseae mostraron el mayor PSR en R0, R1 y R2. En las NI permaneció estable hasta R2 y luego se redujo un $39 \%$ con respecto a R0. En las IM la reducción del PSR fue del 34\% en R3 comparadas con R0, mientras que no se observaron modificaciones significativas para IB1 (Figura 23).

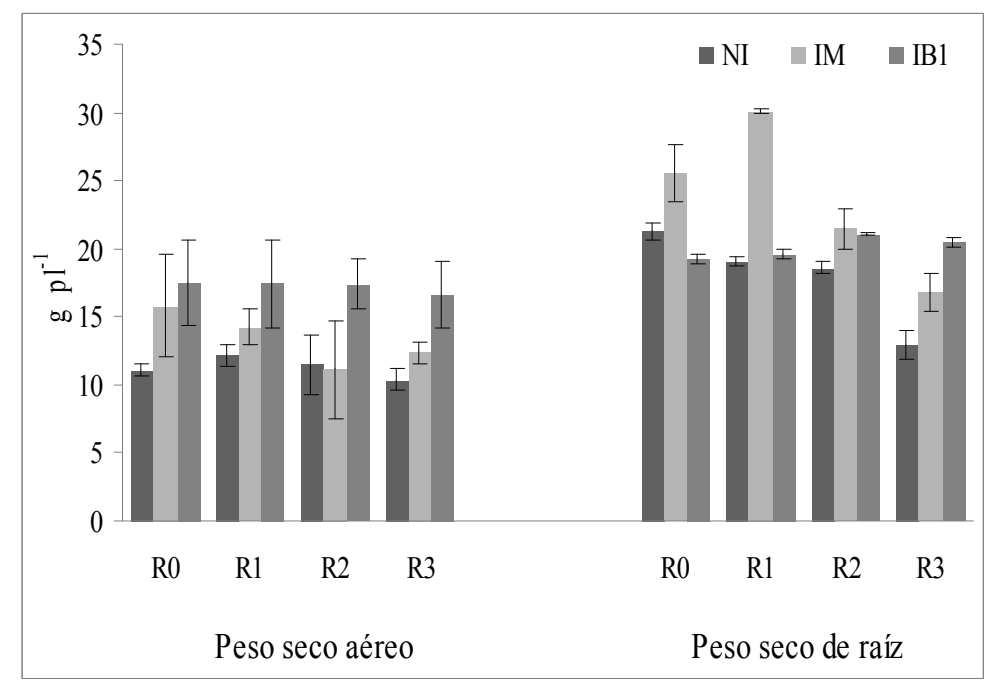

Figura 23. Efecto de los aleloquímicos provenientes de rizomas de sorgo de Alepo sobre el Peso seco aéreo y el Peso seco de raíz de plantas de Mentha x piperita L. no inoculadas (NI) o inoculadas con Funneliformis mosseae (IM) y Rhizophagus intraradices (IB1). R0: $0 \mathrm{~g} \mathrm{~m}^{-2} \mathrm{MS}$ de rizomas, R1: $250 \mathrm{~g} \mathrm{~m}^{-2}$ MS de rizomas, R2: $500 \mathrm{~g} \mathrm{~m}^{-2} \mathrm{MS}$ de rizomas, R3: $800 \mathrm{~g} \mathrm{~m}^{-2} \mathrm{MS}$ de rizomas.

Tabla 27. Análisis de Varianza de los efectos de la micorrización (NI, IM y IB1) y los rizomas de SA (R0, R1, R2 y R3) y su interacción sobre el Peso seco aéreo de plantas de Mentha x piperita L. no inoculadas (NI) o inoculadas con Funneliformis mosseae (IM) y Rhizophagus intraradices (IB1). Referencias: H: micorrización, R: rizomas de SA.

\begin{tabular}{llcl}
\hline Fuente de variación & Gl & CM & Valor-P \\
\hline H:Micorrización & 2 & 146,274 & $<0,001$ \\
R:Rizomas & 3 & 8,63382 & 0,0932 \\
Interacción H X R & 6 & 5,43066 & 0,2230 \\
\hline
\end{tabular}

Gl: grados de libertad; CM: cuadrado medio; P: valor de probabilidad de la prueba de F 
Tabla 28. Análisis de Varianza de los efectos de la micorrización (NI, IM e IB1) y los rizomas de SA (R0, R1, R2 y R3) y su interacción sobre el Peso seco de raíz de plantas de Mentha x piperita L. no inoculadas (NI) o inoculadas con Funneliformis mosseae (IM) y Rhizophagus intraradices (IB1). Referencias: H: micorrización, R: rizomas de SA.

\begin{tabular}{llcl}
\hline Fuente de variación & Gl & CM & Valor-P \\
\hline H:Micorrización & 2 & 123,663 & 0,0073 \\
R:Rizomas & 3 & 88,1745 & 0,0143 \\
Interacción H X R & 6 & 45,8954 & 0,0773 \\
\hline
\end{tabular}

Gl: grados de libertad; CM: cuadrado medio; P: valor de probabilidad de la prueba de F

\section{Proteinas foliares}

El análisis de las proteínas foliares mostró diferencias significativas entre los tratamientos de micorrización, no observándose diferencias significativas ni entre los tratamientos con rizomas ni la interacción doble $(p>0,05)$ (Figura 24). Las plantas NI mostraron mayores valores de proteína, expresado en $\mu \mathrm{g} \mathrm{cm}^{-2}$ que las plantas inoculadas, siendo dichas diferencias estadísticamente significativas en R2 y R3.

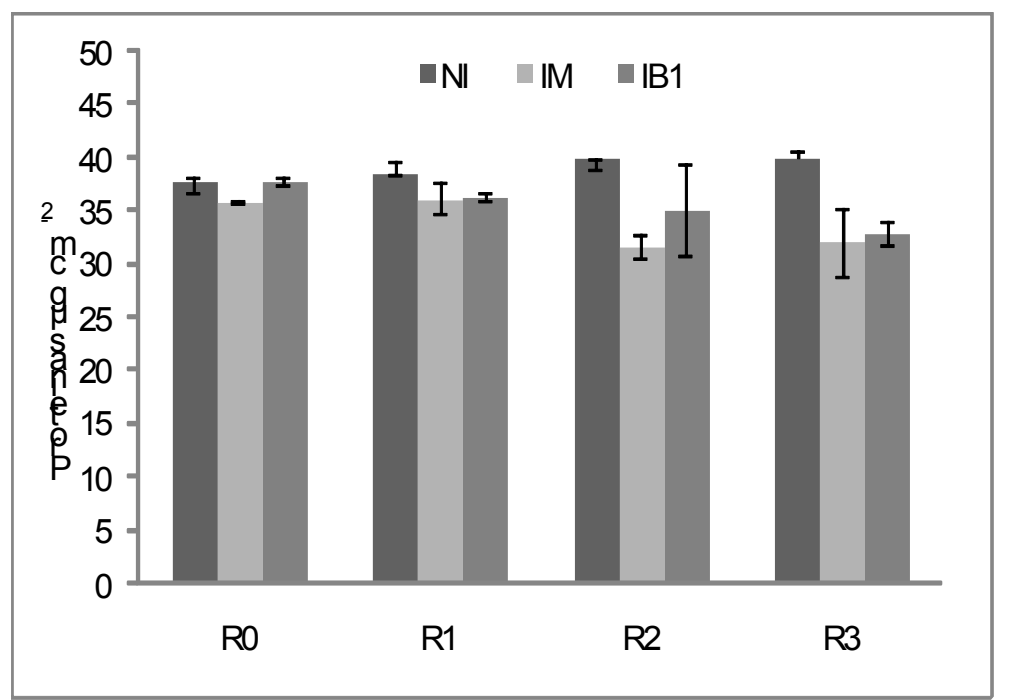

Figura 24. Efecto de los aleloquímicos provenientes de rizomas de sorgo de Alepo sobre el contenido de proteínas foliares de plantas de Mentha x piperita L. no inoculadas (NI) o inoculadas con Funneliformis mosseae (IM) y Rhizophagus intraradices (IB1). R0: $0 \mathrm{~g} \mathrm{~m}^{-2} \mathrm{MS}$ de rizomas, R1: $250 \mathrm{~g} \mathrm{~m}^{-2} \mathrm{MS}$ de rizomas, R2: $500 \mathrm{~g} \mathrm{~m}^{-2} \mathrm{MS}$ de rizomas, R3: $800 \mathrm{~g} \mathrm{~m}^{-2} \mathrm{MS}$ de rizomas. 
Tabla 29. Análisis de Varianza de los efectos de la micorrización (NI, IM e IB1) y los rizomas de SA (R0, R1, R2 y R3) y su interacción sobre el contenido de proteínas foliares $\left(\mu \mathrm{g} \mathrm{cm}^{-2}\right)$. Referencias: H: micorrización, R: rizomas de SA.

\begin{tabular}{llcl}
\hline Fuente de variación & Gl & CM & Valor-P \\
\hline H:Micorrización & 2 & 82,0415 & 0,0003 \\
R:Rizomas & 3 & 10,5625 & 0,2308 \\
Interacción H X R & 6 & 11,1308 & 0,1853 \\
\hline
\end{tabular}

Gl: grados de libertad; CM: cuadrado medio; P: valor de probabilidad de la prueba de F

\section{Clorofila y Carotenoides}

El contenido de clorofila total, expresado en $\mu \mathrm{g} \mathrm{cm}^{-2}$, mostró diferencias significativas para la presencia de aleloquímicos provenientes de rizomas de sorgo de Alepo y para la inoculación $(p<0,001)$. La interacción inoculación x rizomas no fue significativa $(p>0,05)$. En R0, se observaron mayores valores en las plantas inoculadas, diferenciándose significativamente de las NI. El contenido de clorofila en R0 fue para las IB1, $40 \%$ y $18 \%$ superior a las NI y a las inoculadas con $F$. mosseae respectivamente. Las plantas inoculadas vieron disminuido significativamente el contenido de clorofila a partir de R1, mientras que en las NI la disminución no fue significativa.

El contenido de carotenoides expresado $\mu \mathrm{g} \mathrm{cm}^{-2}$ siguió la misma tendencia que el contenido de clorofila, en R0 las plantas inoculadas con IB1 mostraron contenidos de carotenoides superiores comparados con IM y NI (Figura 25 y 26). 


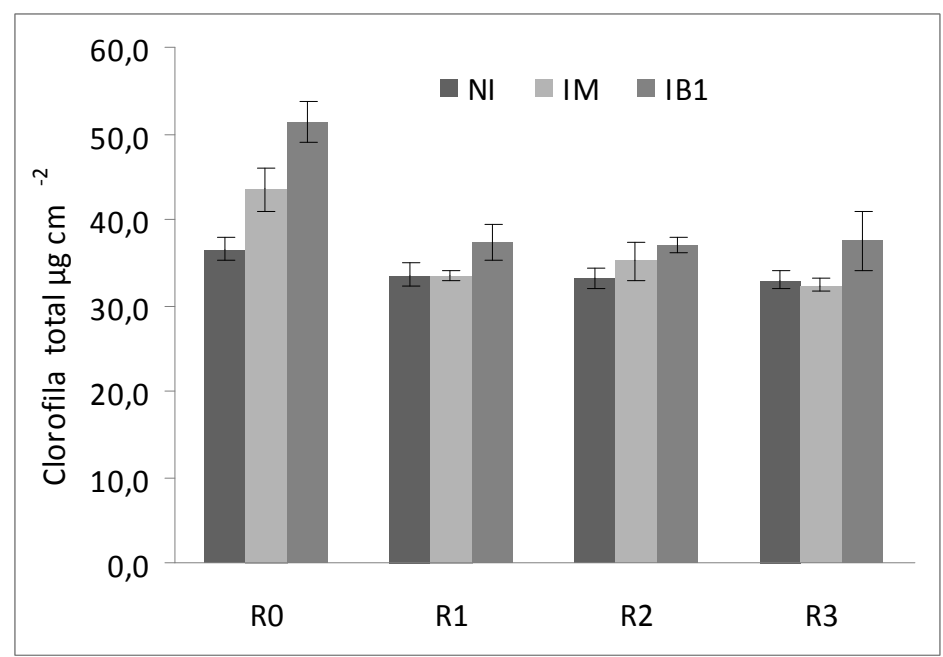

Figura 25. Efecto de los aleloquímicos provenientes de rizomas de sorgo de Alepo sobre la concentración de clorofila total de plantas de Mentha x piperita L. no inoculadas (NI) o inoculadas con Funneliformis mosseae (IM) y Rhizophagus intraradices (IB1). R0: $0 \mathrm{~g} \mathrm{~m}^{-2} \mathrm{MS}$ de rizomas, R1: $250 \mathrm{~g} \mathrm{~m}^{-2} \mathrm{MS}$ de rizomas, R2: $500 \mathrm{~g} \mathrm{~m}^{-2} \mathrm{MS}$ de rizomas, R3: $800 \mathrm{~g} \mathrm{~m}^{-2} \mathrm{MS}$ de rizomas.

Tabla 30 . Análisis de Varianza de los efectos de la micorrización (NI, IM e IB1) y los rizomas de SA (R0, R1, R2 y R3) y su interacción sobre la concentración de clorofila total $\left(\mu \mathrm{g} \mathrm{cm}^{-2}\right)$. Referencias: H: micorrización, R: rizomas de SA.

\begin{tabular}{llcl}
\hline Fuente de variación & Gl & CM & Valor-P \\
\hline H:Micorrización & 2 & 195,966 & $<0,001$ \\
R:Rizomas & 3 & 250,565 & $<0,001$ \\
Interacción H X R & 6 & 31,3666 & 0,0573 \\
\hline
\end{tabular}

Gl: grados de libertad; CM: cuadrado medio; P: valor de probabilidad de la prueba de F

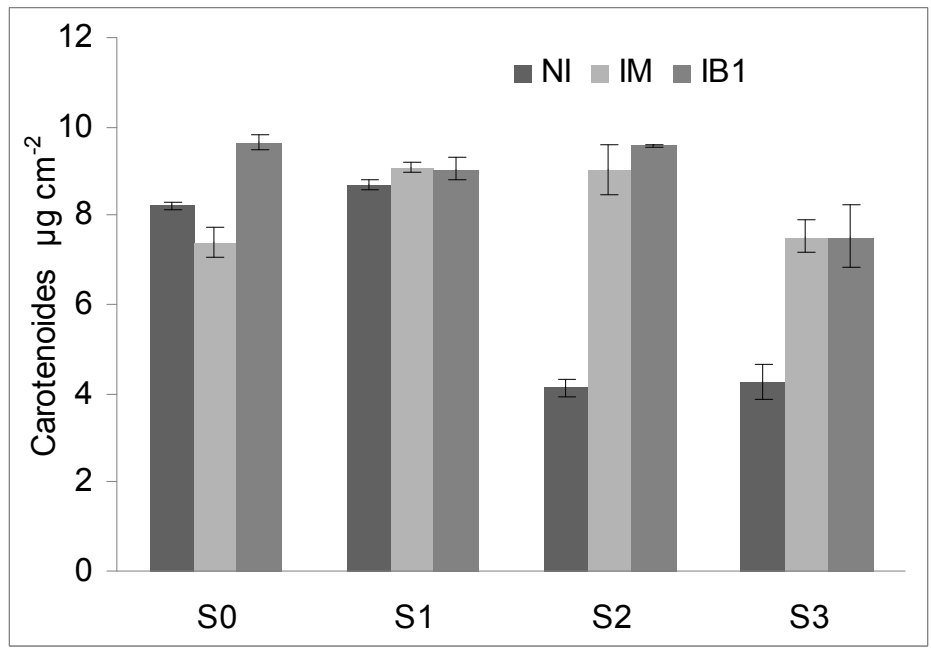

Figura 26 . Efecto de los aleloquímicos provenientes de rizomas de sorgo de Alepo sobre la concentración carotenoides de plantas de Mentha x piperita L. no inoculadas (NI) o inoculadas con Funneliformis mosseae (IM) y Rhizophagus intraradices (IB1). R0: $0 \mathrm{~g} \mathrm{~m}^{-2} \mathrm{MS}$ de rizomas, $\mathrm{R} 1: 250 \mathrm{~g} \mathrm{~m}^{-2} \mathrm{MS}$ de rizomas, R2: $500 \mathrm{~g} \mathrm{~m}^{-2} \mathrm{MS}$ de rizomas, $\mathrm{R} 3: 800 \mathrm{~g} \mathrm{~m}^{-2} \mathrm{MS}$ de rizomas. 
Tabla 31. Análisis de Varianza de los efectos de la micorrización (NI, IM y IB1) y los rizomas de SA (R0, R1, R2 y R3) y su interacción sobre la concentración carotenoides $\left(\mu \mathrm{g} \mathrm{cm}^{-2}\right)$. Referencias: H: micorrización, R: rizomas de SA.

\begin{tabular}{llcl}
\hline Fuente de variación & Gl & CM & Valor-P \\
\hline H:Micorrización & 2 & 8,27858 & $<0,001$ \\
R:Rizomas & 3 & 2,41599 & 0,0132 \\
Interacción H X R & 6 & 0,791463 & 0,2624 \\
\hline
\end{tabular}

Gl: grados de libertad; CM: cuadrado medio; P: valor de probabilidad de la prueba de F

\section{Fotosintesis neta (PN)}

Las plantas inoculadas con $F$. mosseae presentaron los valores de PN más bajos, diferenciándose significativamente en $\mathrm{R} 0$ y $\mathrm{R} 2$ con respecto a las NI y IB1. La interacción micorrización $\mathrm{x}$ rizomas de SA fue significativa $(p<0,05)$. A partir de R1 la PN disminuyó significativamente en las NI, mientras que en las IM se produjo a partir de R2 y en IB1 en R3 (Figura 27).

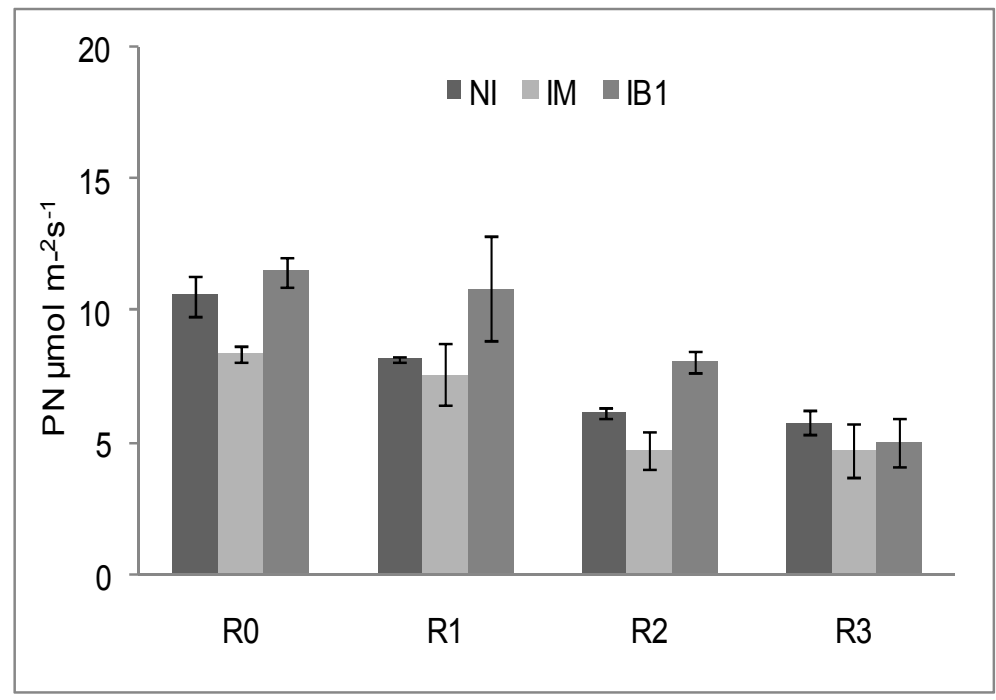

Figura 27. Efecto de los aleloquímicos provenientes de rizomas de sorgo de Alepo sobre la fotosíntesis neta (PN) de plantas de Mentha x piperita L. no inoculadas (NI) o inoculadas con Funneliformis mosseae (IM) y Rhizophagus intraradices (IB1). R0: $0 \mathrm{~g} \mathrm{~m}^{-2} \mathrm{MS}$ de rizomas, R1: $250 \mathrm{~g} \mathrm{~m}^{-2}$ MS de rizomas, R2: $500 \mathrm{~g} \mathrm{~m}^{-2}$ MS de rizomas, R3: $800 \mathrm{~g} \mathrm{~m}^{-2}$ MS de rizomas. 
Tabla 32. Análisis de Varianza de los efectos de la micorrización (NI, IM e IB1) y los rizomas de SA (R0, R1, R2 y R3) y su interacción sobre la fotosíntesis neta (PN). Referencias: H: micorrización, R: rizomas de SA.

\begin{tabular}{llcc}
\hline Fuente de variación & Gl & CM & Valor-P \\
\hline H:Micorrización & 3 & 38,4626 & $<0,001$ \\
R:Rizomas & 2 & 22,9244 & 0,0036 \\
Interacción H X R & 6 & 13,3797 & 0,0051 \\
\hline
\end{tabular}

Gl: grados de libertad; CM: cuadrado medio; P: valor de probabilidad de la prueba de F

\section{Conductancia Estomática (CS)}

La conductancia estomática disminuyó con el aumento en la cantidad de rizomas de sorgo de Alepo en el sustrato en todos los tratamientos de inoculación, indicando un cierre estomático. No se observó una interacción significativa entre micorrización $\mathrm{x}$ rizomas de SA $(p>0,05)$. En las plantas NI y IB1 la disminución se produjo a partir de R2, mientras que en IM ocurrió a partir de R1 (Figura 28).

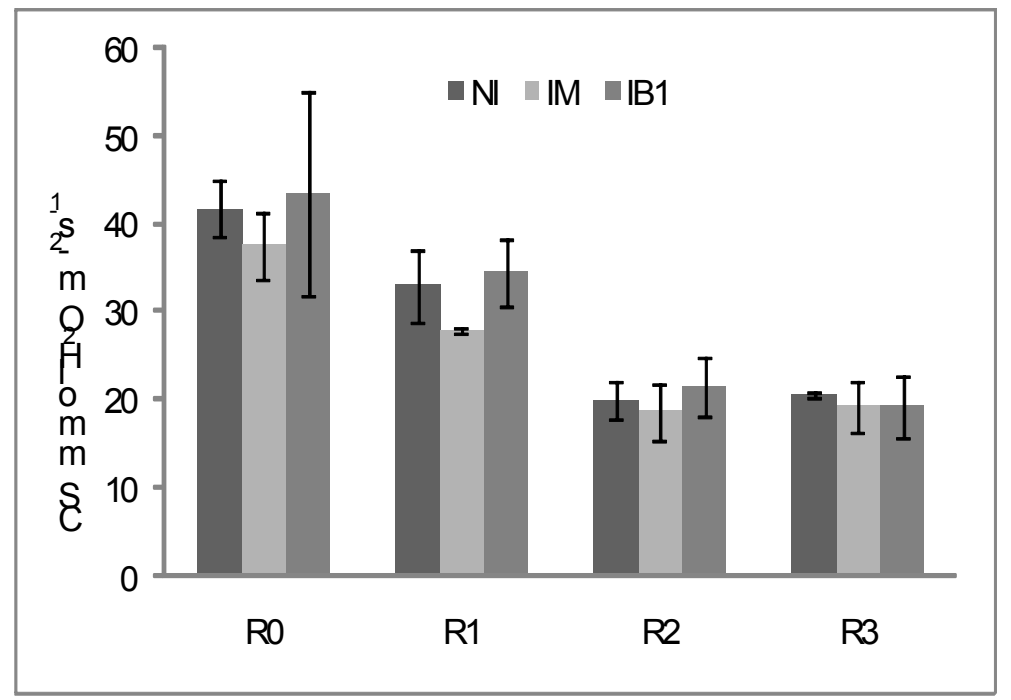

Figura 28. Efecto de los aleloquímicos provenientes de rizomas de sorgo de Alepo sobre la conductancia estomática (CS) de plantas de Mentha x piperita L. no inoculadas (NI) o inoculadas con Funneliformis mosseae (IM) y Rhizophagus intraradices (IB1). R0: $0 \mathrm{~g} \mathrm{~m}^{-2} \mathrm{MS}$ de rizomas, R1: $250 \mathrm{~g} \mathrm{~m}^{-2} \mathrm{MS}$ de rizomas, R2: $500 \mathrm{~g} \mathrm{~m}^{-2} \mathrm{MS}$ de rizomas, R3: $800 \mathrm{~g} \mathrm{~m}^{-2} \mathrm{MS}$ de rizomas. 
Tabla 33. Análisis de Varianza de los efectos de la micorrización (NI, IM e IB1) y los rizomas de SA (R0, R1, R2 y R3) y su interacción sobre la conductancia estomática (CS). Referencias: $\mathrm{H}$ : micorrización, R: rizomas de SA.

\begin{tabular}{llcc}
\hline Fuente de variación & Gl & CM & Valor-P \\
\hline H:Micorrización & 2 & 228,71 & 0,0668 \\
R:Rizomas & 3 & 743,252 & $<0,001$ \\
Interacción H X R & 6 & 96,9045 & 0,3010 \\
\hline
\end{tabular}

Gl: grados de libertad; CM: cuadrado medio; P: valor de probabilidad de la prueba de F

\section{Conductividad relativa de hojas (CRH)}

La conductividad relativa de hojas mostró diferencias significativas entre los tratamientos con residuos de rizomas de sorgo de Alepo $(p<0,001)$ pero sin diferencias entre los tratamientos de inoculación. La interacción micorrización x rizomas no fue significativa. Las IB1 incrementaron significativamente los valores de CRH en R2 y R3, mientras que IM y NI solo en R3, Las plantas NI mostraron los mayores valores en R3 diferenciandose significativamente con IB1 (Figura 29).

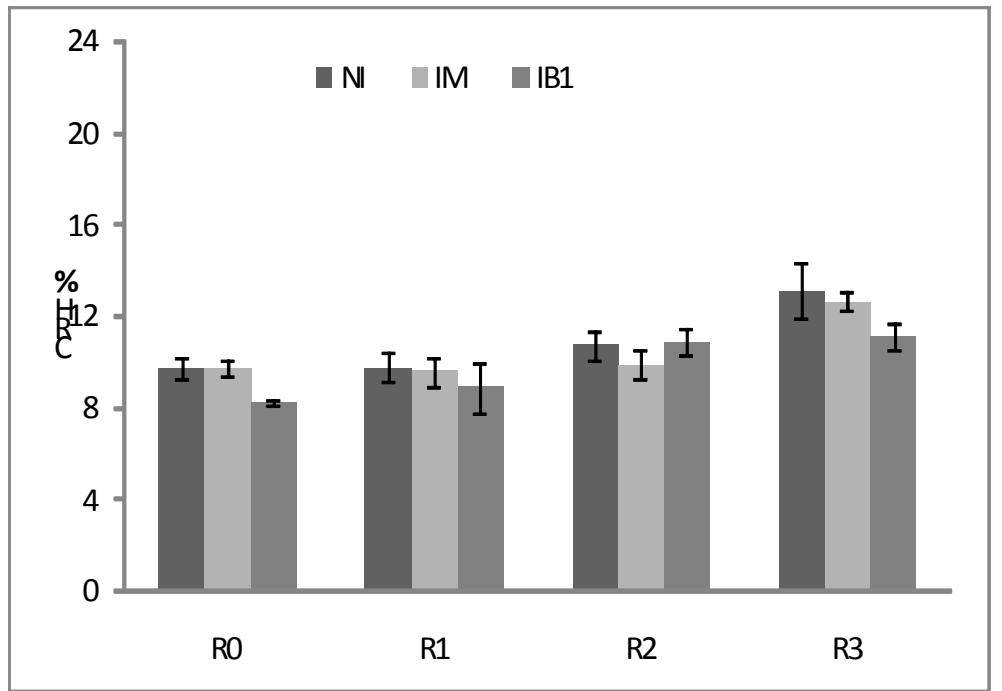

Figura 29. Efecto de los aleloquímicos provenientes de rizomas de sorgo de Alepo sobre la conductividad relativa de hojas $(\mathrm{CRH})$ de plantas de Mentha x piperita L. no inoculadas (NI) o inoculadas con Funneliformis mosseae (IM) y Rhizophagus intraradices (IB1). R0: $0 \mathrm{~g} \mathrm{~m}^{-2} \mathrm{MS}$ de rizomas, R1: $250 \mathrm{~g} \mathrm{~m}^{-2}$ MS de rizomas, R2: $500 \mathrm{~g} \mathrm{~m}^{-2}$ MS de rizomas, R3: $800 \mathrm{~g} \mathrm{~m}^{-2} \mathrm{MS}$ de rizomas. 
Tabla 34. Análisis de Varianza de los efectos de la micorrización (NI, IM e IB1) y los rizomas de SA (R0, R1, R2 y R3) y su interacción sobre la conductividad relativa de hojas (CRH). Referencias: H: micorrización, R: rizomas de SA.

\begin{tabular}{llcc}
\hline Fuente de variación & Gl & CM & Valor-P \\
\hline H:Micorrización & 2 & 3,44469 & 0,1081 \\
R:Rizomas & 3 & 17,772 & $<0,001$ \\
Interacción H X R & 6 & 1,17303 & 0,5567 \\
\hline
\end{tabular}

Gl: grados de libertad; CM: cuadrado medio; P: valor de probabilidad de la prueba de F

\section{Conductividad relativa de raíces (CRR)}

Se observaron diferencias significativas para los tratamientos de micorrización $(p<0,05)$ y sorgo de Alepo $(p<0,05)$ con respecto a la conductividad relativa de raíces $(C R R)$. La interacción no fue significativa $(p>0,05)$. El daño de membranas de las raíces de las plantas NI y IM fue significativamente incrementado en R2 y R3, mientras que en IB1 no se observaron diferancias significativas con el aumento de las concentraciones de rizomas de SA. El incremento en R3 fue del $41 \%$ y $20 \%$ en las NI e IM respectivamente con respecto a $\mathrm{R} 0$.(Figura 30$)$.

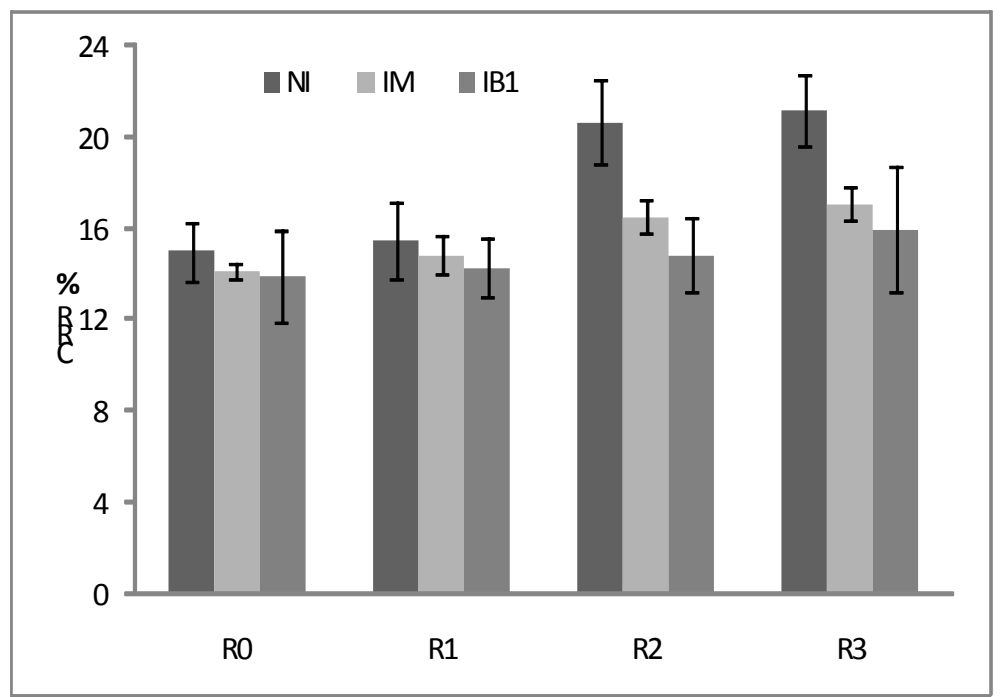

Figura 30. Efecto de los aleloquímicos provenientes de rizomas de sorgo de Alepo sobre la conductividad relativa de raíces (CRR) de plantas de Mentha x piperita L. no inoculadas (NI) o inoculadas con Funneliformis mosseae (IM) y Rhizophagus intraradices (IB1). R0: $0 \mathrm{~g} \mathrm{~m}^{-2} \mathrm{MS}$ de rizomas, R1: $250 \mathrm{~g} \mathrm{~m}^{-2} \mathrm{MS}$ de rizomas, R2: $500 \mathrm{~g} \mathrm{~m}^{-2} \mathrm{MS}$ de rizomas, R3: $800 \mathrm{~g} \mathrm{~m}^{-2} \mathrm{MS}$ de rizomas. 
Tabla 35. Análisis de Varianza de los efectos de la micorrización (NI, IM e IB1) y los rizomas de SA (R0, R1, R2 y R3) y su interacción sobre la conductividad relativa de raíces (CRR). Referencias: H: micorrización, R: rizomas de SA.

\begin{tabular}{llcl}
\hline Fuente de variación & Gl & C M & Valor-P \\
\hline H:Micorrización & 2 & 35,1439 & 0,0151 \\
R:Rizomas & 3 & 30,1809 & 0,0144 \\
Interacción H X R & 6 & 5,38543 & 0,6017 \\
\hline
\end{tabular}

Gl: grados de libertad; CM: cuadrado medio; P: valor de probabilidad de la prueba de F

\section{Aceites esenciales}

El contenido de aceites esenciales mostró diferencias significativas para los inóculos utilizados $(p<0,001)$ y las cantidades de rizomas de sorgo de Alepo $(p<0,001)$, mientras que la interacción micorrización $\mathrm{x}$ rizomas no fue significativa $(p>0,05)$ (Figura 31).

Las plantas inoculadas registraron mayores porcentajes de aceites esenciales en los tratamientos sin rizomas. No se observaron diferencias significativas entre los tratamientos con incorporación de rizomas en las NI, mientras que las inoculadas con $F$. mosseae, la disminución fue significativa en R1 y R2 y en las inoculadas con $R$. intraradices el \%AE disminuyó significativamente a partir de R1. En R3 las plantas inoculadas con IM e IB1 superaron a las NI en aproximadamente un 13\%.

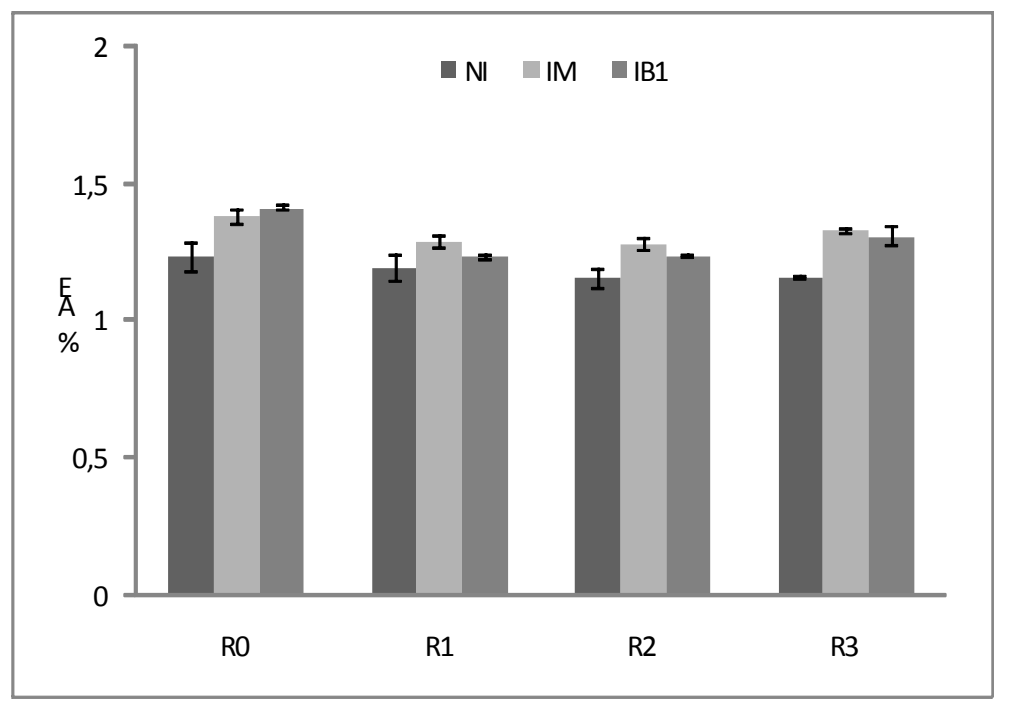

Figura 31. Efecto de aleloquímicos provenientes de rizomas de sorgo de Alepo sobre el porcentaje de aceites esenciales (\% AE) de plantas de Mentha x piperita L. no inoculadas (NI) o inoculadas con Funneliformis mosseae (IM) y Rhizophagus intraradices (IB1). R0: $0 \mathrm{~g} \mathrm{~m}^{-2} \mathrm{MS}$ de rizomas, R1: $250 \mathrm{~g} \mathrm{~m}^{-2} \mathrm{MS}$ de rizomas, R2: $500 \mathrm{~g} \mathrm{~m}^{-2} \mathrm{MS}$ de rizomas, R3: $800 \mathrm{~g} \mathrm{~m}^{-2} \mathrm{MS}$ de rizomas. 
Tabla 36. Análisis de Varianza de los efectos de la micorrización (NI, IM y IB1) y los rizomas de SA (R0, R1, R2 y R3) y su interacción sobre el porcentaje de aceites esenciales (\% AE). Referencias: H: micorrización, R: rizomas de SA.

\begin{tabular}{llcc}
\hline Fuente de variación & Gl & CM & Valor-P \\
\hline H:Micorrización & 2 & 0,0806331 & $<0,001$ \\
R:Rizomas & 3 & 0,031463 & $<0,001$ \\
Interacción H X R & 6 & 0,00427477 & 0,2454 \\
\hline
\end{tabular}

Gl: grados de libertad; CM: cuadrado medio; P: valor de probabilidad de la prueba de F 


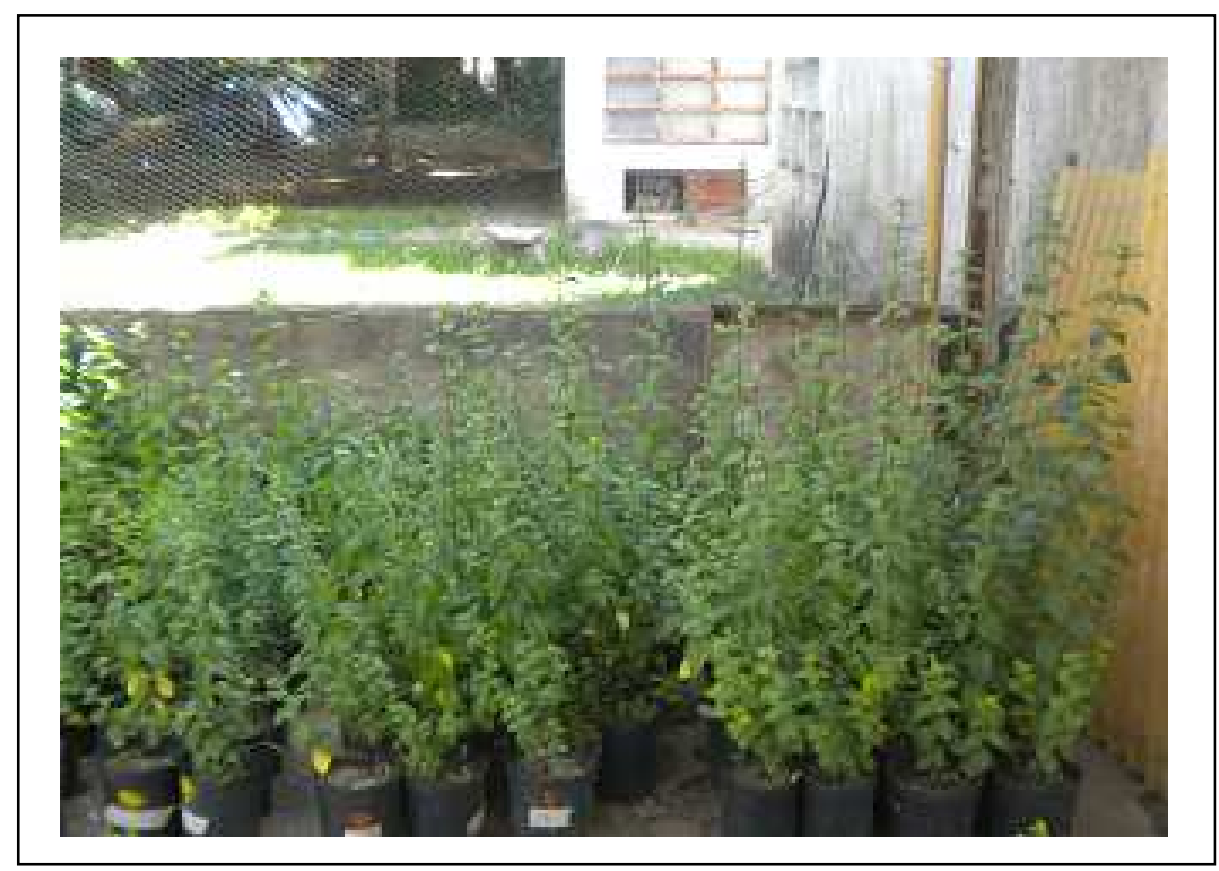

Figura 32. Ensayo $\mathrm{N}^{\circ}$ 3. Plantas de Mentha x piperita L. no inoculadas o inoculadas con Funneliformis mosseae y Rhizophagus intraradices IB1creciendo en sustrato con distintas cantidades de rizomas de Sorgo de Alepo.

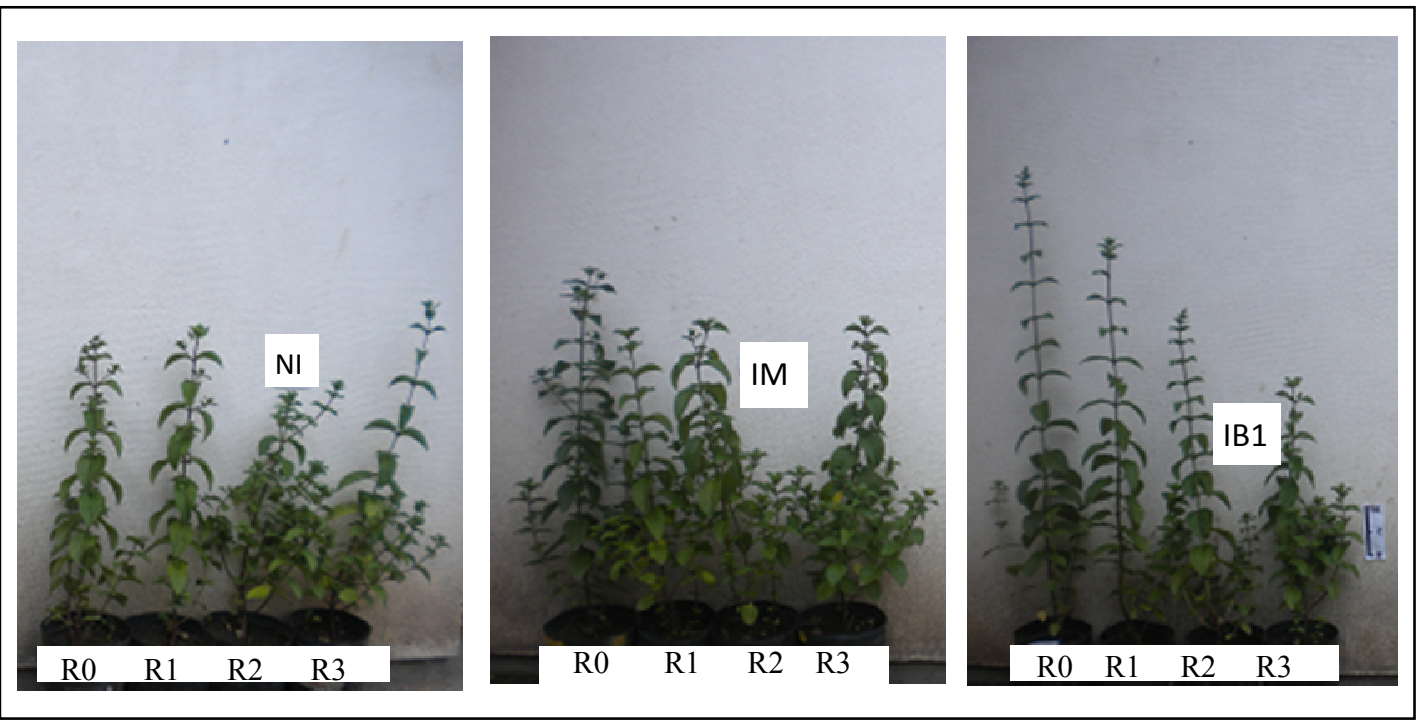

Figura 33. Plantas de Mentha x piperita L. no inoculadas (NI) o inoculadas con Funneliformis mosseae (IM) y Rhizophagus intraradices (IB1). R0: $0 \mathrm{~g} \mathrm{~m}^{-2}$ MS de rizomas, R1: $250 \mathrm{~g} \mathrm{~m}^{-2} \mathrm{MS}$ de rizomas, R2: $500 \mathrm{~g} \mathrm{~m}^{-2}$ MS de rizomas, R3: $800 \mathrm{~g} \mathrm{~m}^{-2} \mathrm{MS}$ de rizomas. 
Capítulo 4

Discusión 
La alelopatía es un fenómeno que se presenta en forma natural en los agroecosistemas cuya importancia radica en que la liberación de sustancias denominadas aleloquímicos reducen el crecimiento y el rendimiento de los cultivos (Inderjit and and Duke, 2003). Las malezas además de interferir con los cultivos por el espacio, agua, luz y nutrientes, pueden ejercer su acción competitiva mediante este tipo de acción (Leguizamón, 1999, Stinson et al., 2006; Zimdshl, 2007). El sorgo de Alepo (Sorghum halepense L.) ejerce una importante acción alelopática sobre cultivos de verano como maíz (Zea mays L.), soja (Glycine max Merr), sorgo granífero y algodón (Gossypium hirsutum L.), entre otros (Lolas and Coble 1982; Rosales Robles et al., 1999; Czarnota et al., 2001; Acciaresi and Asenjo, 2003).

Los compuestos químicos liberados al suelo por ciertas plantas pueden ejercer el efecto de un estrés biótico, afectando la simbiosis con hongos benéficos como los que forman las micorrizas arbusculares (Koide and Li, 1991; Scervinio et al., 2005; Hirosulke et al., 2002; Tsai and Phillips, 1991).

En este capítulo se discutirán los resultados más relevantes de la investigación realizada en relación al efecto alelopático del sorgo de Alepo sobre la micorrización con HMA y la menta.

Efecto de los extractos acuosos de rizomas de sorgo de Alepo sobre la micorrización el crecimiento, parámetros fisiológicos y bioquímicos de plantas de Mentha $\mathrm{x}$ piperita L. (Ensayos $N^{\circ} 1$ y 2 )

Los ensayos 1 y 2 se realizaron en speedling utilizando como sustrato una mezcla de perlita:vermiculita:arena en proporción 1:1:1. Los tratamientos de sorgo de Alepo se realizaron a través del riego con extractos acuosos de rizomas.

Micorrización, viabilidad de la estructuras fúngicas y dependencia micorrícica

El porcentaje de micorrización, arbúsculos y vesículas en las plantas de menta piperita fue elevado, indicando que es una especie altamente micotrófica, en coincidencia con lo encontrado por otros autores en la misma y otras especies de menta (Gupta et al, 1994; 2002; Cabello et al., 2005; Arango et al., 2006). En los ensayos 1 y 2 
donde se evaluó el efecto de los extractos acuosos de rizomas de sorgo de Alepo, el porcentaje de micorrización de las plantas de Mentha x piperita se vio afectado en forma negativa, independientemente del inóculo utilizado. La mayor concentración de extracto experimentada (15\%) acentuó la reducción. Los aleloquímicos presentes en los extractos acuosos obtenidos a partir de rizomas de sorgo de Alepo ejercieron un efecto fitotóxico sobre los hongos micorrícicos. Esta fitotoxicidad afecta la simbiosis, dando como resultado una menor absorción de agua y nutrientes, fundamentales para el crecimiento y desarrollo de las plantas (Koide and Li, 1991). Estos resultados coinciden con estudios en los que se evaluaron los efectos de extractos acuosos de tallos y exudados radiculares de Imperata cylindrica sobre la asociación micorrícica de hongos micorrícicos autóctonos, Glomus fasciculatum y G. mosseae con especies leguminosas como Medicago denticulata, Vicia sativa, Phaseolus vulgaris, Vigna radiata, entre otras, en las que el extracto de la maleza redujo la micorrización (Bajwa et al., 1996; Afzal et al., 2000). La inhibición observada puede darse por efectos directos del extracto sobre los hongos micorrícicos o bien, por una modificación del $\mathrm{pH}$ del sustrato por efecto de los extractos de SA. Dentro de la composición química de los extractos de rizomas de Sorgo de Alepo, se encuentran compuestos fenólicos tales como sorgoleona, ácidos $p$-cumárico, ferúlico y vanílico, $p$-benzoquinonas (Guenzi and McCalla, 1966; Einhellig, 1996; Cherney et al 1991; Czarnota et al.,2001; Sene et al., 2001). La acumulación de estos ácidos reduce el $\mathrm{pH}$ del suelo. El pH de la rizosfera es un factor importante no solo para la absorción de nutrientes sino también para la actividad microbiana como los HMA. Estos hongos se desarrollan en forma satisfactoria entre $\mathrm{pH}$ 5 a 6 (Potty, 1984; Smith and Smith, 1990). No obstante, el papel que juegan los compuestos fenólicos sobre los HMA es complejo, dependiendo de múltiples factores como el tipo de compuesto fenólico, su concentración, la especie de hongo micorrícico y la etapa de desarrollo de la simbiosis (Scervino et al., 2005).

En este trabajo, se observó que al avanzar en el estado de desarrollo de las plantas, la formación de arbúsculos fue más sensible que la formación de vesículas, en las concentraciones de 10 y $15 \%$, tanto en $F$. mosseae como en $R$. intraradices. Los arbúsculos son los principales sitios de intercambio de nutrientes entre el hongo y la planta hospedante (Smith and Gianinazzi-Pearson, 1990), por lo tanto la reducción del porcentaje de arbúsculos indicaría que la funcionalidad de la simbiosis podría verse disminuida (Giovannetti et al., 1994). 
Las vesículas tienen como función el almacenamiento temporario de reservas (Sieverding, 1991; Martínez and Pugnaire, 2009), por lo tanto podría ser una estrategia de estos hongos para afrontar situaciones de estrés, como en este caso el efecto fitotóxico de los extractos. Javaid, (2008) determinó una disminución del porcentaje de micelio y arbúsculos y un incremento en el \% de vesículas en las raíces de distintas especies de plantas leguminosas creciendo en presencia de compuestos aleloquímicos provenientes de Imperata cylindrica en el suelo. La actividad de la enzima succinato deshidrogenasa (SDH), permite evaluar la viabilidad de las estructuras del hongo (Hamel et al., 1990), aquí se observó que la viabilidad fue afectada negativamente por el extracto. La inactividad de las hifas podría ser debido a un daño indirecto por compuestos aleloquímicos lo que provoca una reducción de la materia seca aérea de las plantas, disminuyendo el traslado de fotoasimilados hacia el hongo (Gaspar et al., 2002). Walton et al., (1994) determinaron que las plantas pueden responder a un estrés químico, sintetizando compuestos que exudados a la rizosfera, modifican la redistribución del carbono.

La dependencia micorrícica (DM) describe la eficiencia de la colonización micorrícica, calculada a través de la relación del peso seco de las plantas micorrizadas respecto de las no micorrizadas, cultivadas en las mismas condiciones (Ruiz-Lozano et al., 1995). En este trabajo, la DM medida a los 60 DDT, fue superior para las mayores concentraciones de extracto. La DM fue de alrededor del $40 \%$ para S0 y S1, y fue superior al $72 \%$ para S2 y S3 independientemente del inóculo utilizado, demostrando la relación favorable que se establece entre las plantas de menta y $F$. mosseae o $R$. intraradices. Este resultado sugiere que si bien la colonización es importante para las plantas crecidas en condiciones no estresantes $(\mathrm{DM}=40 \%)$, la colonización micorrícica en menta, adquiere mayor relevancia en condiciones de estrés en las plantas de menta piperita (DM=72\%) (Sánchez-Díaz and Honrubia, 1994; Ruscitti et al., 2011).

En estudios de heredabilidad de la dependencia de las micorrizas, Hetrick et al., (1992) determinaron que la respuesta a la simbiosis varía significativamente entre los cultivares de una misma especie. Estos autores, trabajando con trigo, determinaron que algunos cultivares se beneficiaron por la micorrización, otros fueron indiferentes, mientras que otros sufrieron una disminución del crecimiento, basados en estas respuestas concluyeron que la dependencia a las micorrizas está bajo el control genético de la planta huésped. 
Las micorrizas facilitan la absorción de los elementos poco solubles o poco móviles, especialmente el fósforo (Smith and Read, 1997; Yao et al., 2003; Garg and Chandel., 2010). El fósforo es transportado por el hongo a través de las hifas como gránulos de polifosfato, los cuales son degradados por las enzimas fosfatasas alcalinas (Subramanian and Charest, 1998).

La actividad de la ALP (enzima fosfatasa alcalina) es un parámetro utilizado para expresar la eficiencia de la simbiosis (Tisserant et al., 1993). En este trabajo se demuestra que la actividad de la ALP aumentó con la concentración de extracto, en particular en $R$. intraradices. Además, Dilly and Nannipieri, (1988), sugieren que la elevada actividad de la ALP podría estar relacionada a una disminución de los niveles de $\mathrm{P}$ en el micelio y en el sustrato, a causa del estrés, alterando la función de absorción. Otros autores han determinado un aumento de los valores de ALP en situaciones de estrés hídrico (Ruscitti et al., 2006), mientras que frente al estrés por $\mathrm{Cu}$ la actividad de la ALP disminuyó en plantas inoculadas con $F$. mosseae y no fue afectada en plantas inoculadas con $R$. intraradices (Ruscitti et al., 2008).

\section{Parámetros de crecimiento}

El mecanismo de acción específico que provoca la reducción del crecimiento y la micorrización por parte de los aleloquímicos no ha sido determinado en forma clara, pero se sabe que compuestos tales como el ácido cinámico, benzoico y ferúlico presentes en los exudados de rizomas de sorgo de Alepo y otros malezas como Imperata cylindrica, pueden resultar tóxicos e interferir alterando la estructura de las membranas plasmáticas, procesos fotosintéticos, reacciones enzimáticas, flujo de carbono, interacciones mediadas por fitohormonas, $\mathrm{y}$ otros procesos fisiológicos en plantas $\mathrm{y}$ microorganismos del suelo (Putman, 1985; Hollapa and Blum, 1991; Rizvi et al., 1992; Hejl et al. 1993; Einhellig, 1995, Hussain and Reigosa, 2011). En estudios previos se reportó que los ácidos fenólicos presentes en el extracto de sorgo de Alepo podrían ser la posible causa de la reducción del crecimiento y rendimiento de los cultivos que crecen asociados a esta maleza (Einhellig and Rasmussen, 1978; Einhellig, 1996, Acciaresi and Asenjo, 2003). Los ácidos ferúlico, vanillico, $p$-hydroxybenzoico, $p$ - 
cumarico y la sorgoleona son algunos compuestos identificados en distintas especies de Sorghum (Guenzi et al., 1967, Abdul-Wahab and Rice, 1967; Cherney et al., 1991 Einhellig and Souza, 1992).

El crecimiento de las plantas de menta piperita fue afectado por los extractos de SA en todos los tratamientos. Esto se vio reflejado en una menor altura, área foliar, peso seco de hojas, tallos y raíces de las plantas, en las mediciones realizadas a los 30 y 60 días del trasplante. Muhammad and Mohammad, (2010) determinaron que los residuos Sorghum halepense mostraron fitotoxicidad sobre la germinación de semillas y desarrollo de plántulas de las especies medicinales como Plantago ovata, Foeniculum vulgare y Ocimum basilicum. La reducción en el crecimiento de la raíz determinada en nuestro trabajo, afecta las funciones fisiológicas de las plantas tales como, anclaje, absorción de agua y nutrientes y posiblemente el balance hormonal. Bukolova, 1971 atribuyó el menor desarrollo de las raíces por efecto de aleloquímicos a una reducción de la actividad mitótica de las células radiculares. Todo esto podría contribuir a la disminución en el peso seco, en coincidencia Bensch et al, (2007).

El crecimiento evaluado en este trabajo a través de peso seco de tallo, hojas y raíz, fue superior en las plantas micorrizadas comparadas con las no inoculadas, en todas las concentraciones de extracto, si bien como se dijo anteriormente, las sustancias presentes en los extractos acuosos de sorgo de Alepo redujeron el porcentaje de colonización micorrícica. La micorrización podría favorecer la transferencia de las sustancias fitotóxicas de los extractos a las plantas hospedantes a través de la red de hifas (Achatz and Rillig, 2014), y esto se comprobó por el menor crecimiento de las plantas inoculadas en presencia de extracto. En las mediciones realizadas a los 60 DDT las plantas inoculadas con $R$. intraradices respondieron mejor que las inoculadas con $F$. mosseae en las concentraciones más bajas, con excepción de la longitud de la raíz donde no se observaron diferencias. El beneficio de la inoculación relacionado con la promoción del crecimiento e incremento de la materia seca puede variar en función de la relación planta-hongo. A partir de los 60 DDT el comportamiento de ambos inóculos puestos a prueba en este trabajo fue similar. Estos resultados coinciden con Bajwa, (2005); Bajwa et al., (1999) y Javaid and Bajwa (1999) quienes demostraron que la inoculación con hongos micorrícicos redujo en forma significativa el efecto negativo del estrés alelopático causado por los extractos acuosos de hojas de Melia azedarach sobre plantas de maíz y de Syzygium cumini sobre Cicer arietinum L. Además, Bajwa et al., 
(2000), determinaron que plantas de trigo micorrizadas con Glomus fasciculatum y $G$. mosseae presentaron mayores rendimientos que aquellas no inoculadas, bajo el estrés alelopático de Imperata cylindrica. En tanto que, Javaid, (2007) relaciona el mayor crecimiento de las plantas micorrizadas a un mejor estado nutricional de la planta huésped, morigerando el efecto de un estrés alelopático. Sin embargo, se han encontrando evidencias de la existencia de mecanismos específicos propios de los hongos arbusculares o inducidos por estos, que le dan a las plantas micorrizadas mayor tolerancia a elementos tóxicos ambientales (Ocampo, 1993, Zhu et al., 2001; GonzálezChávez et al., 2004). Así, se determinó que las raíces de Cicer arietinum en contacto directo con los aleloquimícos presentes en extractos acuosos de hojas de Syzygium comini fueron más afectadas que la parte aérea, provocando una reducción de la concentración de $\mathrm{N}$ y $\mathrm{P}$ foliar, como consecuencia de una disminución en la capacidad de absorción de dichos elementos (Bajwa et al., 1999). El mismo autor concluyó que las micorrizas arbusculares pueden producir y segregar al suelo compuestos químicos que neutralizan los efectos de los aleloquímicos responsables de la inhibición de la mitosis de las células radiculares y el crecimiento de la parte aérea. La alteración en el crecimiento de las raíces por parte de los aleloquímicos, conduciría a un menor desarrollo aéreo debido a una reducción en la absorción de nutrientes, la micorrización podría revertir esta situación, sobre todo si se tiene en cuenta el incremento en el volumen de raíz en las plantas micorrizadas, como fue observado por Ronco et al. (2008), en plantas de pimiento inoculadas con G. mosseae.

El papel de los compuestos fenólicos y de los distintos compuestos fitotóxicos sobre la simbiosis micorrícica no está claro, y sus efectos parecen estar relacionado con la concentración de los aleloquímicos en el sustrato, pudiendo estimular o inhibir la colonización (Leadir et al., 1997). Tampoco se conoce con certeza la respuesta diferencial de las micorrizas arbusculares en la sensibilidad de las plantas frente a los extractos de rizomas de sorgo de Alepo, este comportamiento podría ser similar al que ocurre con los metales pesados o pesticidas acumulados en el suelo, en que se modifica la sensibilidad y/o tolerancia que le pueden proporcionar los hongos arbusculares a las plantas hospedantes (Barea et al., 2005b; Ruscitti et al., 2011; Kaya et al., 2009; Kohler et al., 2008; Manoharan et al., 2010, Beltrano et al., 2013b). 


\section{Proteinas foliares}

Las plantas micorrizadas presentaron valores de proteínas foliares más elevados en todas las concentraciones de extracto utilizado, respecto de las no inoculadas, sin embargo la concentración de $15 \%$ de extracto, disminuyó el porcentaje de proteínas en las plantas inoculadas con ambos inóculos, respecto de las control en ausencia de extracto. Las plantas inoculadas con $F$. mosseae mostraron mayor acumulación de proteínas respecto de las NI y las inoculadas con $R$. intraradices.

La disminución en el contenido de proteínas podría ser causada por las sustancias alelopáticas presentes en el extracto de sorgo de Alepo, entre las que se incluyen compuestos fenólicos como por ejemplo, el ácido clorogénico, ácido ferúlico y p-hydrobenzoico, los cuales han sido reportados como inhibidores de la síntesis proteica (Baziramakenga et al., 1997; Mersie and Singh, 1993; Hussain and Rigosa., 2011). La reducción del contenido de proteínas como del crecimiento podrían estar relacionados también al hecho que las hifas de los HMA facilitan el transporte de los aleloquímicos presentes en los de los extractos, hacia la planta hospedante como fue comprobado por Achatz and Rillig (2014).

\section{Clorofila y carotenoides}

La reducción en el contenido de clorofila de las plantas no inoculadas, crecidas con altas concentraciones de extracto, se asocia a la situación de estrés alelopático y consecuentemente a la disminución de la fotosíntesis observada en estas plantas. En este trabajo se observó que en las plantas micorrizadas el contenido de clorofila y carotenoides solo se vio reducido en la concentración más elevada (15\%) de extracto de los rizomas de SA. Otros factores de estrés, tales como la sequía, salinidad, metales pesados, también han sido vinculados con la pérdida de pigmentos fotosintéticos (Levit, 1980; Beltrano et al., 1999; Porcel and Ruiz-Lozano, 2004; Ruscitti et al., 2011; Beltrano et al., 2013a, b). Por otro lado, en coincidencia con los resultados obtenidos en este trabajo, Einhellig and Rasmussen (1978), Yang et al., (2002), Sampietro (2002), Hussain and Reigosa (2011) determinaron que los compuestos fenólicos con acción alelopática inhiben la síntesis de clorofila. Mientras que el incremento de la síntesis de 
clorofila en las plantas micorrizadas estaría asociado a una alta tasa de fotosíntesis y crecimiento (Mathur and Vyas, 2000).

Fotosintesis neta (PN), Conductancia estomática (CS) y Transpiración (E)

Los aleloquímicos pueden afectar procesos fundamentales para el crecimiento y desarrollo de los cultivos, como la absorción de nutrientes y agua, fotosíntesis, respiración, actividad enzimática y hormonal (Sampietro, 2002).

La inoculación con hongos micorrícicos produce una mejora en la fotosíntesis y la conductancia estomática en plantas en situaciones de estrés comparado con las plantas no inoculadas (Augé 2001; Wu and Xia 2006; Brown and Bethlenfalvay, 1988)

En nuestro trabajo, las plantas inoculadas mostraron valores de PN superiores a las NI cuando crecieron libres de de extracto de sorgo de Alepo. La presencia de extractos disminuyó significativamente la fotosíntesis neta en las concentraciones S2 y $\mathrm{S} 3$ en las plantas NI, mientras que sólo las inoculadas con $R$. intraradices redujeron la fotosíntesis a partir de S1, aunque con valores superiores a las NI. Estos resultados demuestran que la simbiosis micorrícica modera los efectos tóxicos provocados por los aleloquímicos, en coincidencia con Rizvi et al., (1992) quienes informaron que altas concentraciones de ácidos ferúlico, $p$-cumárico y cinámico provocan el cierre de los estomas y alteran la síntesis de pigmentos clorofilianos inhibiendo el proceso fotosintético. Además, se ha determinado que la sorgoleona (benzoquinona) presente en los exudados radiculares de sorgo, es capaz de desacoplar el transporte de electrones en el fotosistema II (Einhellig, 1995). Por otro lado Einhellig (1995) consigna que el efecto inhibitorio de las sustancias alelopáticas sobre la fotosíntesis podría explicarse como resultado de la modificación en los niveles de clorofila o por la disminución de la conductancia estomática, lo que provocaría una reducción en el suministro de $\mathrm{CO}_{2}$ esencial para la producción de fotoasimilados (Einhellig 1995).

En este trabajo, se observó que en todos los tratamientos la conductancia estomática fue mayor en las plantas inoculadas, y fue inhibida significativamente en S3 y en las NI con un reducción del 48,7\% comparada con el control, libre de extracto. Mientras que la reducción para IM e IB1 fue de 23\% y $24 \%$ respectivamente con respecto a S0. La transpiración tuvo un comportamiento similar a la conductancia estomática, fue mayor en las inoculadas y se redujo con el agregado de extracto. Esta 
reducción fue del 62\%, 20\% y 39\% en las NI, IM e IB1 respectivamente en S3 con respecto a sus controles sin extracto. En resumen, la micorrización podría mejorar la capacidad de intercambio gaseoso y disminuir la resistencia estomática, e incrementar la transpiración ante situaciones de estrés, en coincidencia con lo encontrado por Subramanian et al., (1995).

\section{Conductividad relativa de membranas de hojas y raices}

Los factores ambientales adversos, diferentes situaciones de estrés, afectan la permeabilidad selectiva de las membranas celulares, alteran la integridad celular y la capacidad de retención de sustancias intracelulares (Beltrano et al., 1999; Lukatkin, 2003). Las membranas celulares de las raíces son los primeros sitios de acción de los compuestos aleloquímicos, pudiendo ser dañadas por una acción directa sobre sus constituyentes o como resultado del deterioro de alguna función metabólica fundamental para el mantenimiento de su funcionalidad (Rice, 1984). Derivados del ácido benzoico y cinámico son capaces de provocar cambios en la polaridad de las membranas, y alterar su estructura, lo que provoca la salida de iones, y reduce la absorción de agua y nutrientes (Baziramakenga et al., 1997; Lehman and Blum, 1999). En este trabajo, el daño provocado por los aleloquímicos de sorgo de Alepo sobre la estabilidad de las membranas celulares, dependió de la interacción entre los tratamientos de inoculación y la concentración de aleloqímicos. Las plantas micorrizadas mostraron menor conductividad relativa de los tejidos de la raíz en todos los tratamientos comparadas con las NI. El menor daño se observó en las plantas inoculadas con $R$. intraradices para todos los tratamientos. El incremento de la conductividad en S3 con respecto a S0 fue de $76 \%$ en las NI y $45 \%$ en la IM.

En las hojas, el daño sobre membranas celulares aumentó significativamente solo en S3 tanto en las NI como en las inoculadas, en relación a S0. Entre los diferentes inóculos las diferencias no fueron significativas. Los valores de CR de IB1 fueron los más bajos para todos los tratamientos comparados con NI y con IM. Estos resultados muestran que bajo condiciones de "estrés alelopático" la simbiosis con hongos micorrícicos protege la integridad de las membranas. Similares resultados encontraron Feng et al., (2002), trabajando con plantas de maíz y Beltrano et al., (2013b) en 
pimiento, bajo condiciones de estrés por salinidad y Beltrano and Ronco (2008), en plantas de trigo bajo condiciones de estrés hídrico.

Efecto de los aleloquímicos provenientes de los rizomas de sorgo de Alepo sobre la micorrización, crecimiento, parámetros fisiológicos y bioquímicos y porcentaje de aceites esenciales de plantas de Mentha x piperita (Experimento $N^{\circ} 3$ )

Micorrización y dependencia micorrícica

Este experimento las plantas crecieron en macetas, utilizando como sustrato una mezcla de suelo y arena (1:1) al cual se le incorporó el inóculo micorrícico junto con distintas cantidades de trozos de rizomas de sorgo de Alepo. En las raíces de las plantas que no fueron inoculadas se observó la presencia de estructuras fúngicas de hongos micorrícicos autóctonos, presentes en el suelo utilizado. La micorrización, tuvo un comportamiento similar a los ensayos donde se evaluó el efecto de extractos acuosos de rizomas. El porcentaje de micorrización, arbúsculos y vesículas de las plantas que crecieron libres de rizomas, fue mayor en las inoculadas comparadas con las NI. Las plantas inoculadas con $F$. mosseae y $R$ intraradices disminuyeron la micorrización, arbúsculos y vesículas a partir de la concentración de 250 g MS de rizomas por metro cuadrado, $R$. intraradices se destacó por presentar el mayor porcentaje de vesículas en las concentraciones más elevadas de rizomas (800 $\left.\mathrm{g} \mathrm{m}^{-2} \mathrm{MS}\right)$ comparado con los observados en los tratamientos NI e IM. La micorrización es un mecanismo que puede explicar la capacidad competitiva de las plantas y por lo tanto la tolerancia a disturbios. En este experimento, la dependencia micorrícica fue muy variable, en presencia de las mayores cantidades de rizomas incorporados aumentó en forma significativamente sólo en las plantas inoculadas con $R$. intraradices, en contraste con lo observado cuando se evaluaron los extractos acuosos, donde se observó un marcado aumento de la DM con altas concentraciones de extractos con ambos inóculos, en coincidencia con SánchezDíaz and Honrubia, (1994) y Ruscitti et al., (2011) quienes reportaron un incremento de la dependencia micorrícica en plantas sometidas a situaciones de estrés. 
Las plantas inoculadas presentaron mayor área foliar, peso seco de tallo, hojas y raíces comparadas con la NI coincidiendo con los ensayos anteriores, donde se evaluó la acción de los extractos acuosos, obtenidos a partir de rizomas de sorgo de Alepo. Sin embargo en este experimento, los parámetros de crecimiento no fueron modificados por los compuestos liberados por los rizomas de sorgo de Alepo. Sólo en las plantas inoculadas con $F$. mosseae, se observó un efecto inhibitorio, sobre el área foliar a partir de $250 \mathrm{~g} \mathrm{~m}^{-2} \mathrm{MS}$ de rizomas. Este resultado podría ser debido a que el tiempo de exposición para permitir el lixiviado de los aleloquímicos de los rizomas fue reducido, a pesar que la cantidad de rizomas utilizados responden a altas tasas de invasión de la maleza. En nuestro caso $F$ mosseae, evidenció una mayor sensibilidad a la presencia de rizomas en el sustrato.

Los mayores valores observados en los parámetros de crecimiento que presentaron las plantas inoculadas con respecto a las NI, micorrizadas con cepas autóctonas, determinan la eficacia de la inoculación, en particular de $R$. intraradices, ya que presentó el mayor crecimiento. Resultados similares fueron obtenidos por Bajwa et al., (2000) quienes observaron que la inoculación con Glomus mosseae y Rhizophagus fasciculatum mostraron un comportamiento más eficiente respecto de las cepas de autóctonos, en condiciones de estrés alelopático de Imperata cylindrica, en cultivo de trigo. Si bien las sustancias aleloquímicas pueden presentar efectos inhibitorios o estimulantes del crecimiento en función de su concentración o su composición química (Kogan, 1992; Einhellig, 1996; Anaya, 1999; Aciaressi and Asenjo, 2003), en nuestro caso, como se manifestó anteriormente, la cantidad de rizomas empleados y el tiempo de exposición de los mismos en el sustrato explicarían la falta de respuesta de los aleloquímicos en el crecimiento. Sin embargo, el peso seco de las raíces de las plantas inoculadas con IM se redujo con 500 y $800 \mathrm{~g} \mathrm{~m}^{-2}$ de rizomas y con $800 \mathrm{~g} \mathrm{~m}^{-2}$ en las NI.

Diversos estudios han demostrado que los HMA tienen la capacidad de adaptarse a diferentes factores del suelo como la presencia de metales pesados, salinidad, compactación, sequía que podrían no ser adecuados para el desarrollo de las plantas y la simbiosis (Al-Karaki, 2006; Ruiz-Lozano et al., 2006; Hildebrandt et al., 2007; Ruscitti et al., 2007; Ruscitti et al., 2011; Beltrano et al., 2013b). En estos casos las micorrizas ejercerían un papel protector a las plantas frente a la toxicidad de metales pesados e incluso de otras sustancias tóxicas presentes en el suelo, almacenándolas en sus paredes 
celulares y núcleos (Cuenca et al., 2001; González Chávez et al., 2002; Castañón-Silva et al., 2013).

Proteinas foliares

La respuesta en el contenido de proteínas foliares en las plantas cultivadas en suelo con rizomas de sorgo de Alepo, difirió del encontrado cuando se evaluaron los extractos acuosos. En este ensayo las plantas NI no mostraron cambios en el contenido de proteínas foliares, con respecto a la concentración de rizomas en el suelo, mientras que en las inoculadas se redujo un $10 \%$ y $13 \%$ para IM e IB1 con $800 \mathrm{~g} \mathrm{~m}^{-2} \mathrm{MS}$ de rizomas respectivamente con respecto sus controles.

Si bien la reducción en el contenido de proteínas foliares de las plantas inoculadas fue estadísticamente significativa, los contenidos de proteínas determinados concentraciones fueron similares a los registrados en las NI que crecieron en ausencia de residuos de rizomas.

\section{Clorofila y carotenoides}

Se observó un efecto inhibitorio de los aleloquimicos provenientes de rizomas de sorgo de Alepo sobre el contenido de clorofila y carotenoides. Las plantas inoculadas vieron modificada la acumulación de estos pigmentos por efecto de los aleloquimicos, en concordancia a lo encontrado por otros autores (Einhellig and Rasmussen, 1978; Yang et al., 2002; Hussain and Reigosa 2011).

\section{Fotosintesis neta y Conductancia estomática}

La fotosíntesis disminuyó con $500 \mathrm{~g} \mathrm{~m}^{-2}$ de MS de rizomas en el sustrato. Las plantas inoculadas con $R$. intraradices mostraron valores significativamente superiores, mientras que con. $800 \mathrm{~g} \mathrm{~m}^{-2}$ no se observaron diferencias entre inoculadas y no inoculadas. Si bien se observó una disminución de la fotosíntesis, el contenido de clorofila sólo se redujo por efecto de la presencia de rizomas en las plantas inoculadas. Peng et al., (2004) determinó que la reducción de la fotosíntesis como consecuencia de los aleloquímicos producidos por algunas malezas, podría ser debido a que estos 
producen una modificación en los niveles de clorofila o por el cierre estomático. En soja los ácidos ferúlico, vaníllico y p-cumárico redujeron el contenido de clorofila (Einhellig and Rasmussen, 1978). Además, Einhellig (1993) encontró que en sorgo las mismas sustancias no provocan esa disminución y sostiene que los ácidos fenólicos actúan en concentraciones relativamente altas inhibiendo el transporte de electrones, lo que sugeriría que el sitio blanco de acción de estas sustancias es otro. Este mismo autor determinó que los compuestos fenólicos sorgoleona y $p$-benzoquinona exudados por raíces de Sorgo bicolor, inhibieron el transporte de electrones provocando la disminución de la eficiencia fotosintética y el crecimiento en plantas de soja.

Los valores de conductancia estomática también fueron afectados negativamente por los residuos de sorgo de Alepo y no se observó una mejora en este parámetro por efecto de la inoculación. El estrés alelopático provocó el cierre de los estomas lo que reduciría el flujo de $\mathrm{CO}_{2}$, afectando la fotosíntesis (Rizvi et al., 1992). Estudios que evalúan el comportamiento de las hormonas en presencia de sustancias fitotóxicas como el ácido ferúlico y otros compuestos fenólicos, evidenciaron un aumento del ácido abscísico (ABA) (Muller, 1970), provocando el cierre de los estomas (Taiz and. Zeiger, 2006; Shao et al., 2008).

\section{Conductividad relativa de membranas de hojas y raíces}

Las membranas celulares de las raíces de las plantas NI fueron afectadas negativamente en las mayores presencias de rizomas en el sustrato, mientras que en las inoculadas no presentaron modificaciones significativas. La conductividad relativa determinada en las raíces fue mayor que la registrada en las hojas. Es posible que las raíces se vieran más afectadas ya que son los primeros sitios de acción de los sustancias fitotóxicas (Lehman and Blum, 1999), no obstante, la inoculación amortiguó el efecto negativo.

La CRH solo se vio afectada ante la presencia de $800 \mathrm{~g} \mathrm{~m}^{-2}$ de rizomas en el sustrato en las NI y la inoculadas. Los valores fueron un $12 \%$ y $15 \%$ inferiores con $F$. mosseae y $R$. intraradices respecto a las NI. Bajo condiciones de estrés salino, Beltrano et al., (2013b) determinaron que plantas de pimiento micorrizadas con HMA mostraron un menor daño de las membranas celulares tanto de hojas como de raíces comparadas con la no micorrizadas. 
Aceites esenciales

Los aceites esenciales son mezclas complejas de compuestos volátiles de más de 100 componentes en los que se incluyen metabolitos secundarios principalmente monoterpenos y sesquiterpenos, aunque algunos son alcoholes simples, ácidos, ésteres, aldehídos o compuestos nitrogenados de sencilla estructura (Ringuelet and Viña, 2013). La biosíntesis de estos compuestos se origina a partir del isopentenil pirofosfato y del dimetilalilpirofosfato (Buchanan et al., 2000). Debido a ello, es importante para su biosíntesis el contenido de fósforo en la planta (Loomis and Corteau, 1972). La biosíntesis de estos compuestos depende de factores genéticos, fisiológicos y de las condiciones ambientales (Sangwan et al., 2001; Figueiredo et al., 2008). Los HMA pueden incrementar el contenido de aceites esenciales, aunque aún no se conocen con certeza cuales son los mecanismos involucrados en el proceso (Toussaint el al., 2007). Se supone que como las micorrizas favorecen la absorción de fósforo, el mejor estado nutricional de las plantas micorrizadas estaría promoviendo la acumulación de metabolitos secundarios (Loomis and Corteau, 1972, Kapoor el al., 2002).

En este trabajo, la inoculación con hongos micorrícicos produjo un incremento significativo del porcentaje de aceites esenciales comparados con las plantas no inoculadas, coincidiendo con resultados de Arango et al., (2006). Estudios realizados sobre Mentha arvensis inoculadas con Glomus clarum, G. etunicatum, Acaulospora scrobiculata y Gigaspora margarita, han demostrado aumentos en la acumulación de AE, coincidiendo con los resultados de este trabajo (Freitas et al., 2004; Khaliq and Janardhanan, 1997). Este efecto también se ha documentado en plantas de orégano (Khaosaad et al., 2006; Morone-Fortunato and Avato, 2008), albahaca dulce (Copetta et al., 2006), у Artemisia annua (Kapoor et al., 2007).

Kapoor et al., (2002) y Toussaint et al., (2007), determinaron que el aumento en la acumulación de aceites esenciales, está mediada por los efectos directos de los hongos micorrícicos e indirectamente por una mejora en el estado de nutrición de las plantas, principalmente el fósforo. Torelli et al., (2000) sostienen que otro efecto indirecto, que favorecería la acumulación de estos compuestos estaría relacionado con cambios en el equilibrio hormonal, como el aumento en la concentración de auxinas en las plantas micorrizadas. 
No se observaron diferencias en el comportamiento de los inóculos micorrícicos utilizados, ante la presencia de residuos de rizomas de Sorgo de Alepo con respecto al porcentaje de aceites esenciales. La concentración de $800 \mathrm{~g} \mathrm{~m}^{-2}$ de rizomas redujo el porcentaje de $\mathrm{AE}$ entre un 3 a $7 \%$ para todos los tratamientos de inoculación con respecto a R0. Sin embargo para esta misma concentración (R3) el \%AE fue un 12,6\% y $14 \%$ superior para IM e IB1 respectivamente, con respecto a las plantas NI. El mayor porcentaje de $\mathrm{AE}$ de las plantas inoculadas estuvo relacionado con la mayor acumulación de materia seca de estas plantas comparadas con las NI, posiblemente debido a un mejor estado nutricional. Esto permitió también un comportamiento más eficiente frente a la presencia de los aleloquímico de los rizomas de sorgo de Alepo. 
Capítulo 5

Conclusiones 
Los resultados de estos experimentos confirman la hipótesis planteada en el trabajo. Los aleloquímicos provenientes de los rizomas de sorgo de Alepo redujeron la micorrización de plantas de Mentha x piperita y su efecto fue dependiente de la concentración tanto de extracto como de la densidad de rizomas utilizados en las condiciones experimentales descriptas.

Las plantas de Mentha x piperita L. respondieron a la inoculación con los hongos micorrícicos $R$. intraradices y $F$. mosseae, al observarse un elevado porcentaje de arbúsculos y vesículas, como señal de que esta especie es altamente micotrófica. Asimismo, el alto grado de dependencia micorrícica observado en presencia de aleloquímicos provenientes de rizomas de sorgo de Alepo, puso de manifiesto la importancia de la simbiosis para sobrellevar esa situación de estrés.

La disminución de la micorrización de las plantas expuestas a elevadas concentraciones de extractos acuosos de rizomas, se correlacionó positivamente con la pérdida peso seco, mientras que los aleloquímicos liberados por los rizomas en el suelo no modificaron los parámetros de crecimiento.

La fotosíntesis fue inhibida por los aleloquímicos de los rizomas de sorgo de Alepo correlacionándose en forma positiva con una disminución del contenido de clorofila y la conductancia estomática en las plantas no inoculadas y en menor medida en las inoculadas con HMA.

Los extractos acuosos de rizomas de sorgo de Alepo provocaron un incremento en la conductividad relativa de las membranas de las raíces en las plantas no inoculadas, mostraron un daño significativo en las mayores concentraciones, mientras que las raíces de las plantas inoculadas no mostraron daño a nivel de membranas lo que determina que bajo condiciones de estrés alelopático la simbiosis con hongos micorrícicos protegió la integridad de las membranas. La reducción en el crecimiento de las raíces por parte de los aleloquímicos, condujo a un menor desarrollo aéreo, la micorrización, revirtió en parte, esta situación.

En los experimentos realizados en macetas con rizomas de sorgo de Alepo, la inoculación con ambas especies de HMA aventajó a los hongos autóctonos, contribuyendo a paliar los efectos fitotóxicos de los residuos de rizomas de SA.

La inoculación con hongos micorrícicos arbusculares incrementó el porcentaje de aceites esenciales en todos los tratamientos. Estos resultados se correlacionan con la mayor producción de materia seca de las plantas inoculadas. 
Los mecanismos de acción que provocaron las reducciones observadas en el crecimiento y la micorrización de las plantas de Menta piperita no son claros.

Las micorrizas arbusculares cumplen un rol importante en los ecosistemas, ya que presentan una amplia plasticidad en su respuesta otorgándole sustentabilidad en los agroecosistemas. La interacción positiva entre las plantas de menta y los hongos micorrícicos arbusculares optimiza el estado nutricional de las plantas, permitiendo incrementar la tolerancia a un estrés alelopático.

Este trabajo aporta información sobre la biología de la interacción alelopática al estudiar el impacto del estrés alelopático sobre la simbiosis con hongos micorrícicos arbusculares en plantas aromáticas como la Menta piperita. La mayoría de los trabajos que evalúan el estrés alelopático, han sido enfocados en los efectos sobre la germinación de semillas y crecimiento inicial de plántulas, pero no sobre plantas obtenidas a partir de estacas, que es la forma comercial de multiplicación de la especie motivo de este estudio. Los efectos de estos aleloquímicos sobre la colonización con hongos micorrícicos arbusculares no han sido aun totalmente dilucidados. Teniendo en cuenta que existe cierto grado de variación de los efectos inhibitorios de acuerdo al origen y la concentración de los aleloquímicos en la colonización y el crecimiento de las plantas, se requieren futuras investigaciones para determinar el grado de interferencia de los mismos.

Así como también es importante continuar las investigaciones a fin de determinar el impacto que puedan tener los aleloquímicos del Sorghum halepense sobre las esporas de los HMA presentes en el suelo. Es importante también poder realizar estudios en situaciones de campo, ya que frecuentemente los resultados de laboratorio no responden a las condiciones que presentan los agroecosistemas, en los cuales se verifican numerosas variables biológicas que pueden modificar los procesos de exudación, movilidad y transformación de los compuestos químicos.

Se concluye que la inoculación con hongos micorrícicos modera los efectos adversos causados por las altas concentraciones de aleloquímicos provenientes de rizomas de sorgo de Alepo en los extractos acuosos y en los sustratos utilizados. El uso de hongos micorrícicos puede ser una alternativa de interés para mejorar la productividad de los cultivos y la eficiencia de los agroecosistemas especialmente bajo situaciones de estrés, al optimizar el uso de los recursos y propiciar un sistema de producción sustentable. 


\section{Bibliografía}

-Abdul-Wahab, A.S. and Rice, E.L. 1967. Plant inhibition by johnsongrass and its possible significance in old-field succession. Bulletin of the Torrey Botanil Club. 94:486-497.

-Abduk-Khaliq, Gupta, M.L. and Kumar, S. 2001. The effect of vesicular-arbuscular mycorrhizal fungi on growth of peppermint. Indian Phytopathology. New Delhi. .54: $82-84$.

-Acciaresi, H. and Asenjo, C. 2003. Efecto alelopático de Sorghum halepense (L.) Pers. sobre el crecimiento de la plántula y la biomasa aérea y radical de Triticum aestivum L. Ecología Austral.13:49-61.

-Achatz, M. and Rillig, M.C. 2014. Arbuscular mycorrhizal fungal hyphae enhance transport of the allelochemical juglone in the field. Soil Biology and Biochemistry. 78: 76-82.

-Achatz, M., Kathryn Morris, E., Müller, F., Hilker, M. and Rillig, M.C. 2014. Soil hypha-mediated movement of allelochemicals: arbuscular mycorrhizae extend the bioactive zone of juglone. Functional Ecology. 28: 1020-1029.

-Afzal, B., Bajwa R. and Javaid, A. 2000. Allelopathy and VA Mycorrhiza VII: Cultivation of Vigna radiata and Phaseolus vulgaris under Allelopathy stress caused by Imperata cylindrica. Pakistan Journal of Biological Science. 3: 1926-1928.

-Akiyama, K., Matsuzaki, K. and Hayashi, H. 2005. Plant sesquiterpenes induce hyphal branching in arbuscular mycorrhizal fungi. Nature. 435:824-827. 
-Alippi, A. M., Ringuelet, J.A., Cerimele, E.L., Re, M.S. and Henning, C.P. 1996. Antimicrobial Activity of Some Essential Oils Against Paenibacillus larvae, the Causal Agent of American Foulbrood Disease. Journal of Herbs, Spices \& Medicinal Plants. 4:9-16.

-Al-Karaki, G.N. 2006. Nursery inoculation of tomato with arbuscular mycorrhizal fungi and subsequent performance under irrigation with saline water. Scientia Horticulturae.109: 1-7.

-Allen, E.B. 1996. The ecology of arbuscular mycorrhizas: a look back into the 20th century and a peek into the $21^{\text {st }}$. Mycological Research. 100:769-782.

-Anaya, A.L. 1999. Allelopathy as a tool in the management of biotic resources in agroecosystems. Critical Reviews of Plant Science. 18:697-739.

-Arango, M.C., M. Ruscitti, M. Ronco and J. Beltrano. 2006. Efecto de la micorrización con Glomus mosseae sobre la biomasa y contenido de aceites esenciales en Mentha $x$ piperita L. I Reunión de Biotecnología Aplicada a Plantas Medicinales y Aromáticas. Sección Temática (6): Productos naturales. Córdoba. Pág. 122-123.

-Arizio, O. and Curioni, A. 2003. (IICA); Productos aromáticos y medicinales (Doc.A6); Estudio I.EG.33.7, Componente A, Préstamo BID 925/OC-AR. Pre II. Coordinación del Estudio: Oficina de la CEPAL-ONU en Buenos Aires, a solicitud de la Secretaría de Política Económica, Ministerio de Economía de la Nación.

-Arizo. O, Curioni, A. and Motta, G. 2008. Evolución de las importaciones y exportaciones argentinas de mentol y aceites esenciales de menta. Análisis de la balanza comercial de la década 1996- 2005. Horticultura Argentina 27(63).

-Asgharipour, M.R. and Armin, M. 2010. Inhibitory effects of Sorghum halepens root and leaf extracts on germination and early seedling growth of widely used medicinal plants. Advances in Environmental Biology. 4:316-324. 
-Augé R.M. 2001. Water relations, drought and vesicular-arbuscular mycorrhizal symbiosis Mycorrhiza. 11:3-42.

-Azcon, R. 2000. Papel de la simbiosis micorrícica y su interacción con otros microorganismos rizosféricos en el crecimiento vegetal y sostenibilidad agrícola. En: Alarcón A., Ferrera-Cerrato R. (eds) Ecología, fisiología y biotecnología de la micorriza arbuscular. Colegio de Postgraduados, Ediciones Munid Prensa, Montecillo, Mexico, pp1-15.

-Bajwa, R., Javaid, A., Tasneem, Z. and Nasim, G. 1996. Allelopathy and VA mycorrhiza. I: Suppression of VA mycorrhiza in leguminous plants by Phytotoxic exudates of Imperata cylindrica (L.) Beauv. Pakistan Journal of Phytopathology. :8: 2527.

-Bajwa, R., Javaid, A. and Haneef, B. 1999. EM and VAM Technology in Pakistan V: Response of chickpea (Cicer arietinum L.) to co-inoculation of effective microorganisms (EM) and VA mycorrhiza under allelopathic stress. Pakistan J Botany 31:387-396

-Bajwa, R., Afzal, B. and Javaid, A. 2000. Allelopathy and VA Mycorrhiza VI: Comparative effectiveness of Glomus mosseae and G. fasciculatum in improving crop growth and yield in wheat (Triticum aestivum L.) allelopathic stress. Pakistan Journal of Biological Science. 3:485-487.

-Bajwa, R. 2005. Effects of arbuscular mycorrhizae (AM) and effective microorganisms (EM) on various plants under allelopathic stress. Allelopathy journal 16:261-272.

-Bandoni, A.L. (ed.). 2002. Los recursos vegetales aromáticos en Latinoamérica. Editorial de la Universidad Nacional de la Plata, Buenos Aires.

-Barea, J.M. 2000. Rhizosphere and mycorrhiza of field crops. In: Toutant JP, Balazs E, Galante E, Lynch JM, Schepers JS, Werner D \& Werry PA (Eds) Biological Resource 
Management: Connecting Science and Policy (OECD) (pp 110-125) INRA, Editions and Springer.

-Barea, J.M., Azcón, R. and Azcón-Aguilar, C. 2005a. Interactions between mycorrhizal fungi and bacteria to improve plant nutrient cycling and soil structure. In: Buscot F, Varma S, eds.Micro-organisms in soils: roles in genesis and functions. Heidelberg, Germany: Springer-Verlag, 195-212.

-Barea, J.M., Pozo, M.J., Azcon, R. and Azcon-Aguilar, C. 2005b. Microbial cooperation in the rhizosphere. Journal of Experimental of Botany. 56:1761-1778.

-Baziramakenga, R., Leroux, G.D., Simard, R.R. and Nadeau, P. 1997. Allelopathic effects of phenolic acids on nucleic acid and protein levels in soybean seedlings. Canadian Journal of Botany. 75: 445-450.

-Bécard, G., Douds, D. and Pfeffer, P. 1992. Extensive in vitro hyphal growth of vesicular-arbuscular mycorrhizal fungi in the presence of $\mathrm{CO} 2$ and flavonols. Applied and Environmental. Microbiology. 58:821-825.

-Bécard, G. and Pfeffer, P.E .1993. Status of nuclear division in arbuscular mycorrhizal fungi during in vitro development. Protoplasma 174: 62-68.

-Beltrano, J. and Montaldi, E.R. 1979. Efecto de la competencia del sorgo de Alepo sobre el maíz en sus primeros estados de crecimiento. Revista de la Facultad de Agronomía. La Plata. 1-2:85-94.

-Beltrano, J. and Montaldi, E.R. 1980. Acción alelopática de los residuos del Pasto Johnson (Sorghum halepense) sobre el crecimiento de plántulas de maíz. Comalfi 7:2935.

-Beltrano, J. and Montaldi, E.R. 1982. Alelopatía mutua entre sorgo de Alepo y maíz. Revista de la Facultad de Agronomía. Buenos Aires. 3:265-269. 
-Beltrano, J. and Caldíz, D.O. 1993. Effects of johnsongrass (Sorghum halepense L. Pers) densities on potato yield. Pesquisa Agropecuaria Brasileira. Brasilia PAB 28:2124.

-Beltrano, J., Ronco, M.G., Montaldi, E.R. 1999. Drought stress syndrome in wheat is provoked by ethylene evolution imbalance and reversed by rewatering, aminoethoxyvinyglycine or sodium benzoate. Journal of Plant Growth Regulation. 18:59-64.

-Beltrano, J. and Ronco, M.G. 2008. Improved tolerance of wheat plants (Triticum aestivum L.) to drought stress and rewatering by the arbuscular mycorrhizal fungus Glomus claroideum: effect on growth and cell membrane stability. Brazilian Journal of Plant Physiology. 20:29-37.

-Beltrano, J. Ruscitti, M.F., Arango, M.C. and Ronco, M.G. 2013a. Changes in the accumulation of shikimic acid in mycorrhized Capsicum annuum L. grown with application of glyphosate and phosphorus. Theoretical and Experimental Plant Physiology. 25: 125-136.

-Beltrano, J., Ruscitti, M., Arango, M.C. and Ronco, M. 2013b. Effects of arbuscular mycorrhiza inoculation on plant growth, biological and physiological parameters and mineral nutrition in pepper grown under different salinity and p levels. Journal of Soil Science and Plant Nutrition. 13: 123-141.

-Benech A., R.L, Ghersa, C.M, Sánchez, R.A and Insausti, P.1990. A mathematical model to predict Sorghum halepense (L.) Pers seedling emergence in relation to soil temperature. Weed Research 30: 91-99.

-Bensch, E.; Schalchli, H., Fuentes, R., Seemann, P. and Jobet, C. 2007. Potencial alelopático diferencial de cultivares de trigo (Triticum aestivum L.) chileno sobre ballica anual (Lolium rigidum) var. Wimmera. Idesia. 25: 81-89. 
-Bhowmik, P.C., Inderjit, J. 2003. Challenges and opportunities in implementing allelopathy for natural weed management, Crop Protection 22: 661-671.

-Blum, U. 1998. Effects of microbial utilization of phenolic acids and their phenolic acids breakdown products on alleopathic interactions. Jorunal of Chemical Ecology. 24:685-708.

-Boufalis, A. and Pellissier, F. 1994. Allelopathic effects of phenolic mixtures on respiration of two spruce mycorrhizal fungi. Journal of Chemical Ecology .Vol 20, Number 9. 2283-2289.

-Bradford, M.M. 1976. A rapid and sensitive method for the quantitation of microgram quantities of protein utilizing the principle of protein dye binding. Analytical Biochemistry. 72:248-254.

-Bridges, D.C. and Chandler, J.M. 1987. Influence of johnsongrass (Sorghum halepense) density and period of competition on cotton yield. Weed Science. 35:63-67.

-Bronick, C.J. and Lal, R. 2005. Soil structure and management: a review. Geoderma $124: 3-22$.

-Brown, M.S. and Bethlenfalvay, G.J. 1988. The Glycine- Glomus- Rhizobium symbiosis. VII. Photosynthetic nutrient use efficiency in nodulated, mycorrhizal soybeans. Plant Physiology. 86, 1292-1297.

-Brundrett, M.C. 2004. Diversity and classification of mycorrhizal associations. Biological Reviews of Cambridge Philosophical Society. 79:473-495.

-Bruneton, J. Elementos de Fitoquímica y de Farmacognosia. 1991. Editorial Acribia, S.A. Zaragoza (España). 
-Buchanan, B., Gruissem, R. and Jones, R. 2000. Biochemistry \& Molecular Biology of Plants. Capítulo 24: Natural products (Secondary metabolites). Maryland: American Society of Plant Physiologist.

-Bukolova, T.P. 1971. A study of the mechanism of action of water-soluble substances of weed on cultivated plants. Physiological Biochemical Basis of Plant Interactionsin Phytocenoses , (Grodzinsky, A,M., ed). Vol. 2, pp: 66-69.

-Burnside, O.C. and Wichks, G.A. 1965. Effects of herbicides and cultivation treatments on Yield components of dryland Sorghym in Nebraska. Agronomie Journal. $57: 21-24$.

-Burt, S. 2004. Essential oils: their antibacterial properties and potential applications in foods - a review, Int. Journal of Food Microbiology. 94:223-253.

-Cabello, M. 1997. Hydrocarbon pollution: its effect on native arbuscular mycorrhizal fungi (AMF). FEMS Microbiology Ecology 22: 233-236.

-Cabello, M., Irrazabak, G., Bucsinszky, A.M., Saparrat, M. and Schalamuk, S. 2005. Effect of an arbuscular-mycorrhizal fungus, Glomus mosseae, and a rock-phosphatesolububilizing fungus, Penicillum thomii, on Mentha piperita growth in a soilless médium. Journal of Basic Microbiology, Weinheim 45:182-189.

-Castañón-Silva, P.A., Venegas-Urrutia, M.A., Lobos-Valenzuela, M.G. and GaeteOlivares, H.J. 2013. Influencia de micorrizas arbusculares glomus spp. en el crecimiento y acumulación de cobre en girasol Helianthus annuus L. Agrociencia.

-Cherney, D.J., Patterson, J.A. Cherney, J.H and Axtell, J.D. 1991. Fibre and soluble phenolic monomer composition of morphological components of sorghum stover. Journal of the Science of Food and Agriculture. 54: 645-649. 
-Copetta A., Língua, G., and Berta, G. 2006. Effects of three AM fungi on growth, distribution of glandular hairs, and essential oil production in Ocimum basilicum L. var. genovese. Mycorrhiza. 16:485-494.

-Cordier, C., Gianinazzi, S. and Gianinazzi-Pearson, V., 1996. Colonisation patterns of root tissues by Phytophthora nicotiana var. parasitica related to reduced disease in mycorrhizal tomato. Plant Soil. 185: 223-232.

-Cuenca, G., Z. De Andrade. and Meneses, E. 2001. The presence of aluminum in arbuscular mycorrhizas of Clusia multiflora exposed to increased acidity. Plant Soil. 231: $233-241$.

-Curioni, A. 2000. La calidad aplicada a la producción, acondicionamiento y comercialización de especies aromáticas y medicinales: I. Conceptos preliminares.

-Curioni, A. and Arizio, O. 2006. Plantas Aromáticas y Medicinales - Labiadas Editorial Hemisferio sur Bs. As.

-Czarnota, M, Paul, R., Dayan, F., Nimbal, C. and Weston, L. 2001. Mode of action, localization of production, chemical nature, and activity of sorgoleone: a potent psII inhibitor in Sorghum spp. root exudates. Weed Technology. 15:813-825.

-Darré, C.A., Novo, R.J., Zumelzu, G. and Bracamonte, E.R. 2004. Alternativas de control químico de malezas anuales en Mentha piperita L. Agriscientia. 21: 39-44.

-Dayan, F.E. 2006. Factors modulating the levels of the allelochemical sorgoleone in sorghum bicolor. Planta. 224:339-346.

-Derwich, E., Benziane, Z. and Boukir, A. 2010. Antibacterial activity and chemical composition of the leaf essential oil of mentha rotundifolia from morocco. Electronic journal of environment, agriculture and food chemistry. 9:19-28. 
-Dilly, O. and Nannipieri, P. 1998. Intracellular and extracellular enzyme activity in soil with reference to elemental cycling. Z. Pflanzenernahr. Bodenk. 161: 243-248.

-Einhellig, F.A. and Rasmussen, J.A. 1978. Synergistic inhibitory effects of vanillic and p-hydroxybenzoic acids on radish and grain sorghum. Journal of Chemical Ecology. 4: 425-436.

-Einhellig, F.A. and Souza, I.F. 1992. Phytotoxicity of sorgoleone formed in grain sorghum root exudates. Journal of Chemistry Ecology. 18:1-11.

- Einhellig, F.A., Rasmussen, J. A., Hejl, A.M. and Souza, I.F. 1993. Effects of root exudate sorgoleone on photosynthesis. Journal of Chemistry Ecology. 19:369-375.

-Einhellig, F.A. 1995. Mechanism of action of alelochemicals in allelopathy.in Inderjit, K.M.M. Dakshini, and F.A. Einhellig (eds.). Allelopathy, Organisms, Processes, and Applications. American Chemical Society Symposium Series 582, Washington, D.C. pp. 96-116.

-Einhellig, F.A.1996. Interactions involving allelopathy in cropping systems. Agronomy Journal. 88: 886-893.

-Ens, E.J., French, K., Bremner, J.B., Korth, J. 2010. Novel technique shows different hydrophobic chemical signatures of exotic and indigenous plant soils with similar effects of extracts on indigenous species seedling growth. Plant and Soil. 326: 403-414.

-Feng, K., Zhou, X.H., Oohashi, T., Morgelin, M., Lustig, A., Hirakawa, S., Ninomiya, Y., Engel, J., Rauch, U. and Fassler, R. 2002. All four members of the Ten-m/Odz family of transmembrane proteins form dimers. Journal of Biological Chemistry. 277:26128-26135.

-Figueiredo, A.C., Barroso, J.G., Pedro, L.G and Scheffer, J.J.C. 2008. Factors affecting secondary metabolic in plants: volatile components and essential oils. Flavour and Fragance Journal. 23:213-226. 
-Freitas, M.S. M, Martins, M.A. and Vieira, I.J.C. 2004. Producao e qualidade de óleos esenciáis de Mentha arvensis em resposta à inoculacao de fungos micorrízicos arbusculares. Pesquisa Agropecuaria Brasileira, Brasilia. 39:887-894.

-Friedman, T. and Horowits, M. 1970. Phytotoxicity of subterranean residues of three perennial weeds. Weed Research. 10:382-385.

-Gange, A.C. and Ayres, R.L. 1999. On the relation between arbuscular mycorrhizal colonization and plant 'benefit'. Oikos. 87:615-621.

-Garcia, D., Sanier, G., Macheix, J.J. and D 'Auzac, J. 1995. Physiological and Molecular Plant Pathology. 47:213-223.

-Garg, N. and Chandel, S. 2010. Arbuscular mycorrhizal networks: process and functions. A review Agron. Sustain. Development. 30:581-599.

-Gaspar, M., L., Cabello, M.N., Cazau, M.C. and Pollero, R.J. 2002. Effect of phenanthrene and Rhodotorula glutinis on arbuscular mycorrhizal fungus colonization of maize roots. Mycorrhiza 12:55-59.

-Ghersa, C.M. and Soriano. A, 1980. Efecto comparado del verdeo de avena y de otros sistemas agrícolas sobre la población de rizomas de Sorghum halepense (L.) Pers. Revista de la Facultad de Agronomía.3:87-92.

-Ghersa, C.M. and Satorre, E.H. 1981. La dinámica de la población de rizomas de sorgo de Alepo en relación con los sistemas de control más frecuentes. Revista de la Facultad de Agronomía. 2:133-138.

-Ghersa, C.M., Satorre, E.H. and Van Esso, M.L. 1985. Seasonal pattern of Johnsongrass seed production in different agricultural systems. Israel. Journal of Botany. 34:24-30. 
-Ghersa, C.M., Satorre, E.H., Van Esso M.L., Pataro A. and Elizagaray, R. 1990. The use of thermal calendar models to improve the efficiency of herbicide applications in Sorghum halepense (L.) Pers. Weed Research. 30:153-160.

-Ghersa, C.M. and Martinez-Ghersa, M.A. 1991. A field method for predicting yield losses in maize caused by Johnsongrass (Sorghum halepense). Weed Technology. $5: 279-285$.

-Ghersa, C.M., Benech-Arnold, R.L. and Martinez-Ghersa, M.A. 1992. The role of fluctuating temperatures in germination and establishment of Sorghum halepense. Regulation of germination at increasing depths. Functional Ecology. 6:460-468.

-Ghersa, C.M., Martinez-Ghersa, M.A, Satorre, E.H., Van Esso, M.L. and Chichotky, G. 1993. Seed dispersal, distribution and recruitment of seedlings of Sorghum halepense (L.) Pers. Weed Research. 33:79-88.

-Gianfrancisco, S., Pastoriza, A. and Riscala, E. 1998. Efecto alelopático de un extracto clorofórmico de Raphanus sativus L. sobre la germinación y el crecimiento de plántulas de achicoria. 1998. Revista de la Facultad de Agronomia (LUZ). 15: 414-421.

-Gianinazzi-Pearson, V., Branzanti, B. and Gianinazzi , S. 1989. In vitro enhancement of spore germination and early growth of a vesicular-arbuscular mycorrhizal fungus by host root exudates and plant flavonoids. Symbiosis. 7: 243-255.

-Gianinazzi-Pearson, V. 1996. Plant cell responses to arbuscular mycorrhizal fungi: getting to the root of the symbiosis. Plant Cell. 8:1871-1883

-Giovannetti, M, Avio, L, Sbrana, C. and Citernesi, A.S. 1993. Factors affecting appressorium development in the vesicular-arbuscular mycorrhizal fungus Glomus mosseae (Nicol. \& Gerd.) Gerd. \& Trappe. New Phytologist. 123: 114-122.

-Giovannetti, M, Sbrana, C. and Logi, C. 1994. Early processes involved in host recognition by arbuscular mycorrhizal fungi. New Phytologyst.127: 703-709 
-Giovannetti M, Fortuna P, Citernesi, AS, Morini S, Nuti MP. 2001. The occurrence of anastomosis formation and nuclear exchange in intact arbuscular mycorrhizal networks. New Phytologist 151:717-724.

-González-Chávez, C., D’Haen, J., Vangronsveld, J. and Dodd, J.C. 2002. Copper sorption and accumulation by the extraradical mycelium of different Glomus spp. (arbuscular mycorrhizal fungi) isolated from the same polluted soil. Plant Soil 2.40: 287-297.

- González-Chávez, M.C.; Carrillo-Gonzáleza, R S.; Wrightb, F and Nicholsc, K.A. 2004. The role of glomalin, a protein produced by arbuscular mycorrhizal fungi, in sequestering potentially toxic elements. Environmental Pollution. 130:317-323.

-Guenzi, WD, and McCalla, T.M. 1966. Phytotoxic substances extracted from soil. Soil Sci Soc Am Proc 30:214-216.

-Guenzi, WD., Mc Calla, T.M. and Norstad, F.A. 1967. Presence and persistence of phytotoxic substances in wheat, oat, corn and sorghum residues. Agronomy Journal.59:163-165.

-Guerra-Sierra, B. 2008. Micorriza arbuscular, recurso microbiológico en la agricultura sostenible. Tecnología En Marcha. Costa Rica. 21: 91-202.

-Gupta, M.L., MohanKumar, V. and Janardhanan, K.K. 1994/1995. Distribution of vesicular-arbuscular mycorrhizae in some important medicinal and aromatic plants. Kavaka 22/23: 29-33.

-Gupta, M.L., Prasad, A., Ram, M., and Kumar, S. 2002. Effect of vesicular-arbuscular mycorrhizal (VAM) fungus Glomus fasciculatum on the essential oil yield related characters and nutrient acquisition in the crops of different cultivars of mentol mint (Mentha arvensis) under field conditions. Bioresource Technology. 81: 77-79. 
-Hamel, C., Fyles, H. and. Smith, D. 1990. Measurement of development of endomicorrhizal mycelium using there different vital stain. New Phytologist 115: 297302.

-Harborne JB. Phytochemical methods: A guide to modern technique of plant analysis', Champman and Hall, London, 1998.

-Harley, R.M. and Brighton, C.A. 1977. Chromosome no. in the genus Mentha. Botanical Journal of the Linnean Society. 74: 71-96.

-Hartley, M.J., 1993. Herbicide tolerance and weed control in culinary herbs. In: Forty Sixth New Zealand Plant Protection Conference, Christchurch, New Zealand, Proceedings. pp.35-39. (In Abstracts).

-Hejl, A.M., Einhellig, F.A., and Rasmussen, J.A.1993. Effects of juglone on photosynthesis and respiration. Journal of Chemical Ecology. 19:559-568.

-Hetrick, B. Wilson, W. and Cox, T. 1992. Mycorrhizal dependence onf modern wheat cultivars, landraces and ancestors. Canadian Journal of Botany. 70:2032-2040.

-Hierro, J.L. and Callaway, R.M. 2003. Allelopathy and exotic plant insasion. Plant and Soil. 256: 29-39.

-Hildebrandt, U., Regvar, M.and Bothe, H.2007.Arbuscular mycorrhiza and heavy metal tolerance. Phytochemistry.68:139-146.

-Hirosuke, O., Tawaraya, K. and Wagatsuma, T. 2002. Inhibition of pre-symbiotic hyphal growth of arbuscular fungus Gigaspora margarita by root exudates of Lupinus spp. Soil Science and Plant Nutrition 48:117-120.

-Hoagland, D.R., and Arnon, D.I. 1950. The water-culture method of growing plants without soil. California Agricultural Experiment Station Circular 347. 
-Holappa, L. D., and Blum, U. 1991. Effects of exogenously applied ferulic acid, a potential allelopathic compound, on leaf growth, water utilization, and endogenous abscisic acid levels of tomato, cucumber, and bean. Journal of Chemical Ecology. $17: 865-886$.

-Holm, L.G., Donald, P., Pancho, J.V., and J.P. Herberger. 1977. The World's Worst Weeds: Distribution and Biology. The University Press of Hawaii, Honolulu, Hawaii. $609 \mathrm{pp}$.

-Horowitz, M. 1973. Spatial Growth of Sorghum halepense. Weed Research. 13:200208.

-Hussain, M.I. and Reigosa, M.J. 2011. Allelochemical stress inhibits growth, leaf water relations, PSII photochemistry, non-photochemical fluorescence quenching and heat energy dissipation in three $\mathrm{C}_{3}$ perennial species. Journal of Experimental of Botany. 62:4533-454.

-Inderjit and Dakshini, K.M.M. 1995. Quercetin and quercetrin from Pluchea lanceolata and their effect on growth of asparagus bean, pp: 86-95. In Inderjit, K.M.N. Dakshini and F.A. Einhellig (eds.). Allelopathy: organisms, processes, and applications. American Chemical Society, Washington, DC.

-Inderjit, and Duke, S.O. 2003. Ecophysiological aspects of allelopathy. Planta 217:529539. Investigaciones realizadas en Costa Rica. Agronomía Costarricense. 21:55.

-Inderjit, 2005. Plant invasions: Habitat invasibility and dominance of invasive plant species. Plant and Soil. 277:1-5

-Janos, D.P. 1980 Mycorrhizae influence tropical succession. Biotropica 12:56-64.

-Jarchow, M.E. and Cook, B.J. 2009. Allelopathy as mechanism for the invasion of Typha angustifolia. Plant Ecology 204:113-124. 
-Javaid, A., Bajwa, R., Tasneem, Z. and Nasim, G. 1995. Allelopathy and VA mycorrhiza. III: Vesicular arbuscular mycorrhizae (VAM) in allelopathic and nonallelopathic grasses. Science International (Lahore).7:545-547.

-Javaid, A., Bajwa, R., Tasneem, Z. and Nasim, G. 1996. Allelopathy and VA mycorrhiza. II: Effect of allelopathic exudates of Dicanthium annulatum (Forssk.) Stapf. on VA mycorrhizae of associated perennial and annual winter weeds. Pakistan Journal of Phytopathology. 82:103-106.

-Javaid, A. and Bajwa, R. 1999. Allelopathy and VA mycorrhiza. IV: Tolerance to allelopathy by VA mycorrhiza in maize. Pakistan Journal of Phytopathology. 11:70-3.

-Javaid, A. and Anjum, T. 2006. Control of Parthenium hysterophorus L., by aqueous extracts of allelopathic grasses. Pakistan Journal of Botany. 38:139-145.

-Javaid, A. 2007. Allelopathy interactions in mycorrhizal associations. Allelophatic Journal 20: 29-42.

-Javaid, A. 2008. Allelopathy in mycorrhizal symbiosis in the Poaceae family. Allelopathy Journal. 21:207-218.

-Jhonson, N.C. 1991.Plant and soil regulation of mycorrhizae in natural and agricultural ecosystems. PhD. University of Minnesota, Minneapolis. Diss. 92-07792.

-Kapoor, R., Giri, B. and Mukerji, K. G. 2002. Mycorrhization of coriander (Coriandrum sativum L.) to enhance the concentration and quality of essential oil. Journal of the Science of Food and Agriculture. 82:339-342.

-Kapoor, R., Chaudhary, V. and Bhatnagar, A. 2007. Effects of arbuscular mycorrhiza and phosphorus application on artemisinin concentration in Artemisia annua L. Mycorrhiza. 17:581-7. 
-Karagiannidis, N., Thomidis, T., Lazari, D., Panou-Filotheou, E. and Karagiannidou, C. 2012. Response of three mint and two oregano species to Glomus etunicatum inoculation, Astralian. Journal of Crop. Science. 6:164-169.

-Kaya, C., Ashraf, M., Sonmez, O., Aydemir, S., Levent Tuna A. and, M. Ali Cullu. 2009. The influence of arbuscular mycorrhizal colonisation on key growth parameters and fruit yield of pepper plants grown at high salinity. Scientia Horticulturae. 121:1-6.

-Khaliq, A. and Janardhanan, K.K. 1997. Influence of vesicular arbuscular mycorrhizal fungi on the productivity of cultivated mints. Jorunal of Medicinal and Aromatic Plant Science. 19:7-10.

-Khaosaad, T., Vierheilig, H., Nell, M., Zitterl-Eglseer, K. and Novak, J. 2006. Arbuscular mycorrhiza alter the concentration of essential oils in oregano (Origanum sp., Lamiaceae). Mycorrhiza, 16:443-446.

-Kogan, M. 1992. Malezas. Ecofisiología y estrategias de control. Santiago. Colección en agricultura. Facultad de Agronomía. Pontificia Universidad Católica de Chile. 402 p.

-Kohler, J., Hernandez, J.A., Caravaca, F. and Roldán, A. 2008. Plant growth promoting rhizobacteria and arbuscular mycorrhizal fungi modify alleviation biochemical mechanisms in water stressed plants. Functional Plant Biology. 35:141-151.

-Koide, R.T. and Li, M. 1991. Mycorrhizal fungi and the nutrient ecology of three old field annual plant species. Oecologia 85:403-41.

-Kumar, S., Wahab, N. and Warikoo, R. 2011. Bioefficacy of mentha piperita essential oil against dengue fever mosquito aedes aegypti. Asian Pacific Journal of Tropical Biomedicine, v:185-8.

-Lawrence, B.M. 2007. Mint: the genus Mentha. Tylor and Francis group, Bocan Raton, London New York. 
-Laynez-Garsaball, J. and, J.R. Méndez-Natera1. 2006. Efectos de extractos acuosos del follaje del corocillo (Cyperus rotundus L.) sobre la germinación de semillas y el crecimiento de plántulas de ajonjolí (Sesamum indicum L.) cv. Arapatol S-15. IDESIA (Chile) Vol: 61-75.

-Leadir, L., M. Fries, R.S., Pacovsky, Safir, G.R and Siqueira, J.O. 1997. Plant growth and arbuscular mycorrhizal fungal colonization affected by exogenously applied phenolic compounds. Journal of Chemical Ecology. 23:1755-1767.

-Leguizamón, E.S.1999. The refinement of the population model of Sorghum halepense (L.) Pers under a soybean crop. Proc. 1999 British Crop Protection Conference-Weeds. Brighton. UK. 364-372.

-Leguizamón, E.S. 2006. Sorghum halepense L. Pers. (Sorgo de Alepo): base de conocimientos para su manejo en sistemas de producción. Departamento de Sistemas de Producción Vegetal - Malezas. Facultad de Ciencias Agrarias. Universidad Nacional de Rosario. Zavalla. Santa Fe. Argentina. 1-24 pp.

-Leguizamón, E.S. 2012. Manejo de Malezas Problema. Sorgo de Alepo Sorghum halepense (L.) Persoon. Bases para su manejo y control en sistemas de producción. ISSN N² 2250-5350 Volumen II. Aapresid.

-Lehman, M.E., and Blum, U. 1999. Evaluation of ferulic acid uptake as a measurement of allelochemical dose: Effective concentration. Journal of Chemical Ecology. 25:2585-2600.

-Leicach, S.R. 2006. Alelopatía. Interacciones químicas en la comunicación y defensa de las plantas. Ed. EUDEBA. 203 pp.

-Levit J. 1980. Responses of Plants to Environmental Stresses, Academic Press, Vol. II, New York. 
-Linderman, R.G. 1992. Vesicular-arbuscular mycorrhizae and soil microbial interactions. In: Bethlenfalvay GJ \& Linderman RG (Eds) Mycorrhizae in Sustainable Agriculture. ASA Spec. Publ., Madison, Wisconsin. pp 45-70.

-Liu, D.L. and Lovett, J.V. 1993. Boplogically active secondary metabolites of barley. 1. Developing techniques and accessing allelopathy in barley. Journal of Chemical Ecology 19:2217-2230.

-Lolas, P.C. and Coble, H.D. 1982. Noncompetitive effects of johnsongrass (Sorghum halepense) on soybean (Glycine max). Weed Science. 30:589-593.

- Loomis, W.D, Corteau, R. 1972. Essential oil biosynthesis. Recent Advanced in Phytochemitry. 6:147-185.

-Lukatkin, A.S. 2003. Contribution of oxidative stress to the development of cold induced damage to leaves of chilling-sensitive plants: 3. Injury of cell membrane by chilling temperatures. Russian Journal of Plant Physiology 50:243-246.

-Lutts, S., Kinet, J.M. and Bouharmont, J. 1996. Effects of various salts and of mannitol on ion and proline accumulation in relation to osmotic adjustment in rice (Oryza sativa L.) callus cultures. Jorunal of Plant Physiology. 149:186-195.

-Lynch, J. M. 1980. Effects of organic acids on the germination of seeds and growth of seedlings. Plant, Cell and Environment. 3: 255.

-Macías, F.A., Galindo, J.C., Molinillo González, J.M., and Cutler, H. G. 2003. Allelopathy chemistry and mode of action of allelochemicals: Bioassays-Useful tools for the study of allelopathy. CRC Press, 315-351 pp.

-Manoharan, P., Shanmugaiah, V., Balasubramanian, N., Gomathinayagam, S., Sharma, M.P., and Muthuchelian, K. 2010. Influence of AM fungi on the growth and physiological status of Erythrina variegate Linn. grown under different water stress conditions. European Journal of Soil Biology. 46:151-156 
-Martínez L.B. and Pugnaire, F.I. 2009. Interacciones entre las comunidades de hongos formadores de micorrizas arbusculares y de plantas. Algunos ejemplos en los ecosistemas semiáridos. Ecosistemas. Revista científica de ecología y medio ambiente. Vol 18 n 2.

http://revistaecosistemas.net/index.php/ecosistemas/issue/view/12

-Marschner, H. and Dell, B. 1994. Nutrient uptake in mycorrhizal symbiosis. Plant and Soil. 159:89-102.

-Mathur, N. and Vyas, A. 2000. Influence of arbuscular mycorrhizae on biomass production, nutrient uptake and physiological changes in Ziziphus mauritiana Lam. under water stress. Journal of Arid Environments. 45:191-195.

-Matsubara, Y. and Harada, H. 1996. Effect of constant and diurnally fluctuating temperatures on arbuscular mycorrhizal fungus infection and growth of infected asparagus (Asparagus officinalis L.) seedlings. Journal Japan Society for Horticultural Science. 65:565-570.

-Mc Whorter, C.G. and Jordan, T.N. 1976. Factors Affecting Dalapon Absorption and Translocation in JohnsongrassPhysiologia Plantarum. 38:166-170.

-McWhorter, C.G. 1981. Johnsongrass as a Weed. Farmers' Bulletin Number 1537. United States Department of Agriculture.

-Mersie, W. and Singh, M. 1993.Phenolic acids affect photosynthesis and protein synthesis by isolated leaf cells of velvet-leaf. Journal of Chemical Ecology. 19: 12931301.

-Mitidieri, A. 1983. El sorgo de Alepo. Importancia, biología y aspectos básicos para su control. Panel de Expertos en Ecología y Control de Malezas Perennes. FAO, Santiago de Chile, pp. 1-43. 
-Moreira, FMS and Siquiera, JO. 2006. Micorrizas (Capítulo 10). Pp 543-657. En:UFLA (Lavras ed.). Microbiología e Bioquímica do Solo, 2da ed. 729 pp.

-Morone-Fortunato, I. and Avato, P. 2008. Plant development and synthesis of essential oils in micropropagated and mycorrhiza inoculated plants of Origanum vulgare L. ssp. hirtum (Link) Ietswaart. Plant Cell, Tissue and Organ Culture. 93:139-149.

-Muhammad, R.A. and Mohammad A. 2010. Inhibiroty effects of Sorghum Halepens root and leaf extracts on germination and early seedling growth of widely used medicinal plants. Advances in Environmental Biology. 4:316-324.

-Muller, C.H. 1969. Allelopathy as a factor in ecological process. Vegetation. 18: 348357.

-Mushteq, S., Firdeus-e-Bareen and Iqbal, S.H. 1993. Allelopathic effects of bark and leaves of Melia azedarach on germination and subsequient mycorrhizal development in Zea mays. Sci. Int. (Lahore).5:299-309.

-Nasim, G. 2010. The role of arbuscular mycorrhizae in inducing resistance to drought and salinity stress in crops. p. 119-141. In: Ashraf, M., M. Ozturk, and M.S.A. Ahmad (Eds.). Plant Adaptation and Phytoremediation. Springer-Verlag, Berlin Heidelberg,

-Ocampo, J.A. and Barea, J.M.. 1982. Depressed metabolic activity of VA mycorrhizal fungi by photosynthesis inhibitor herbicides, p. 267-270. In: S. Gianinazzi, V. Gianinazzi-Pearson, and A. Trouvelot (eds.). Mycorrhizae, an integral part of plants: Biology and perspectives for their use. INRA Publ. Colloq., France.

-Ocampo, J.A. 1993. Influence of pesticides on VA mycorrhizal. p.214-226In: Pesticide-plant pathogen interactions in crop production: beneficial and deleterious effects, CRC Press, Boca Raton, FL.. (Altman, J. ed).

-O-Quezada, G. Ojeda-Barrios, A., Damaris, L., Hernández-Rodríguez, O. A., SánchezChávez, E., and Martínez-Tellez, J. 2011. Biomasa, prolina y parámetros nitrogenados 
en plántulas de nogal bajo estrés hídrico y fertilización nitrogenada. Revista Chapingo. Serie Horticultura. 17: 13-18.

-Pank, F., 1990. The influence of chemical weed control on quality characters of medicinal and aromatic plants. Herba Hungarica. 29:51-58.

- Peng, S.L., Chen, Z.Q., Wen, J. and Shao, H. 2004. Is allelopathy a driving force in forest succession? Allelopathy Journal 14: 197-204.

-Pengue, W.A., Monterroso, I. and Binimelis, R. 2009. Bioinvasiones y bioeconomía: el caso del sorgo de Alepo resistente al glifosato en la agricultura argentina. Proyecto alarm. Instituto de ciencia y tecnología ambientales (ICTA) (UAB). Facultad latinoamericana de ciencias sociales, flacso-guatemala. Grupo de ecología del paisaje y medio ambiente (GEPAMA) (UBA). Capítulo 1; pag. 21.

-Phillips, J.M. and Hayman, D.S. 1970. Improved procedures for clearing roots and staining parasitic and vesicular-arbuscular mycorrhizal fungi for rapid assessment of infection. Transactions of the British Mycological Society. 55:158-163.

-Plenchette, C., Fortin, J.A. and Furlan, V. 1983. Growth responses of several plant species to mycorrhizae in a soil of moderate phosphorus fertility. I. Mycorrhizal dependency under field conditions. Plant and Soil, 70: 199-209.

-Podila, G.K., Zheng, J., Balasubramanian, S., Sundaram, S., Hiremath, S., Brand, J.H. and Hymes, M.J. 2002. Fungal gene expression in early symbiotic interactions between Laccaria bicolor and red pine. Plant and Soil. 244:117-128.

-Porcel R, Ruiz-Lozano JM. 2004. Arbuscular mycorrhizal influence on leaf water potential, solute accumulation and oxidative stress in soybean plants subjected to drought stress. Journal of Experimental Botany 55:1743-1750.

-Potty, V.P. 1984. Plan microbe interrelationship in tuber crops. Indian Farming. 33: 4142. 
-Prakash, V. 1990. Leafy Spices. CRC Press. Boca Ratón, Florida, USA.

-Putnam, A.R. 1985. Weed allelopathy. En: Duke, S. O. (ed.) Weed physiology. Vol I. Reproduction and Ecophysiology. CRC Press, Boca Raton, FL. p. 131-155.

-Putnam, A.R. and Weston, L.A. 1986. Adverse impacts of allelopathy in agricultural systems. In The Science of Allelopathy, eds. A. R. Putnam and C. S. Tang. John Wiley and Sons, New -York. p. 43-56. (A.R. Putnam \& Tang, C.S. eds)

-Putnam, A.R. and Tang, C.S. 1986. Allelopathy: State of the science, pp: 1-19, in A.R. Putnam \& C.S.Tang (eds.). The science of allelopathy. John Wiley, New York.

-Rasouli-Sadaghiani MirHassan, Abbas Hassani, Mohsen Barin, Younes Rezaee Danesh and Fatemeh Sefidkon. 2010. Journal of Medicinal Plants Research. 4:2222-2228.

-Rejmánek, M., Richardson, D.M. and Pyšek, P. 2005. Plant invasions and invasibility of plant communities. En E. van der Maarel (ed.), Vegetation Ecology, pp. 332-355. Oxford, Blackwell.

-Ribeiro, P.G.F. and Diniz, R.C. 2008. Plantas aromáticas e medicinais: cultivo e utilizacão. Londrina, BR, IAPAR. 218 pp.

-Rice E.L. 1984. Allelopathy, Academic Press, Orlando, FL. 422 pp.

-Ringuelet, J.A. and Cerimele E. 2002. Los recursos vegetales aromáticos en Latinoamérica. Cap.VII. Aspectos agronómicos de la producción de especies aromáticas. Ed. Bandoni A.L. CYTED. p 93-113.

Ringuelet, J.A. and Viña, S.Z. 2013. Productos Naturales Vegetales. Editorial de la Universidad Nacional de La Plata (EDULP). 
-Rizvi, S.J.S., Haque, H., Singh, V.K. and Rizvi, V. 1992. A discipline called allelopathy. In: Allelopathy: Basic and applied aspects. Chapman \& Hall, Londres. p.110. (Rizvi, S.J.S. \& Rizvi, V. eds)

-Ronco, G., Ruscitti, M.F., Arango, M.C. and Beltrano. J. 2008. Glyphosate and mycorrhization induce changes in plant growth and root morphology and architecture in pepper plants (Capsicum annuum L.). Journal of Horticultural Science and Biotechnology. 83(43):497-505

-Rosales Robles, E., Chandler, J.M., Senseman, S.A. and Prosteko, E.P. 1999. Integrated johnsongrass (Sorghum halepense) management in field corn (Zea mays) reduces rates of nicosulfuron and cultivation. Weed Technology. 13:367-373.

-Ruiz-Lozano, J.M., Azcón R., and Gómez, M. 1995. Effects of arbuscular mycorrhizal Glomus species on drought tolerance: physiological and nutritional plant responses. Applied and Environmental Microbiology. 61:456-460.

-Ruiz-Lozano, J.M., Porcel, R. and Aroca, R. 2006. Does the enhanced tolerance of arbuscular mycorrhizal plants to water deficit involve modulation of drought-induced plant genes? New Phytologist. 171:693-698.

-Ruscitti, M.F., Arango, M.C., Ronco, M.G., Peluso, O. and Beltrano, J. 2006. Fisiología de la micorrización con Glomus mosseae en pimiento. Efecto del estrés hídrico. XXVI Reunión de la Asociación Argentina de Fisiología Vegetal. Chascomús Buenos Aires - Argentina.

-Ruscitti, M., Arango, M.C., Ronco, M.G., Peluso, O. and Beltrano, J. 2007. Efecto del estrés hídrico simulado y la inoculación con esporas de Glomus mosseae sobre el crecimiento y la partición de biomasa en Avena sativa L. Terra Latinoamericana. 25:135-143.

-Ruscitti, M., Arango, C. Ronco, M. and Beltrano, J. 2008. Respuesta de pimiento (Capsicum annuum L.) inoculado con Glomus intraradices o Glomus mosseae a 
concentraciones crecientes de cobre. XIII Reunión Latinoamericana y XXVII Reunión Argentina de Fisiología Vegetal. 21 al 24 de Septiembre de 2008. (PVII 305). Pág. 210. Rosario. Argentina.

-Ruscitti, M.F., Arango, M.C., Ronco, M.G. and Beltrano, J. 2011. Inoculation with mycorrhizal fungi Glomus mosseae or G. intraradices- modifies proline metabolism and increases chromium tolerance in pepper plants (Capsicum annuum L.). Brazilian Journal of Plant Physiology. 23:15-25.

-Sampietro, D.A. 2002. Alelopatía: Concepto, características, metodología de estudio e importancia. Universidad Nacional de Tucumán, Argentina.

http:/fai.unne.edu.ar/biologia/alelopatia/alelopatia.htm. (Consultado noviembre 2010).

-Sánchez-Díaz M, Honrubia M (1994) Water relations and alleviation of drought stress in mycorrhizal plants. Pp, 167-178. In: Gianinazzi S, Schüepp H (eds) Impact of arbuscular mycorrhizas on sustainable agriculture and natural ecosystems. Birkhäuser, Boston.

-Sánchez, E. García, D., Carballo, C.and Crespo, M. 1996. Estudio farmacognóstico de Mentha $x$ piperita L. (toronjil de menta). Revista Cubana de Plantas Medicinales.v.1 n.3.

-Sangwan, N.S., Faroqui, A.H.A. Shabih, F. and Sangwan, R.S. 2001. Regulation of essential oli production in plants. Plant Growth Regulation. 34:3-21.

-Scervino, M., Ponce, M.A., Erra-Bassels, R., Ocampo, J.A. and Godeas, A. 2005. Arbuscular mycorrhizal colonization of tomato by Gigaspora and Glomus species in presence of roots flavonoids. Journal of Plant Physiology. 162: 625-633.

-Schubler, A., Schawrzott, D., and Walker, C. 2001 "A new phylum, the Glomermycota: phylogeny and evolution." Mycological Research. 105:1413-1421. 
-Schwarzott, D., Walker, C., and Schüssler, A. 2001. Glomus the largest genus of the arbuscular mycorrhizal fungi (Glomales) is nonmonophyletic. Mol Phylogenet Evol 21:190-197.

-Secretaría de Agricultura, Ganadería, Pesca y Alimentos, 2000. Hierbas en Argentina. Foro Internacional de Hierbas. Tokio, Japón. Pag: 2-25.

-Sene, M., Galle, C. and Dore, T. 2001. Phenolic compounds in a Sahelian sorghum (Sorghum bicolor) genotype (ce145-66)) and associated soils. Journal of Chemical Ecology. 27: 81-92.

-Shabani, L., Bagheri, S., Ahmadi Khoei, M., Heydarizadeh, P. and Ali Ebrahimi, M. 2013. Effect of two arbuscular mycorrhizal fungi on growth and nutrient uptake in different genotypes of Mentha spicata L. Journal of Plant Process and Function. 2:1324.

-Shao, H.B., W.Y. Song and Chu, L.Y. 2008. Advances of calcium signals involved in plant anti-drought. C.R. Biol. 331:587-596.

-Sieverding, E. 1991. Vesicular Arbuscular Mycorrhizae Management in Tropical Agroecosystems. Technical Cooperation, Federal Republic of Germany. Eschborn,. p. 271.

-Singleton, V.L. and. Rossi Jr., J.A. 1965. Colorimentry of total phenolics with phosphomolybdic-phosphotungstic acid reagents. American Journal of Enology and Viticulture, 16:144-158

-Siqueira, J.O., Brown. D.G., Safir, G.R. and Nair, M.G., 1992. Field application of the VAM stimulating isoflavonoid formononetin on corn and soybean in Brazil. The International Symposium of Management of Mycorrhizae, University of Western Australia, Perth, p. 132. 
-Sirohi, S.S. and Singh, O.S. 1983. Relationship of endomycorrhizal association of unsterilized soils with available soil phosphorus, plant growth, phosphorus uptake and oil synthesis in peppermint. Scientia Horticulturae. 20:185-91.

-Smith, S.E. and Gianinazzi-Pearson, V. 1990. Phosphate uptake and arbuscular activity in mycorrhizal Allium cepa L.: effects of photon irradiance and phosphate nutrition. Aust J Plant Physiol 17:177-188.

-Smith, S.E. and Smith, F.A. 1990. Structure and function of the interfaces in biotrophic symbioses as they relate to nutrient transport. New Phytol. 114:1-38.

-Smith, S.E. and Read, D.J. 1997. Mycorrhizal symbiosis, $2^{\text {nd }}$ edn. Academic Press, San Diego and London. 605 pp.

-Stermitz, F.R., Bais, H.P, Foderaro, T.A. and Vivanco, J.M. 2003. 7, 8-Benzoflavone: a phytotoxin from root exudates of invasive Russian knapweed. Phytochemistry 64: 493497.

-Stinson, K.A., Campbell, S.A., Powell, J.R., Wolfe, B.E., Callaway, R.M., Thelen, G.C., Hallett, S.G., Pratti, D. \& Klironomos, J.N. 2006. Invasive plant suppresses the growth of native tree seedlings by disrupting below ground mutualisms.Public Library of Science Biology. 4:140.

-Subramanian, K.S., Charest, C., Dwyer, L.M. and Hamilton R.I. 1995. Arbuscular mycorrhizas and water relations in maize under drought stress at tasselling. New Phytologist. 129:643-650.

-Subramanian, KS and Charest, C. 1998. Arbuscular mycorrhyzae and nitrogen assimilation maize after drought and recovery. Physiologia plantarum.120:285-296.

-Sylvia, D.M., Williams, S.E. 1992. Vesicular arbuscular mycorrhizae and environmental stress. Cap 5.p, 101-123. In. Mycorrhizae in sustainable Agriculture. 
Bethlenfalvay and Linderman eds. ASA Special Publication $N^{\circ} 54$ Madison, Wisconsin, USA.

-Taiz, L. and E. Zeiger. 2006. Plant physiology. 3rd ed. Sinauer Associates, Sunderland, MA.

-Tisserant, B, Gianinazzi-Person, V; Gianinazzi, S. and Gollote, A. 1993. In planta histochemical staining of fungal alkaline phosphatase activity for analysis of efficient arbuscular mycorrhizal infections. Mycological Research. 97:245-250.

-Trappe J.M. 1987. Phylogenetic and ecologic aspects of mycotrophy in the angiosperms from an evolutionary standpoint.InEcophysiology of VA Mycorrhizal Plants. Ed. G R Safir. pp 2-25. CRC Press, Boca Raton, FL.

-Trouvelot, A., Kough, J. and Gianinazzi-Pearson, V. 1986. Mesure du taux de mycorrhization VA d'un systeme radiculaire. Recherche de methodes d'estimation ayant une signification fonctionnelle. p.217-221. In: Mycorrhizae: Physiological and Genetical Aspects. INRA-Press, Dijon, France. (Gianinazzi-Pearson, V. \& Gianinazzi, S. eds).

-Toussaint, J.P. 2007. Investigating physiological changes in the aeria parts of AM plants: what do we know and where should we be heading? Mycorrhiza 17:349-353.

-Torelli, A., Trotta, A., Acerbi, L., Arcidiacono, G., Berta, G. and Branca, C. 2000. IAA and ZR. content in leek (Allium porrum L.), as influenced by P nutrition and arbuscular mycorrhizae, in relation to plant development. Plant Soil, 226:29-35, 2000.

-Tsai, S.M., and Phillips, D.A. 1991. Flavonoids released naturally from alfalfa promote development of symbiotic Glomus spores in vitro. Appl. Environ. Microbiol. 57:14851488.

-Varma A, Hock B (eds) (1998) Mycorrhiza: structure, function, molecular biology and biotechnology. Springer, Berlin Heidelberg New York. 
-Velu, G., and A. Rajagopal. 1996. Allelopathic impact of purple nutsedge (Cyperus rotundus) and bermudagrass (Cynodon dactylon) on soybean (Glycine max). Indian Journal of Agricultural Science. 66:363-365.

-Vierheilig, H. and J.A. Ocampo. 1991. Susceptibility and effectiveness of vesiculararbuscular mycorrhizae in wheat cultivars under different growing conditions. Biology and Fertility of Soils, Volume 11, Number 4, Page 290.

-Vierheilig, H. and Piché Y.2002. Signalling in arbuscular mycorrhiza: facts and hypotheses, p.23-39. In: Flavonoids in cell functions, Eds. Buslig B., Manthey J., Kluwer Academic/Plenum Publishers, New York.

-Voets L, De La Providencia IE, Declerck S. 2006. Glomeraceae and Gigasporaceae differ in their ability to form hyphal networks. New Phytologist 172: 185-188.

-Walton, B.T., Hoylman, A.M., Perez, M.M., Anderson, T.A., Johnson, T.R., Guthrie, E.A. and Christman, R.F. 1994. Rhizosphere microbial communities as a plant defense against toxic substances in soils. P, 82-92. In: Anderson TA, Coats JR (eds) Bioremediation through rhizosphere technology. ACS symposium series no. 563. American Chemical Society, Washington, D.C.

-Watanabe, K., Ohno, N., Yoshioka, H., Gershnzon, J. and Mabry, T.J. 1982. Phytochemistry. 21:709:713.

-Wellburn, A.R. 1994. The spectral determination of chlorophylls a and b, as well as total carotenoids, using various solvents with spectrophotometers of different resolution. Journal of Plant Physiology. 144:307-313.

-Wu, Oiang-Shemg and Xia, Ren-Xue. 2006. Arbuscular mycorrhizal fungi influence growth, osmotic adjustment and photosynthesis of citrus under well-watered and water stress conditions. Journal of Plant Physiology. 163:417-425. 
-Xuan, T.D. Eiji, T. Hiroyuki, T, Mitsuhiro, M, Kanh, T.D. and Chung, I. 2004. Crop Protection.23: 335-345.

-Yamane, A., H. Nishimura and Mizutani, J. 1992. Allelopathy of yellow field cress (Rorippa sylvestris): Identification and characterization of phytotoxic constituents. J. Chem. Ecol.18:683-691.

-Yang, C.M., Lee C.N., and Chou, C.H. 2002. Effects of three allelopathic phenolics on chlorophyll accumulation of rice (Oryza sativa) seedlings: I. Inhibition of supplyorientation. Bot. Bull. Acad. Sin. 43: 299-304.

-Yang, J., I. Ordiz, J. Jaworski and Beachy, R. 2011. Induced accumulation of cuticular waxes enhances drought tolerance in Arabidopsis by changes in development of stomata. Plant Physiol. Biochem. 49:1448-1455.

-Yao, H.Y., Xu, J.M. and Huang, C.Y. 2003. Substrate utilization pattern, biomass and activity of microbial communities in a sequence of heavy metal-polluted paddy soils. Geoderma.115:139-148.

-Zamorano M.C. 2006. Alelopatía: un nuevo reto en la ciencia de las arvenses en el trópico. Agronomía. 14:7-15.

-Zandavalli, R.B., Dillenburg, L.R. and de Souza, P.V.D. 2004. Growth responses of Araucaria angustifolia (Araucariaceae) to inoculation with the mycorrhizal fungus Glomus clarum. Appl Soil Ecol. 25:245-255.

-Zhu, Ch., Hua, F.Q. and Burdenb, D.S. 2001.Multi-component reactive transport modeling of natural attenuation of an acid groundwater plume at a uranium mill tailings site. Journal of Contaminant Hydrology. 52:85-108.

-Zimdahl, R.L. 2007. Fundamentals of Weed Science. Elsevier, USA. 
-Zweig, G., Carrol, J., Tamas, I. and Sikka, H.C. 1972. Studies on effects of certain quinones. II. Photosynthetic incorporation of $14 \mathrm{CO}_{2}$ by Chlorella. Plant Physiology, 49: 385 . 